University of Louisville

ThinkIR: The University of Louisville's Institutional Repository

$12-2012$

\title{
Tobacco dependence treatment education for dental students using standardized patients.
}

Jacqueline A. Singleton 1955-

University of Louisville

Follow this and additional works at: https://ir.library.louisville.edu/etd

\section{Recommended Citation}

Singleton, Jacqueline A. 1955-, "Tobacco dependence treatment education for dental students using standardized patients." (2012). Electronic Theses and Dissertations. Paper 1333.

https://doi.org/10.18297/etd/1333

This Doctoral Dissertation is brought to you for free and open access by ThinkIR: The University of Louisville's Institutional Repository. It has been accepted for inclusion in Electronic Theses and Dissertations by an authorized administrator of ThinkIR: The University of Louisville's Institutional Repository. This title appears here courtesy of the author, who has retained all other copyrights. For more information, please contact thinkir@louisville.edu. 


\title{
TOBACCO DEPENDENCE TREATMENT EDUCATION FOR DENTAL STUDENTS USING STANDARDIZED PATIENTS
}

\author{
By \\ Jacqueline A. Singleton \\ B.S., University of Kentucky, 1977 \\ M.Ed, University of Louisville, 2001

\begin{abstract}
A Dissertation
Submitted to the Faculty of the

School of Public Health and Information Sciences of the University of Louisville In Partial Fulfillment of the Requirements

for the Degree of
\end{abstract} \\ Doctor of Philosophy in Public Health Sciences with a Concentration in \\ Health Promotion \\ Department of Health Promotion and Behavioral Sciences \\ University of Louisville \\ Louisville, Kentucky
}

December 2012 

USING STANDARDIZED PATIENTS

\section{By}

Jacqueline A. Singleton

B.S., University of Kentucky, 1977

M.Ed., University of Louisville, 2001

\section{A Dissertation Approved on}

October 22, 2012

by the following Dissertation Committee:

Dr. Richard W. Wilson, Dissertation Director

Dr. David Scott

Dr. John Myers

Dr. Ruth Carrico 


\section{DEDICATION}

This dissertation is dedicated to my husband and sons

Mr. Alan Singleton

and

Mr. Lee Singleton and Mr. Michael Singleton

who have given me unselfish support.

I also dedicate it to my grandfather, Sylvester Greenwell

and my aunt, Charlotte Greenwell, who both

suffered with

Chronic Obstructive Pulmonary Disease

from smoking. 


\section{ACKNOWLEDGEMENTS}

I would like to thank the chair of my committee, Dr. Richard Wilson, for his guidance and patience, and the other committee members, Dr. Ruth Carrico, Dr. John Myers, and Dr. David Scott for their assistance and advice. I would also like to express my sincere thanks to Celeste Worth, Jaime Wientjes, and Kris Paul at the James Graham Brown Kentucky Cancer Program for their hard work and effort in training the dental students in tobacco cessation treatment. I extend my thanks to Carrie Bohnert, Mime Reddy, and the members of the Standardized Patient Program who provided assistance and feedback during the training. It is with deep gratitude I express my thanks to Dr. Guy Brock for his assistance in the data analysis of the study. It is also with deep gratitude I express my thanks to the Department of Public Health and Wellness and Ellie Schweizer for their support of the training. 


\begin{abstract}
TOBACCO DEPENDENCE TREATMENT EDUCATION FOR DENTAL STUDENTS USING STANDARDIZED PATIENTS
\end{abstract}

Jacqueline A. Singleton

October 22, 2012

Dentists can play a key role in helping patients quit tobacco use by providing tobacco cessation treatment (TCT) in their practice. Although the majority of dentists receive training in TCT, most do not provide adequate intervention. Many feel they are not adequately trained. Using standardized patients (SPs) shows promise in TCT training by providing a simulated clinical environment for students to practice counseling skills with individuals trained to portray patients. Standardized patients evaluate students' skills and provide immediate feedback. The purpose of this study is to determine if there is a difference in dental students' attitudes, perceived barriers, subjective norms, perceived skills, self-efficacy, intentions to provide TCT, and cessation knowledge between those students who receive a lecture along with practice sessions using SPs and those students who receive a lecture only. Variables were selected to coincide with the constructs of the theory of planned behavior.

Freshman dental students in an introductory clinical course were invited to participate in the study by completing a pre- and post-questionnaire. The pre- 
questionnaire was administered to all students in the course prior to a two hour tobacco cessation lecture. The intervention group of students $(n=42)$ completed the second questionnaire after the lecture, practice sessions with SPs and a debriefing session. The control group $(n=52)$ completed the second questionnaire after the lecture.

The training using SPs increased dental students' perceived barriers, subjective norms, perceived skills, self-efficacy, and intentions to provide TCT $(\mathrm{p}<.05)$ more than lecture only; however, it did not significantly increase attitude and knowledge. Dental students' attitude, perceived barriers, subjective norms, perceived skills and knowledge significantly impacted intent to provide TCT $(\mathrm{p}<.005)$, while training type, tobacco status and use did not. The time between the groups receiving the lecture and practice sessions with SPs did not significantly affect the variables. The findings suggest that using SPs is a valuable educational method that increases dental students' social pressures, skills, confidence and intentions to provide TCT. The training using SPs did increase students' awareness of barriers in providing TCT. Additional research is needed to reduce barriers in providing TCT. 


\section{TABLE OF CONTENTS}

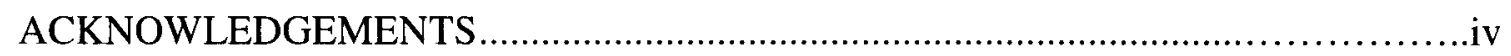

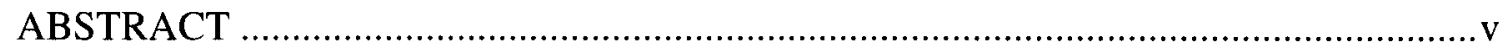

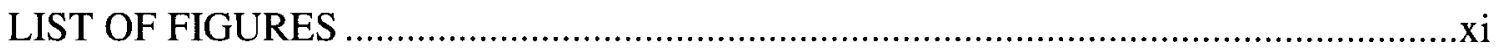

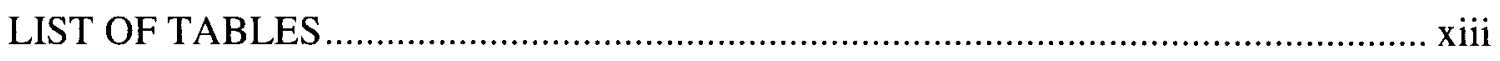

$\begin{array}{ll}\text { Chapter } & \text { Page }\end{array}$

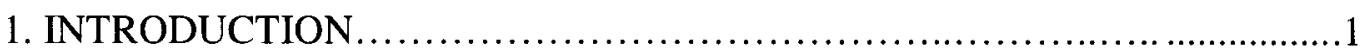

1.1 Health Effects of Tobacco Use .............................................................

1.2 The Role of the Dental Professional .....................................................5

1.3 Dental Professionals Do Not Provide Services ………………….........

1.4 Areas of Focus and Gaps in the Literature ......................................... 8

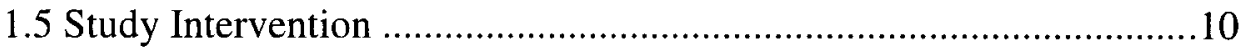

1.6 Statement of Purpose ......................................................................13

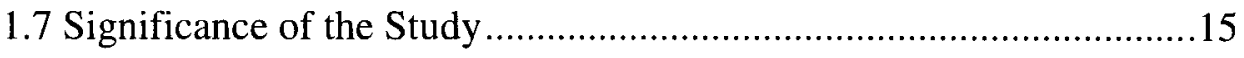

1.8 Research Questions.........................................................................15

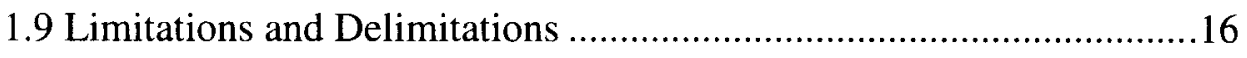

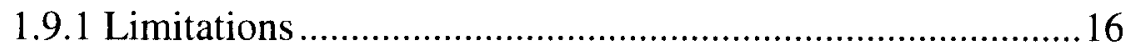

1.9.2 Delimitations....................................................................

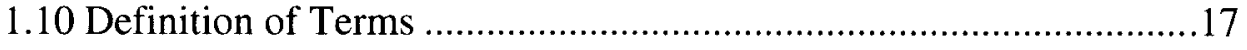




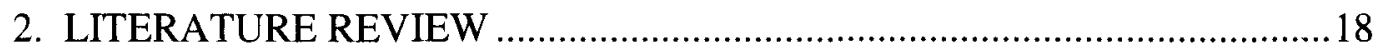

2.1 Factors Influencing Cessation Treatment ..........................................18

2.1.1 Attitudes toward Tobacco Cessation Treatment....................18

2.1.2 Status of Tobacco Cessation Treatment ..............................20

2.1.3 Perceived Barriers to Tobacco Cessation Treatment ............24

2.2 Tobacco Dependence Treatment Education Programs .........................26

2.3 Treatment Education Programs Using Standardized Patients ............33

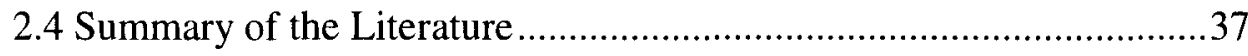

2.5 Statement of Research Questions ......................................................38

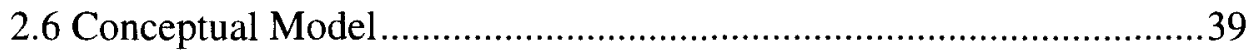

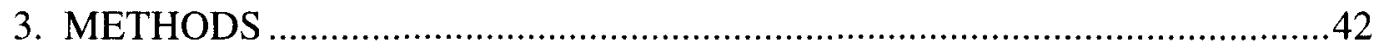

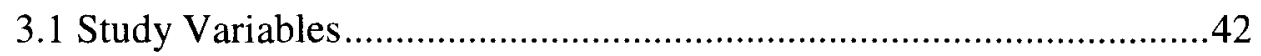

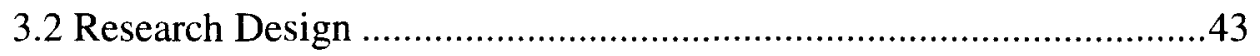

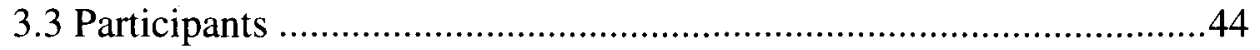

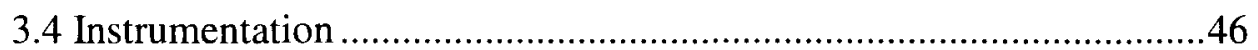

3.5 Reliability and Validity of the Instrument ..........................................50

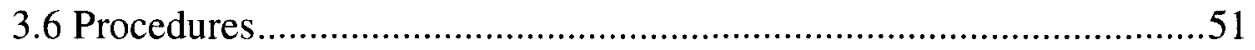

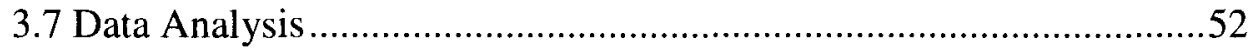

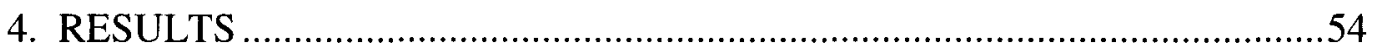

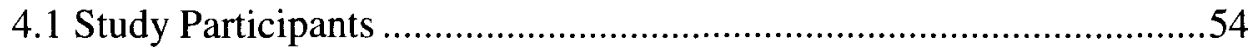

4.2 Reliability and Validity of the Instrument ........................................57

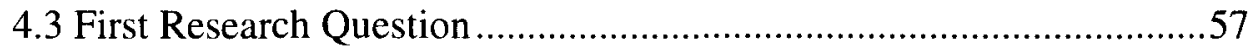

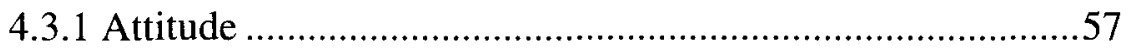


4.3.2 Perceived Barriers

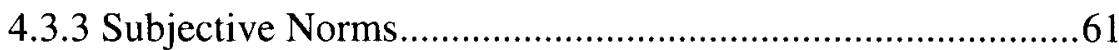

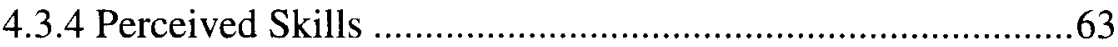

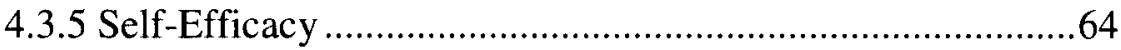

4.3.6 Intentions to Provide Tobacco Cessation Treatment .............66

4.3.7 Tobacco Cessation Treatment Knowledge ..........................67

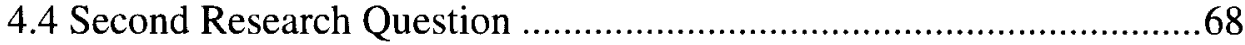

4.4.1 Effect of Variables on Intent to Provide Tobacco Cessation

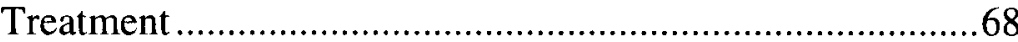

4.5 Third Research Question ..............................................................69

4.5.1 Effect of Training Dates on Variables ..................................69

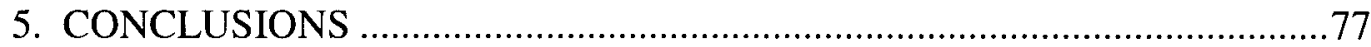

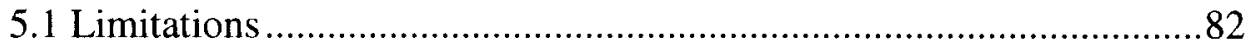

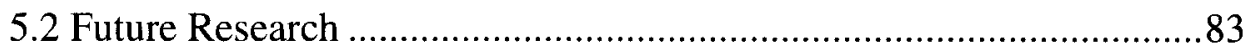

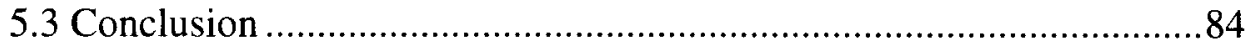

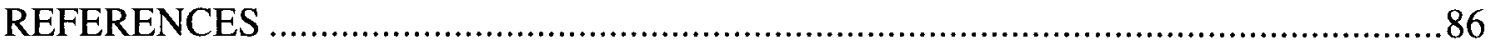

APPENDIX

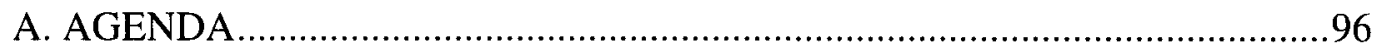

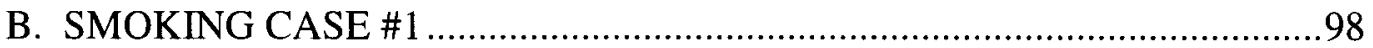

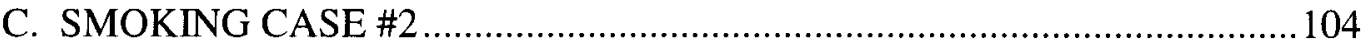

D. SMOKING CASE \#3

E. PREAMBLE

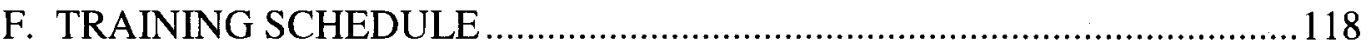


G. PRE-LECTURE QUESTIONNAIRE .............................................. 120

H. POST-LECTURE QUESTIONNAIRE ............................................ 127

I. POST-PROGRAM QUESTIONNAIRE .............................................. 135

J. KEY POINTS FOR STANDARDIZED PATIENT CASES ...................... 144

CURRICULUM VITAE .......................................................................... 147 


\section{LIST OF FIGURES}

Figure

Page

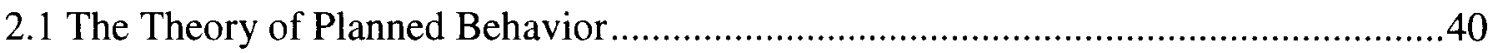

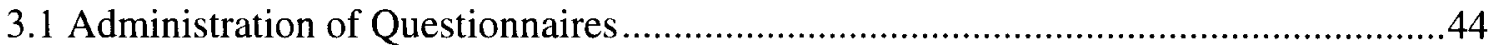

4.1 Consort 2010 Flow Diagram of Participants in Study .......................................55

4.2 The Difference in Attitude Toward Tobacco Cessation

Treatment between the Intervention and Control

Groups from Time 1 to Time 2

4.3 The Difference in Perceived Barriers between the Intervention and Control Groups from Time 1 to Time 2.

4.4 The Difference in Subjective Norms between the Intervention and Control Groups from Time 1 to Time 2

4.5 The Difference in Perceived Skills between the Intervention and Control Groups from Time 1 to Time 2

4.6 The Difference in Self-Efficacy between the Intervention and Control Groups from Time 1 to Time 2

4.7 The Difference in Intentions to Provide Tobacco Cessation Treatment between the Intervention and Control

Groups from Time 1 to Time 2

4.8 The Difference in Tobacco Cessation Treatment Knowledge between the Intervention and Control Groups

from Time 1 to Time 2 .

4.9 The Difference in Attitude Toward Providing Tobacco Cessation Treatment between the Intervention and Control Groups from Time 1 to Time 2 at Different Training Dates

4.10 The Difference in Perceived Barriers between the Intervention and Control Groups from Time 1 to Time 2 at Different Training Dates 
4.11 The Difference in Subjective Norms between the Intervention and Control Groups from Time 1 to Time 2 at Different Training Dates

4.12 The Difference in Perceived Skills between the Intervention and Control Groups from Time 1 to Time 2 at Different Training Dates

4.13 The Difference in Self-Efficacy between the Intervention and Control Groups from Time 1 to Time 2 at Different Training Dates

4.14 The Difference in Intentions to Provide Tobacco Cessation Treatment between the Intervention and Control Groups from Time 1 to Time 2 at Different Training Dates

4.15 The Difference in Tobacco Cessation Treatment Knowledge between the Intervention and Control Groups from Time 1 to Time 2 at Different Training Dates 


\section{LIST OF TABLES}

Table

Page

3.1 Item Differences between Pre-Lecture, Post-Lecture, and

Post-Questionnaires

4.1 Demographic Differences between the Intervention and

Control Groups at Time 1

4.2 Differences in Variables between the Intervention and Control

Groups at Time 1 and Time 2. In Addition, Analysis of Differences

in Variables over Time 


\section{CHAPTER 1}

\section{INTRODUCTION}

Dental professionals can play a key role in reducing tobacco use and helping their patients quit by providing tobacco cessation treatment (TCT) in their practice (Department of Health and Human Services, 2005; Rikard-Bell, Groenlund, \& Ward, 2003; Tomar, 2001; Vered, Livny, Zini, Shabaita, \& Sgan-Cohen, 2010). Although the majority of dental professionals receive training in TCT, most do not provide adequate intervention (Fried, Reid, \& DeVore, 2004; O'Donnell, Hamilton, Markovic, \& Close, 2010; Vanobbergen, Nuytens, Herk, \& Visschere, 2007). One of the primary reasons they fail to provide adequate intervention is that they do not feel adequately trained to provide TCT (Clareboets, Sivarajasingam, \& Chestnutt, 2010; Rikard-Bell et al., 2003; Vanobbergen et al., 2007). Students not adequately trained in TCT will lack confidence in their counseling skills and will less likely provide intervention in practice (Giacona, 2004; Rajasundaram, Sequeira, \& Jain, 2011; Rikard-Bell et al., 2003).

It is evident that better methods of training must be found to increase TCT in the dental setting (Cannick, Horowitz, Reed, Drury, \& Day, 2006; Vanobbergen et al., 2007). Further research in training methods is indicated to increase dental students' intentions to provide cessation counseling in their practice (Botelho, Wassum, Benzian, Selby, \& Chan, 2009; Rajasundaram et al., 2011; Vanobbergen et al., 2007). At a dental school in southeastern United States, only 39\% of first through fourth year students reported that they were adequately trained to provide cessation treatment and only $14.1 \%$ were quite or very confident in their counseling skills (Cannick et al., 2006). 
Using standardized patients (SPs) in training health care professionals has shown promise in increasing confidence in treatment skills, but more research is needed to determine if this method is effective (Brame, Martin, Tovac, Stein, \& Curran, 2012; Walsh et al., 2007). Standardized patients are individuals who are trained to portray patients in simulated clinical settings. Using SPs allow students an opportunity to practice cessation counseling skills before clinical practice (Walsh et al., 2007). Students are able to practice counseling skills in a non-threatening environment where they are offered constructive feedback from SPs to improve their skills (Walsh et al., 2007). Debriefing sessions conducted by tobacco health specialists after the three encounters with SPs provide an opportunity for clarification and to answer any questions (Walsh et al., 2007).

Using standardized patients is an established teaching method in medicine, but is a novel approach to training dental students in TCT (Becker, Rose, Berg, Park, \& Shatzer, 2006; Long-Bellil et al., 2011). It has been used successfully in teaching communication, interviewing, and clinical skills in medicine and nursing (Bolstad, Shen, Covelli, \& Torpey, 2012; Bornais, Raiger, Krahn, \& El-Masri, 2012; Long-Bellil et al., 2011; Weidner, Gimpel, Boulet, \& Solomon, 2010). The National Board of Medical Examiners is now using SPs in their medical licensing examination (Becker et al., 2006). Advantages in using SPs include: (a) providing uniformity in case scenarios to standardize teaching and evaluation, (b) stimulating critical thinking, knowledge, and skills, (c) providing an opportunity to practice skills in a safe learning environment, (d) providing available and flexible training opportunities, (e) providing a systematic and structured approach to training, and (f) providing reliable and valid evaluation of 
students' performance (Becker et al., 2006; Bolstad et al., 2012; Bornais et al., 2012; Long-Bellil et al., 2011). The cost of recruiting, training, and managing the SP Program could be a disadvantage to this approach (Bolstad et al., 2012). However, there would be costs to using faculty to train students in TCT. Another disadvantage of using SPs is the possibility of students becoming nervous and anxious prior to the training. Students have expressed that the feelings of nervousness and anxiety dissipated once the training began (Becker et al., 2006).

\subsection{Health Effects of Tobacco Use}

Tobacco use is the leading cause of preventable morbidity and mortality in the United States (Centers for Disease Control and Prevention, 2011 a; Fiore et al., 2008; U.S. Department of Health and Human Services, 2010). Approximately 443,000 Americans die from tobacco-related illnesses each year (Centers for Disease Control and Prevention, 2011 ; U.S. Department of Health and Human Services, 2010). For every person who dies from tobacco use, another twenty suffer with at least one serious tobacco- related illness (Centers for Disease Control and Prevention, 2011 a; U.S. Department of Health and Human Services, 2010). Cigarette smoke is known to cause lung cancer, chronic obstructive pulmonary disease (COPD), cardiac disease, stroke, and complications of

pregnancy (Fiore et al., 2008; U.S. Department of Health and Human Services, 2010). In 2004 , tobacco-related illnesses cost the nation more than $\$ 96$ billion in direct medical expenses, and the estimated loss of productivity each year was $\$ 97$ billion (Centers for Disease Control and Prevention, 2011 b; Fiore et al., 2008; U.S. Department of Health and Human Services, 2010). In 1999, 14.3 billion dollars was spent on periodontal and preventive procedures (Brown, Johns, \& Wall, 2002). These costs could be reduced by 
following the cost-effective preventive approach to treating tobacco dependence and disease recommended in the U.S. Department of Health and Human Services Clinical Practice Guideline (Centers for Disease Control and Prevention, 2011b; Cromwell, Bartosch, Fiore, Hasselbad, \& Baker, 1997).

Tobacco use and its harmful effects is a great concern to the dental profession (Research Science and Therapy Committee of the American Academy of Periodontology, 1999). Its use increases the risk of oral cancer, carcinoma of the larynx, periodontal diseases, and other tobacco related oral diseases (Weaver, Whittaker, Valachovic, \& Broom, 2002). Smoking is a major risk factor for periodontal diseases (Johnson \& Slach, 2001; Research Science and Therapy Committee of the American Academy of Periodontology, 1999). Smokers are between two and fourteen times more likely to develop periodontal disease than non-smokers (Scott, Palmer, \& Stapleton, 2001). There is a strong association between tobacco use and impairment of wound healing and implant failure (Tomar, 2001). Other problems found in people who use tobacco are bad breath, stained teeth, tooth loss, loss of taste, gingival recession, and mouth sores. Tobacco users have been shown to have increased amounts of nicotine stomatitis, candidiasis, leukoplakia, dental caries, and calculus (American Academy of Periodontology, 2011).

In the United States, $19.3 \%$ of the adult population smokes cigarettes (Centers for Disease Control and Prevention, 2011b). About 4,000 youths try a cigarette each day, and as many as 1,200 children and adolescents become smokers (Fiore et al., 2008). The high rate of adult smokers increases the need for prevention and cessation services (Department of Health and Human Services, 2005). Many adult smokers want to quit 
and have attempted to quit tobacco use (Centers for Disease Control and Prevention, $2011 \mathrm{~b})$. The Centers for Disease Control and Prevention's (CDC) analysis of the data from the 2001-2010 National Health Interview Surveys (NHIS) found that $68.8 \%$ of adult smokers want to quit tobacco use, $52.4 \%$ had made a quit attempt in the past year, $6.2 \%$ had recently quit, $48.3 \%$ had been advised by a health professional to quit, and $31.7 \%$ had used counseling and/or medications when they tried to quit (Centers for Disease Control and Prevention, 2011b). Quit attempts rose in smokers aged 25-64 from 20012010 (Centers for Disease Control and Prevention, 2011c).

\subsection{The Role of the Dental Professional}

The majority of health care students in dental hygiene, dentistry, medicine, nursing, pharmacy, and physical therapy agree they have a professional responsibility to help smokers and smokeless tobacco users to quit (Fried et al., 2004; Warren et al., 2011). The 2011 CDC's report concerning smoking among adults in the United States recommends that health care providers identify tobacco users on a consistent and routine basis, advise them to quit, and help those wanting to quit (Centers for Disease Control and Prevention, 2011b). The American Academy of Periodontology recommends that members advise patients of the negative health effects of tobacco use, inform patients of the benefits of quitting, and provide cessation treatment in the dental office (Research Science and Therapy Committee of the American Academy of Periodontology, 1999). Preventing adolescents from starting tobacco use should be emphasized as well as helping tobacco users to quit (Giacona, 2004). Dental professionals can improve the outcome of dental treatment and prevent oral disease by providing cessation treatment services in their offices (Johnson \& Slach, 2001; Tomar, 2001). 
Research has shown that dental professionals can be effective in counseling patients to quit tobacco use (Gelskey, 2002; Tomar, 2001). Brief and simple advice from health care professionals can make a difference in tobacco quit rates (Centers for Disease Control and Prevention, 2011b; Tomar, 2001). Tobacco cessation treatment training has been shown to increase the number of patients counseled to quit tobacco use and has been found to be a cost-effective intervention to provide in dental practice (Cromwell et al., 1997).

Dental professionals are in a unique position to raise their patients' awareness of the harmful effects of tobacco use, educate their patients of the signs and symptoms of tobacco related oral disease, and to assist their patients in quitting at regular dental visits (Tomar, 2001; Vered et al., 2010). Dentists and dental hygienists can actually show patients the visible signs of oral disease during routine dental exams. They can simply use a hand mirror or an intraoral camera to show patients the visible changes to their tissues as a result of tobacco use (Giacona, 2004). Regular recall appointments provide an opportunity to consistently provide advice and assistance to patients (Tomar, 2001). The majority of tobacco users see their dentist at least once a year (Giacona, 2004; Tomar, 2001).

Dental professional organizations promote tobacco cessation counseling to their members and encourage tobacco curriculum content in the formative years of dental training to help reduce the health impact of tobacco use (Barker, Williams, Taylor, \& Barker, 2001; Tomar, 2001). The importance of dentistry's role in solving the problems of tobacco use is stressed in the Healthy People 2020 objective of tobacco use to increase 
tobacco screening and counseling in dental care settings (U.S. Department of Health and Human Services, 2010).

\subsection{Dental Professionals Do Not Provide Services}

The problem is that dental professionals are not routinely providing tobacco cessation treatment to patients who are willing to quit (Barker et al., 2001; Vanobbergen et al., 2007). Many dental professionals feel they are not adequately trained to offer intervention services to patients (Clareboets et al., 2010). Health care providers as well as students lack cessation related knowledge and counseling skills (Clareboets et al., 2010; Rajasundaram et al., 2011; Rikard-Bell et al., 2003; Vanobbergen et al., 2007). It has been shown that many health care providers lack the understanding of the chronic and addictive nature of tobacco dependence and are not comfortable in their ability to counsel patients (Fiore et al., 2008). Multiple attempts to quit tobacco use and the need for repeated intervention make counseling a challenging task for the dental professional (Fiore et al., 2008). The lack of training in effective interventions keeps dentists and dental hygienists from providing tobacco cessation counseling in practice (Gordon, Severson, Seeley, \& Christiansen, 2004).

Dental students report they do not provide TCT because they do not feel adequately prepared to counsel patients and they lack the time needed to provide adequate intervention (O'Donnell et al., 2010; Vanobbergen et al., 2007). These barriers are likely reflected in dental students' low acceptance of tobacco use interventions during their years of education. Cannick et al. (2006) reported less than 20 percent of dental students in a study were confident in their ability to assist patients in stopping smoking, 
preventing patients from starting to use tobacco products, and assessing and treating nicotine dependence.

Although dentists ask about their patients' tobacco use, only $20 \%$ actively help patients through the process of quitting (Coan, Christen, \& Romito, 2007; Dolan, McGorray, \& Grinstead-Skigen, 1997). A survey of dental hygienists and dental school alumni revealed that over $87 \%$ of dental students and $100 \%$ of dental hygiene students ask their patients about tobacco use, $82 \%$ of dental students and $96 \%$ of dental hygiene students document tobacco status, and $87 \%$ of dental students and $98 \%$ of dental hygiene students advise patients about tobacco cessation options (Barker et al., 2001). A smaller number of the dental students $(22 \%)$ and dental hygiene students $(19 \%)$ referred patients to cessation counselors or support groups, $7 \%$ of dental students and $13 \%$ of dental hygiene students set a quit date, and $32 \%$ of dental students and $36 \%$ of dental hygiene students distributed self-help materials in their practices (Barker et al., 2001).

\subsection{Areas of Focus and Gaps in the Literature}

The areas of focus in the field of dentistry have been in studying attitudes toward tobacco cessation counseling, the role of the dental professional in cessation counseling, the barriers that exist in offering tobacco cessation counseling in the dental practice, and the impact of traditional training methods such as lectures. More research is needed to determine the effectiveness of using standardized patients in cessation treatment education for dental students. Evidence in the literature supports the use of standardized patients in training health care professionals in tobacco cessation counseling in general, but how the use of SPs affects use of TCT needs further study (Martin \& Chewning, 2011; Walsh et al., 2007). Evaluation of cessation training methods in dentistry that 
provide hands-on training, application of knowledge, and fostering critical thinking skills are missing from the literature. A study evaluating the curricular effects on medical students' knowledge and self-perceived skills in cancer prevention indicated that handson instructional strategies that allow students opportunities to practice their counseling skills promote knowledge acquisition and self-perceived competency in their skills (Wilkerson, Lee, \& Hodgson, 2002) .

The literature reveals a gap in developing and implementing comprehensive tobacco cessation and preventive programs that effectively address dental students' perceived barriers in providing cessation counseling (Harris, Patton, Wilder, Peterson, \& Curran, 2009; Pendharkar et al., 2010; Vanobbergen et al., 2007; Weaver et al., 2002). Dental educators are finding it difficult to overcome barriers to tobacco cessation counseling and achieving successful learning outcomes (Tomar, 2001). They report that the lack of integration of the didactic course material and clinical instruction make it difficult to train students in cessation counseling. The curriculum does not allow time to develop supportive intervention skills such as interviewing, pharmacotherapy options, and relapse instruction (Coan et al., 2007; Spangler, George, Foley, \& Crandall, 2002). Missing in the literature is how to address the problem of dental professionals being uncomfortable discussing tobacco cessation with patients. Dental professionals state the lack of adequate training as the reason for not providing cessation treatment in practice (Clareboets et al., 2010; Rajasundaram et al., 2011; Vanobbergen et al., 2007). Educational methods such as didactic training, interactive CD-ROM programs, and motivational interviewing are described in the literature, but additional research is needed to evaluate their effectiveness in the dental setting. 
Missing information has created an awareness of the need to develop more comprehensive and interactive programs that are effective in encouraging dental professionals to provide tobacco cessation counseling in their practices (Vanobbergen et al., 2007). Current methods of training have not eliminated the barriers that exist in providing intervention in the dental office (Vanobbergen et al., 2007). Dental professionals continue to fail to offer interventions after receiving training in their curriculum (Vanobbergen et al., 2007). Training programs are needed that increase dental students' intentions to offer tobacco cessation counseling (Rajasundaram et al., 2011; Vanobbergen et al., 2007).

\subsection{Study Intervention}

The study intervention included a didactic portion and a hands-on treatment portion that allowed the freshman dental student to counsel standardized patients in three different case scenarios. The agenda for the two hour didactic portion of the training is included as Appendix A (see page 96). The didactic portion closely followed the Treating Tobacco Use and Dependence: 2008 Update, a Public Health Service-sponsored Clinical Practice Guideline that includes strategies and recommendations in delivering effective treatments for tobacco use and dependence (Fiore et al., 2008). It also followed the recommendation of the American Dental Hygienists' Association to Ask, Advise, and Refer (American Dental Hygienists' Association, 2009). The objectives and the approximate times given to each objective of the didactic portion were: (a) discuss the impact of tobacco dependence, especially as it relates to oral health (15 minutes), (b) provide recommended interventions for patients willing and not willing to make a quit attempt (40 minutes), (c) discuss approved pharmacological treatments and their proper 
usage (45 minutes), and (d) refer patients to external or community resources, especially Kentucky's Quit Line, for follow-up and support (20 minutes).

The didactic portion included instruction in the " $5 \mathrm{~A}$ ' $\mathrm{s}$ " model for treating tobacco use and dependence and the "5 R's" model of enhancing motivation to quit (Fiore et al., 2008). The five components of the "5 A's" model are: (1) ask about tobacco use, (2) advise patient to quit, (3) assess patient's willingness to make a quit attempt, (4) assist patient in quit attempt, and (5) arrange follow-up contacts. The five components of the "5 R's" model are: (1) encourage the patient to indicate why quitting is personally relevant, (2) ask the patient to identify the risks of tobacco use that are personally relevant, (3) ask the patient to identify the rewards or the potential benefits of quitting, (4) ask the patient to identify roadblocks to quitting, and (5) repeat motivational intervention (Fiore et al., 2008).

Students learned that tobacco cessation counseling is a process and were asked to apply the transtheoretical model (TTM) of behavioral change in their treatment (Rimer \& Glanz, 2005). Different models and strategies are indicated based on the patient's stage of change. The Prochaska and DiClemente's Transtheoretical Model explains that individuals must go through stages of precontemplation, contemplation, preparation, action, and maintenance before changing their behavior (Fiore et al., 2008). Patients who are pre-contemplating quitting tobacco use should be encouraged and advised to quit. Patients who are contemplating and prepared to quit should be assisted in their quit attempt, and patients in the action and maintenance stage should receive relapse prevention strategies (Fiore et al., 2008). 
Students were given practical strategies to help counsel patients during difficult times of withdrawal and addiction. Students received information from the Rx for Change: Clinician-Assisted Tobacco Cessation Curriculum at the University of California, San Francisco for use with pharmacy students (University of California San Francisco, 2011). They received information about Kentucky's Tobacco Quitline and were asked to refer patients who are contemplating quitting to the quitline at 1-800-QUIT NOW (Kentucky's Cabinet for Health and Family Services, 2011). It is a free telephonebased treatment service which offers one-on-one proactive counseling and information about local resources for patients willing to quit. It also provides support and information to health care providers (Kentucky's Cabinet for Health and Family Services, 2011).

The "hands-on" practice sessions of the training consisted of three encounters with standardized patients who role-played different stages of willingness to quit tobacco use. The standardized patients represent tobacco using patients willing to quit, contemplating quitting, and resistant to quitting (see Appendices B, C, and D). The standardized patients are trained by the University of Louisville School of Medicine Standardized Patient Program. At the start of their training, standardized patients complete a twenty hour training in providing medical examinations and giving feedback. Each SP must receive an acceptable inter-reliability score before being trained in other examinations. Resources are limited at the SP Program, and inter-rater reliability of SPs is only conducted on summative learning experiences. The following steps are taken to determine the inter-rater reliability of SPs for summative learning experiences: (a) one SP observes another SPs live interaction with a student, (b) each SP completes a checklist on the same student, and (c) Cohen's kappa is used to determine the agreement between 
the two checklists. The Standardized Patient Program's Director stated that the SPs achieve a Cohen's kappa of 0.9 during the summative evaluation, and they are highly satisfied by their level of agreement. In the literature, the standard of inter-reliability for SPs is a Cohen's kappa of 0.7-0.8 (Landis \& Koch, 1977).

The SPs receive two hours of additional TCT training by tobacco health specialists prior to the counseling sessions. During this training, the specialists address the expectations of the checklist for each case. In addition, the specialists watch the cases and provide feedback each time the practice sessions take place. The Director of the SP Program said this contributes to the process that is called "fine tuning" in SP education.

Each student was asked to counsel a patient for ten minutes and then the standardized patient provided four minutes of feedback. A written case study was provided immediately before the student entered the counseling session. For quality control and to access fidelity, several of the sessions were observed by tobacco health education specialists, the course director, and the researcher. The debriefing session, held immediately after all three patient encounters were completed by the students, allowed time for the specialists and course director to answer any questions the students had about the counseling encounters and to provide additional feedback.

\subsection{Statement of Purpose}

After receiving cessation treatment education, dental students do not feel confident providing cessation counseling in practice (Cannick et al., 2006). Without confidence in their ability to counsel patients in quitting tobacco use, dental students will fail to offer intervention services to patients while in school or in practice. These services are needed to address the negative impact of tobacco use on oral health. To overcome this problem, 
barriers to offering cessation services should be overcome and effective tobacco cessation training methods should be included in the dental curriculum.

The purpose of this study was to determine if there was a difference in dental students' attitudes, perceived barriers, subjective norms, perceived skills, self-efficacy, intentions to provide cessation treatment and tobacco cessation knowledge between those students who receive a lecture along with practice sessions using standardized patients and those students who receive lecture only. These variables were selected based on the constructs of the theory of planned behavior. Measuring the change in these constructs provided insight into dental students' intention to provide tobacco cessation treatment in practice. A secondary aim was to determine if dental students' attitude, perceived barriers, subjective norms, perceived skills, self-efficacy, cessation knowledge, and tobacco status predicts intentions to provide TCT. The third aim was to determine if the time between receiving the lecture and participating in the practice and debriefing sessions affected dental students' attitudes, perceived barriers, subjective norms, perceived skills, self-efficacy, intentions to provide cessation treatment, and tobacco cessation knowledge.

This study proposed that the training method using standardized patients is a better strategy to increase dental students' intentions to provide tobacco cessation treatment than offering a traditional lecture alone. Information gained from the evaluation will provide an understanding of how dental students' attitudes, barriers, subjective norms, perceived skills, self-efficacy, knowledge, and tobacco use influence intent to counsel patients to quit tobacco use in practice. It will provide insight into how these variables can change as a result of treatment education. This study will provide 
valuable information that may or may not find support for the method of using standardized patients in cessation treatment education.

\subsection{Significance of the Study}

The results of this study will contribute to the body of knowledge that explores effective training methods that increase dental students' intentions to provide cessation counseling in their practices. The results of the study may be generalized to other populations of dental students, but may not be generalized to other health professionals due to using a convenience sample of dental students. The results may be beneficial in designing effective cessation programs in the dental curriculum in the future.

\subsection{Research Questions}

The first research question being addressed in the study was: Is there a difference in dental students' attitudes, perceived barriers, subjective norms, perceived skills, selfefficacy, intentions to provide cessation treatment and tobacco cessation knowledge between those students receiving a lecture along with practice sessions using standardized patients and those students receiving lecture only.

Other questions were: Do dental students' attitudes toward TCT, perceived barriers, subjective norms, perceived skills, self-efficacy, tobacco cessation knowledge, and their type of training, tobacco status and use of tobacco predict their intent to offer cessation treatment in practice? Does the time between receiving the lecture and participating in the practice sessions affect attitudes, barriers, subjective norms, perceived skills, self-efficacy, intentions to provide cessation treatment and tobacco cessation knowledge? 


\subsection{Limitations and Delimitations}

\subsubsection{Limitations}

Limitations threaten the internal and external validity of the study. Using group randomization that limited control over the intervention created a sampling bias. The dental students' self-reporting when completing the questionnaires limits the accuracy of the results of the study. The assumption is made that the dental students' self-report will be honest, accurate, and complete. Administering the questionnaires before the lecture may have created testing effects. Dental students' memory of taking the first questionnaire may have influenced completing the second questionnaire. The effect of dental students' tobacco status and differences in time between the lecture and counseling sessions using standardized patients may have influenced the dental student's intent to provide TCT. This effect was analyzed and reported. The assumption based on theory is made that intention approximates actual behavior of dental graduates in practice (Rimer \& Glanz, 2005).

\subsubsection{Delimitations}

Delimitations threaten the internal and external validity of the study. Delimitation was created by assigning students to small groups alphabetically and in descending order. A group randomization process allowed approximately half of the students (52) to be placed in a control group and the other half (42) to be assigned to the intervention group. Since it was required for all students in the course to participate in the practice sessions using SPs, the nineteen students who missed the lecture were included in the training schedule. The students who missed the lecture completed post- questionnaires as well as those students participating in the study. This created the unequal distribution of group 
members between the intervention and control groups. Pre- and post-questionnaires were linked after the training was completed. The schedule could not be changed after learning that nineteen students were absent from the lecture. It was developed in July and the other course activities taking place at the same time could not be changed.

\subsection{Definition of Terms}

- Perceived barriers are beliefs that there are psychological and economic costs associated with the behavior (Rimer \& Glanz, 2005).

- Self-efficacy represents an individual's confidence in his/her ability to perform a behavior (Rimer \& Glanz, 2005).

- Standardized patients (SPs) are individuals trained to portray patients in simulated clinical environments to allow students to practice interviewing, counseling, and clinical skills. The SP's are trained to evaluate students' skills and to provide immediate feedback (Walsh et al., 2007).

- Subjective norms are beliefs that people who influence your actions approve or disapprove of the behavior (Rimer \& Glanz, 2005) .

- Tobacco cessation treatment education is the training provided to students to treat patients' tobacco dependence (Butler et al., 2009). 


\section{CHAPTER 2}

\section{LITERATURE REVIEW}

\subsection{Factors Influencing Cessation Treatment in Dental Settings}

Factors discussed in the literature that influence tobacco cessation treatment's current status include health professional's attitudes, perceived barriers, subjective norms, perceived skills, self-efficacy, intentions, and TCT knowledge. Understanding the influence of these factors on providing TCT in dental settings is important to improving training programs. Fried reported that course content about the dental professional 's role in providing TCT has been included in a dental curriculum, yet less than half of dental students felt adequately prepared to help smokers and smokeless tobacco users quit (Fried et al., 2004).

\subsubsection{Attitudes toward Tobacco Cessation Treatment}

Despite the lack of confidence in their ability to counsel patients, dental students are supportive of tobacco cessation training and have a positive attitude toward providing tobacco use interventions (O'Donnell et al., 2010; Vered et al., 2010). They feel that training in cessation treatment is an important part of dental education (O'Donnell et al., 2010). Students' attitude toward providing interventions has shown to be more positive after education in counseling methods (O'Donnell et al., 2010; Vered et al., 2010).

Attitudes are thought to influence dental students' receptivity to training and the extent of which they provide TCT (Victoroff, Danjulich-Huryn, \& Haque, 2004). The majority of incoming students at a midwestern dental school agreed they had a professional responsibility to promote tobacco cessation (Victoroff et al., 2004). Fewer 
students agreed on which cessation treatments were within the scope of dental practice (Victoroff et al., 2004). Only $20 \%$ of the students felt that cessation treatment could help patients quit tobacco use (Victoroff et al., 2004).

Treatment education has been shown to increase the number of patients counseled to quit tobacco use. A greater number of patients in Canada reported they received counseling after students went through a cessation educational program than before the students went through it (Gelskey, 2002). Alumni from a midwestern dental school credited the influence of scientific evidence of tobacco's effect on oral health, involvement in the School of Dentistry's tobacco cessation clinical program, and professional journal articles related to tobacco interventions on providing cessation treatment in their offices (Barker et al., 2001). To a lesser degree they credited encouragement of the staff and materials from health agencies for influencing their cessation activity (Barker et al., 2001).

When comparing students in the health professions who use tobacco to students who did not, there were no statistically significant differences found in students' attitudes towards professional responsibility to help smokers and smokeless tobacco users to quit. When asked if their program adequately prepared them to help smokeless tobacco users to quit, non-smokers and non-smokeless tobacco users were more likely to agree than current smokers and smokeless tobacco users (Fried et al., 2004). The Global Health Professions Student Survey (GHPSS) was conducted among third year dental students in forty-four countries, the Gaza Strip/West Bank, and three cities of Baghdad, Rio de Janeiro, and Havana (Warren et al., 2011). It revealed that in more than half of the sites surveyed that over $20 \%$ of the students currently smoked cigarettes. In thirty of the sites, 
males had significantly higher smoking rates than females. The students surveyed recognized that they would be role models in society and felt it was important to receive cessation treatment education (Warren et al., 2011). The researchers concluded that dental students should be encouraged to quit tobacco use through tobacco control efforts, promoting smoke-free workplaces, and effective cessation treatment education (Warren et al., 2011).

\subsubsection{Status of Tobacco Cessation Treatment}

Patients who use tobacco may or may not be receiving tobacco cessation treatment during their dental visits (Barker et al., 2001). A total of 161 dental hygiene and dental alumni from a midwestern university were surveyed about their cessation treatment practices and factors that influenced it. The majority asked their patients about tobacco use and advised them to quit (Barker et al., 2001). Fewer respondents referred patients to cessation counselors or support groups, set a quit date, and distributed resources (Barker et al., 2001).

Factors that influenced their practice included scientific evidence of tobacco's effect on oral health, involvement in a cessation program while in training, continuing education, professional journals, encouragement of staff, and materials from health agencies (Barker et al., 2001). Over 39\% of the respondents reported the reason they did not provide TCT was due to limitations of the practice setting. They were limited in their ability to make their own decisions in practice as graduate students, associates, or by working in a military or public health clinic. (Barker et al., 2001). When asked if they anticipate any changes in their cessation treatment practice in the future, $40 \%$ of the dental hygienists and $63 \%$ of the dentists responded that they anticipated a more 
extensive program. Only $4.2 \%$ of the dental hygienists and $5.6 \%$ of the dentists anticipated a less extensive program (Barker et al., 2001).

A study was conducted to assess the cessation treatment knowledge, attitudes, and current practices among licensed practicing dental hygienists in a southern state willing to participate in a program called Cancer Program's Providers Practice Prevention: Treating Tobacco Use and Dependence Continuing Education Program (Studts, Burris, Kearns, Worth, \& Sorrell, 2011). Of the 1,671 dental hygienists in the state, $18 \%$ responded to the pre-program survey. Lack of knowledge and confidence in providing cessation treatment were reported (Studts et al., 2011). Approximately 60\% of the respondents had not heard of the Public Health Service's Clinical Practice Guidelines and less than $2 \%$ had followed its recommendations. Over $80 \%$ of the responding hygienists were somewhat or very comfortable with discussing cessation with their patients, yet more than $50 \%$ of the hygienists were not comfortable helping a patient develop a quit plan or recommending pharmacotherapies (Studts et al., 2011). Barriers to treatment listed most often by the respondents were the perception that cessation is a low priority for patients and time constraints (Studts et al., 2011).

All dental students in a study from the United Kingdom reported asking about patients' smoking status all or nearly all the time (Clareboets et al., 2010). The majority of students documented smoking habits in dental progress notes (Clareboets et al., 2010). Approximately one third of students advised patients to quit smoking all or nearly all the patient visits and the majority of students advised their patients to quit more than $50 \%$ of the time (Clareboets et al., 2010). A small number of first year students advised none of their patients to quit smoking (Clareboets et al., 2010). Very few students discussed the 
effects of passive smoking, strategies such as setting a quit date, or offered any written information (Clareboets et al., 2010).

Over a third of health professionals in a southern state (802) responded to a survey regarding tobacco-related knowledge, attitudes, and intervention behavior that was sent to 2043 family physicians, dentists, and nurse practitioners (Applegate, Sheffer, Crews, Payne, \& Smith, 2008). The responses varied by profession. Nurse practitioners responded to the survey at a rate of $47.8 \%$, physicians responded at $35.6 \%$, and dentists responded at 35.7\%. Dentists made up $41.4 \%$ of the sample (Applegate et al., 2008). The results revealed that $24.3 \%$ of the responders had received cessation treatment education, $33.7 \%$ were aware of the Public Health Service Clinical Practice Guideline, and $90 \%$ indicated that it was their role to prevent tobacco use (Applegate et al., 2008).

The study found that physicians assisted patients to quit tobacco use more frequently than nurse practitioners and dentists. Only $25 \%$ of the dentists assisted $51 \%$ or more of their patients (Applegate et al., 2008). Over 50\% of the physicians were assisting patients to quit with feedback, support, and reinforcement while over $80 \%$ of the dentists were only making patients aware of the need to quit and the need to develop a plan to quit (Applegate et al., 2008). Over two thirds of the doctors and nurse practitioners felt it was their responsibility to assist patients in quitting tobacco use as compared to less than half of the dentists. Over $80 \%$ of the physicians and nurse practitioners felt that they should assist patients to quit regardless of barriers to treatment. Only $56.8 \%$ of the dentists felt this strongly (Applegate et al., 2008). Approximately $80 \%$ of physicians and nurse practitioners and only $63.9 \%$ of dentists felt that their peers were emphasizing cessation treatment in practice (Applegate et al., 2008). 
Providers who had received treatment education reported providing more cessation treatment and greater self-efficacy, preparedness and fewer barriers. Physicians and nurse practitioners reported more self-efficacy, preparedness and fewer barriers than dentists (Applegate et al., 2008). Dentists reported that they provide cessation treatment at about half the frequency of other providers. Few dentists prescribed nicotine replacement $(21.2 \%)$, bupropion $(6.7 \%)$, or second-line therapies $(1.2 \%)$. Dentists showed greater increases in self-efficacy, preparedness, and treatment after receiving treatment education (Applegate et al., 2008).

Follow up interviews of patients treated by Canadian dental hygiene students revealed their cessation program needed improvement. Ninety percent of the patients said they were advised to quit tobacco use, and $98 \%$ said they were advised of the health risks associated with tobacco use (Maillet, Tax, Neish, \& Denny, 2010). Over 50\% of patients were given information pamphlets and strategies to quit. Only $8 \%$ of patients were given follow-up after their cessation counseling and $2 \%$ of patients permanently quit tobacco use (Maillet et al., 2010). These studies revealed the need to work toward reducing the barriers to providing cessation treatment and implementing effective cessation training methods in the dental curriculum. Out of 54 dental schools surveyed by the American Dental Education Association, 45 had tobacco use prevention in their curricula, 44 taught cessation treatment skills, 53 taught detection and diagnosis of tobacco-related pathology, and 51 taught clinical management and treatment of tobaccorelated pathology (Giacona, 2004). 


\subsubsection{Perceived Barriers to Tobacco Cessation Treatment}

Patients who use tobacco are at risk for oral disease, but dental professionals are not comfortable discussing this issue with their patients (Cannick et al., 2006;

Rajasundaram et al., 2011). Less than $40 \%$ of first- through fourth year dental students at a school in the southern United States felt adequately trained and over half lacked confidence in providing tobacco cessation education to patients (Cannick et al., 2006). Similar results from a university in Israel revealed that approximately $39 \%$ of the students reported not having sufficient skills for counseling at their present stage of training (Vered et al., 2010). Dental students at a university in Australia and at three universities in India in all years of training reported lack of confidence in counseling smokers to quit (Rajasundaram et al., 2011; Rikard-Bell et al., 2003). In another international study, $47 \%$ of the clinical dental students surveyed felt that lack of training to give effective advice was a barrier to counseling patients in tobacco cessation (Clareboets et al., 2010). Over $80 \%$ of dental students in the study perceived patients' disinterest in receiving advice as a barrier to providing treatment (Clareboets et al., 2010). Dental students in India also perceived patients' disinterest as a barrier (Rajasundaram et al., 2011). Over $70 \%$ of the dental students at a university in Israel agreed that smoking patients lack motivation to quit (Vered et al., 2010). Similar results were found at a university in Australia with over $59 \%$ of dental students agreeing that smoking patients lack motivation to quit tobacco use (Rikard-Bell et al., 2003) .

Dental students feel they lack adequate preparation in providing cessation counseling (Clareboets et al., 2010; O'Donnell et al., 2010). About $42 \%$ of the dental students expressed the lack of patient education resource materials as a barrier to 
providing treatment (Clareboets et al., 2010). Other perceived barriers were lack of available time during appointments (32\%), concerns about effectiveness of giving advice (25\%), the amount of time required to give advice (25\%), insufficient support from supervising staff (20\%), and $13 \%$ of the students expressed concern in the possibility of damaging patient rapport (Clareboets et al., 2010).

Sixty-eight incoming fourth year dental students at a midwestern university completed a survey to determine the perceived barriers to cessation treatment (Pendharkar et al., 2010). The students reported that the cessation curriculum was adequate at their school, yet only $55 \%$ felt prepared to provide cessation treatment (Pendharkar et al., 2010). The study found that $96 \%$ of the students reported patients' resistance to tobacco intervention services and inadequate time available for providing intervention services as barriers to cessation treatment (Pendharkar et al., 2010). Forgetting to provide TCT was reported as a barrier by $91 \%$ of the students (Pendharkar et al., 2010). Other perceived barriers related to tobacco intervention services reported by the students were: Inadequate skills (75\%), inadequate knowledge about nicotine replacement drugs (75\%), lack of training to counsel patients who use smokeless tobacco (65\%), and lack of training to counsel patients who use smoked tobacco (64\%) (Pendharkar et al., 2010).

A survey of twenty-six students and four faculty members after a two hour didactic training found that barriers such as lack of adequate preparation and perceived time needed for cessation treatment in a dental setting played a role in preventing students from providing cessation treatment to patients (O'Donnell et al., 2010). The study indicated that barriers could be overcome with training combined with supervised 
practice opportunities (O'Donnell et al., 2010). Third and fourth year dental students and interns from three dental colleges in India reported on a survey that practical skills training would be effective methods to use in cessation treatment education (Rajasundaram et al., 2011).

\subsection{Tobacco Dependence Treatment Education Programs}

Tobacco cessation treatment education programs can be effective in treating tobacco use and dependence (Hudmon et al., 2003; Rankin, Jones, \& Crews, 2010). A study of the impact of a dental/dental hygiene tobacco use cessation curriculum on practice showed that a comprehensive educational program can significantly increase student intervention (Gelskey, 2002). A program based on the Public Health Service Clinical Practice Guideline for Treating Tobacco Use and Dependence was implemented by a dental school in Canada (Gelskey, 2002). A pre- and post- program phone survey was conducted with patients identified as tobacco users to evaluate the effect of the program on students' cessation treatment activity. Of 1,579 adults with complete charts receiving care between August 1997 and May 1998 by dental and dental hygiene students, 302 reported using tobacco. Of those adults interviewed, 256 reported current use of tobacco. Over $45 \%$ said they were informed by a student of the health consequences of tobacco use, and $40 \%$ said they were advised to quit. Of 2,129 adults with complete charts receiving care between August 1999 and May 2000 by dental and dental hygiene students, 407 reported using tobacco. Fifty-seven percent said they were informed by a student of the health consequences of tobacco use, and $65 \%$ said they were advised to quit. The results of the survey found an $11.7 \%$ increase in students' 
counseling of the health consequences associated with tobacco use and a $23 \%$ increase in students' advice to quit (Gelskey, 2002).

Providing lectures has been shown to be a cost-effective method to train dental professionals in tobacco cessation interventions (Rankin et al., 2010; Sheffer, Barone, \& Anders, 2009). Most dental hygiene students from twelve educational programs in an eastern state reported they were comfortable in providing tobacco cessation counseling to both smokers (92\%) and smokeless tobacco users (93\%) after their didactic training and its integration into their clinical curriculum (Harris et al., 2009). Instruction was mainly from lecture $(99 \%)$, health organization pamphlets $(63 \%)$, case studies $(54 \%)$, and inclass audiovisual slides and video (42\%). The sources used for instruction were dental hygiene textbooks and journal articles (Harris et al., 2009). However, $26 \%$ of the dental hygiene students were not comfortable providing quit messages to patients unwilling to quit (Harris et al., 2009).

As part of the dental curriculum, a northern university trained students in a tobacco counseling cessation protocol (Shibly, 2010). Dental students received eight hours of didactic instruction during their first and second year of training. They were provided an additional hour of instruction during their third year. During their fourth year, they were given a fifteen minute reminder of the protocol. Lecture materials and the protocol were available on the school's website and videos of counseling techniques were available on request. Students provided ten minutes of counseling to a patient and were supervised by faculty members trained in cessation treatment (Shibly, 2010).

To determine the effectiveness of the program, researchers surveyed patients by phone and third and fourth year dental students through the school's e-mail system. On 
average, patients were surveyed six months after being seen in the clinic. The phone survey found that $14 \%$ of the patients reported reducing cigarettes smoked per day and $22 \%$ had quit smoking after about six months (Shibly, 2010). Patients reported that cessation treatment was received well and was thought to be helpful (Shibly, 2010). Dental students were surveyed about their TCT for all patients seen over the previous six months. Less than half of the students surveyed reported providing TCT on a routine basis. Of 106 patients planned to have TCT, only 89 received intervention. Of those patients receiving TCT, $51 \%$ made a commitment to quit within two weeks of their intervention. Students reported that $32 \%$ of the patients counseled were tobacco free after the cessation treatment. The quit rate reported by patients and students in the study were higher than rates reported in the literature (Shibly, 2010). However, the protocol was reported only in $56 \%$ of the treatment plans (Shibly, 2010). As a result of the study, it is now mandatory for the students to follow the protocol (Shibly, 2010). The researchers concluded that the success of the protocol is influenced by reinforcement in the clinic setting and improved follow-up and maintenance is needed to avoid patient relapse (Shibly, 2010).

Over 500 pharmacy students in a western state participated in a tobacco cessation treatment education program, $\mathrm{Rx}$ for Change, to evaluate its effectiveness in improving students' counseling skills (Hudmon et al., 2003). The training program consisted of approximately four to six hours of lecture and two hours of a workshop that included hands-on activities such as role playing using case scenarios. The program's content was based on information from the Public Health Service's Clinical Practice Guideline (Hudmon et al., 2003). The participants completed a survey after participating in the 
program and reported a significant increase in abilities to help patients quit tobacco use. The percentage of students reporting their abilities as good, very good, or excellent before the program was $14 \%$ and increased to $90 \%$ after completing the program (Hudmon et al., 2003). The results of the study indicated the need to integrate a comprehensive approach to training students in tobacco cessation treatment education. The researchers concluded that developing and implementing a program such as the $\mathrm{Rx}$ for Change could standardize training in tobacco cessation treatment education and conserve resources (Hudmon et al., 2003).

The clinician-assisted tobacco cessation educational program, Rx for Change, and a survey instrument was pilot tested in baccalaureate nursing students to determine if the program made a difference in nursing students' skill, confidence, knowledge, and perception of the nurse's role in cessation treatment (Butler et al., 2009). The study also determined if a six hour version of the training would increase skill, confidence, knowledge, and perception of the nurse's role more than a two hour version of the training. One group of students received a pre-training survey to evaluate the survey instrument and intervention. A second group of students received a pre- and posttraining survey and received either two or six hours of training. The groups showed a difference in skill, confidence, knowledge, and perceptions as a result of the training. Those students receiving two hours of training did not differ in skill, confidence, knowledge, and perceptions from those students receiving six hours of training (Butler et al., 2009).

An online tobacco cessation course incorporating the $\mathrm{Rx}$ for Change curriculum was created to train students from pharmacy, nursing, and other health professions as a 
joint project by several professors from different midwestern universities (Schmelz, Nixon, McDaniel, Hudmon, \& Zillich, 2010). The purpose of the online technology was to create an active learning environment by offering students the opportunity to view and interact with videos of clinical case scenarios, gain feedback on their performance through online quizzes, conveniently discuss topics online with other students and faculty members, and deliver more training to students. The course was evaluated by students completing pre- and post-training surveys that assessed their ability to provide cessation treatment (Schmelz et al., 2010). The study found that the online training improved students' self-reported ability to provide treatment and had a positive impact on their selfefficacy (Schmelz et al., 2010). Students took the course on an elective basis limiting the study to highly motivated students (Schmelz et al., 2010).

An evaluation of an interactive CD-ROM tobacco cessation program found strong support of its use in training dental and dental hygiene students and changing their knowledge, attitudes, and beliefs in cessation treatment (Gordon et al., 2004). The program provided an interactive step-by-step approach to educating dental professionals in cessation treatment using video demonstrations, graphics, text, and an online resource library (Gordon et al., 2004). The evaluation of the CD-ROM program was conducted in three phases. The first phase consisted of a pilot test including ten dentists and dental hygienists who provided feedback on the format, content, and navigation of the program to be used in future program development. The second phase was an evaluation by fortyseven dental and thirty dental hygiene students who completed pre- and post-tests. Phase three of the program consisted of an evaluation by an advisory committee. Students were positive in their evaluation of the program and significant change was found in tobacco 
knowledge, attitudes, and beliefs. The committee provided positive feedback of the program.

After receiving a didactic portion of training, dental hygiene students were mentored by expert faculty members in analyzing a patient assessment questionnaire and in developing cessation treatment strategies for a tobacco user (Coan et al., 2007). Students provided the information to the patients and wrote a paper about their experience. The results of the student survey found that $80 \%$ of the students felt that the mentored session was useful in learning treatment strategies, $83 \%$ felt more confident in counseling patients, $83 \%$ felt they would use the strategies, and $86 \%$ would recommend the training program (Coan et al., 2007).

Student's self-reported use of motivational interviewing (MI) techniques shows promise in tobacco cessation counseling (Hinz, 2010). This technique centers on the individual's motivation to change their behavior that is consistent with their values. Dental students felt MI enhanced their relationship with the patient by helping them express concern for the patient and to talk with them about oral health behavior change in a nonjudgmental approach (Hinz, 2010). This approach was found effective when students recognized the patient's stage of readiness to change and responded appropriately (Hinz, 2010). It can be time consuming and requires specialized training and supervision (Hinz, 2010). Two groups of eleven junior and senior dental students each from a midwestern dental school participated in a study in which the experimental group received twelve hours of training in brief motivational interviewing (BMI) and the control group received none (Koerber, Crawford, \& O'Connell, 2003). Both groups received a two to three hour seminar on the oral health effects of tobacco use and the 
principles of smoking cessation counseling. The groups showed significant differences in the amount of BMI techniques used and the involvement of patients in the session. The evaluations of the program were positive but students felt that twelve hours of training was excessive (Koerber et al., 2003).

The Second European Workshop 2008 Education Working Group's focused on the paradigms of the U.S. Public Health Service 5As and 5Rs, FDI World Dental Federation/WHO 4 As, New Zealand's ABC (ask, brief advise and cessation report) and the WHO Framework Convention on Tobacco Control Report on Tobacco Dependence and Cessation to arrive at a consensus (Davis et al., 2010). The consensus was to move from tradition training methods to techniques that engage and motivate the patient. The group suggests a model of health behavior change that utilizes motivational interviewing (MI) in tobacco prevention and cessation treatment (Davis et al., 2010).

Incoming fourth year dental students at a midwestern university were asked to complete a written survey to assess perceived barriers to providing TCT. The adequacy of the TCT curriculum and the importance of incorporating an objective structured clinical examination teaching method into the program were significantly related to the students' perceived barriers. Students reported that valuable cessation treatment educational methods include didactic lectures (91\%), web-based learning (83\%), problem-based learning (79\%), CD-ROM instruction (68\%), and objective structured clinical examination $(67 \%)$. Almost $31 \%$ of the students reported that they needed more clinical experience, and $23 \%$ needed more training in nicotine replacement therapy (Pendharkar et al., 2010). The researchers concluded that cessation treatment education 
could be improved by providing simulated and clinical experiences in students' formative years of training (Pendharkar et al., 2010).

Botelho discussed the international variability of tobacco use among health care professionals and students and the gaps in tobacco cessation treatment training. The publication included a series of papers that explored the issue in providing TCT in medicine, nursing, dentistry, and pharmacy. He encouraged the ongoing approach of using international surveys to monitor smoking rates among health care professionals and to advocate for comprehensive TCT training programs. Botelho discussed the need for developing professional organizational alliances to create social movements to address the gaps in tobacco dependence treatment education and services (Botelho et al., 2009). The limitations of evidence-based guidelines would be addressed by switching from teaching individuals about changing-specific behaviors to engaging individuals to learn how to change risk behavior. Teaching healthy habits would potentially address the gaps in health promotion, disease prevention, and cessation services (Botelho et al., 2009). He suggested that community-based programs for patients and led by patients may be the best option for countries that cannot afford costly TCT programs.

\subsection{Treatment Education Programs Using Standardized Patients}

Pharmacists' counseling performance in asking patients about tobacco use, advising patients to quit, assessing willingness to quit, assisting patients in quitting, and arranging follow-up were assessed after training using standardized patients. The program was designed for practicing pharmacists and consisted of an eight hour live training workshop. The training program provided two SP encounters with scenarios based on the national tobacco cessation guidelines and targeting the preparation and 
action phases of the transtheoretical model. An observation tool using the guidelines and transtheoretical model was developed for each case scenario to assess the participants' behavior performance. Two independent observers were trained in using the observation tool and scored the videotaped sessions. The pharmacists performance improved significantly from the training (Martin \& Chewning, 2011). Twelve months following the training, phone interviews and submitted invoices indicated that $75 \%$ of the pharmacists who completed the training attempted to implement a program in practice. Up to one year after completing training, over $50 \%$ of pharmacists assisted patients to quit tobacco use. The researchers concluded that practice sessions using standardized patients were beneficial to student learning and may predict whether they offer cessation treatment in practice (Martin \& Chewning, 2011). They concluded that the observation tool could be used as an educational tool to provide positive feedback of strengths and to identify areas in need of improvement. It can also be used to validate the change in behavior due to the training method.

Dental hygiene students, dental residents and medical residents reported a change in comfort level in aspects of providing tobacco cessation intervention after training using standardized patients (Walsh et al., 2007). Participants attended a one- to two-hour lecture based on the clinical practice guidelines to treating tobacco use and dependence and then participated in three practice sessions with SPs. The three SP cases were designed to represent patients in various stages of changing tobacco use behavior. Thirty-six participants completed a pre-program survey before the lecture and a postprogram survey after the practice sessions with SPs. The participants' level of comfort increased significantly in discussing tobacco cessation with their patients, helping 
patients develop a quit plan, and recommending appropriate pharmacological treatments and their usage (Walsh et al., 2007). Participants' intentions to ask patients about tobacco use, advise patients to quit, and assist patients in quitting also increased significantly as a result of the training using standardized patients (Walsh et al., 2007). Participants reported that their confidence in advising their patients to quit was increased, the feedback from the SPs was helpful, and that they would recommend the training to others interested in developing cessation treatment skills (Walsh et al., 2007).

A randomized controlled pilot study was conducted to determine the difference in dental hygiene students' confidence between those students receiving a lecture followed by a practice session using a SP and those students receiving a lecture only (Brame et al., 2012). The study found that the practice session using a SP improved students' initial confidence and that the confidence level was sustained, but not significantly. After the lecture, students received a baseline test of knowledge and confidence. They were assigned to intervention ( $n=14)$ and control groups $(n=13)$ based on their knowledge scores. There was no significant difference in tobacco cessation treatment knowledge between the intervention and control groups after the lecture. Additional tests were given at one week and six months following the practice session using the SP. At one week, students' confidence in providing TCT was significantly higher for those students receiving training using the SP than those students receiving the lecture only. At six months, there was a slight decline in the intervention group members' confidence $(\mathrm{n}=$ 13) while the control group members' confidence $(n=13)$ increased. The groups' overall confidence was comparable. Additional research was suggested to determine the 
sustainability of students' confidence after the training using SPs and the role of clinical experience in developing confidence in providing TCT (Brame et al., 2012).

A randomized controlled trial in two internal medicine clinics was conducted to determine if residents trained in cessation treatment using standardized patients were effective in helping people quit tobacco use (Cornuz et al., 2002). One group of physicians received training in the stages of change model and pharmacotherapy techniques and the other group received no relevant cessation treatment training. The training program consisted of a two half-day sessions. The first session included three videotaped counseling sessions with tobacco-using patients, a theory-based interactive workshop, and role-playing activities. The second session included four practices sessions using two female SPs and two male SPs who portrayed patients in various stages of willingness to quit tobacco use. Several SPs were asked to portray patients with cardiovascular risk factors or tobacco-related illnesses. One year later, the patients of the experimental group showed a significant increase in smoking cessation (Cornuz et al., 2002). It was concluded that active learning approaches would increase the effectiveness of tobacco cessation treatment education (Cornuz et al., 2002).

When a program in oral cancer prevention and detection skills was evaluated using an objective structured clinical examination (OSCE), the results suggested that a faculty-facilitated standardized patient-based training in oral cancer prevention and detection, interpersonal communication and cessation treatment was not effective in increasing communication skills (Cannick et al., 2007). All first and second year dental students received instruction in communication and cessation treatment skills prior to the study (Cannick et al., 2007). A baseline OSCE was performed while the student 
communicated and provided cessation treatment with a standardized patient during head and neck examination. After the baseline OSCE, first and second year dental students were randomized into intervention and control groups. The students in the intervention group participated in a two hour training session with standardized patients. The control group did not receive the specialized training (Cannick et al., 2007). In the training session, dental faculty members demonstrated how to communicate with patients and how to provide cessation treatment during a head and neck examination. After the demonstration using the standardized patient, the students in the intervention group practiced communication and treatment skills on each other while being observed by the faculty members. At the post OSCE, the intervention group of students was evaluated by standardized patients. There was not a significant difference in the OSCE scores between the intervention and control groups. There was a significant increase in tobacco cessation communication scores for both the intervention and control groups of first year dental students. However, there was a significant decline in interpersonal communication scores for both groups of second year dental students. It was concluded that the intervention was not successful and a more comprehensive communication training course was indicated (Cannick et al., 2007).

\subsection{Summary of the Literature}

The problems of tobacco use indicate the need for dentists to play a significant role in treating patients' tobacco use and dependence (Barker et al., 2001; Coan et al., 2007; Department of Health and Human Services, 2005; Fiore et al., 2008; Fried et al., 2004; Giacona, 2004; Tomar, 2001; Weaver et al., 2002). The literature reveals a gap in the area of tobacco cessation training methods that effectively address dental students' 
perceived barriers in providing cessation counseling (Harris et al., 2009; Pendharkar et al., 2010; Weaver et al., 2002). The need for developing and implementing comprehensive tobacco cessation and preventive programs is evident in the dental curriculum (Cannick et al., 2006; Harris et al., 2009; Pendharkar et al., 2010; Weaver et al., 2002). Evidence in the literature provides limited support for the use of standardized patients in training health professionals in tobacco cessation counseling, but how the use of SPs affects dental professionals' tobacco cessation knowledge, confidence, selfefficacy, social norms, barriers, and intentions needs further study (Martin \& Chewning, 2011; Walsh et al., 2007).

\subsection{Statement of Research Questions}

The first research question being address in the study was: Is there a difference in dental students' attitudes, perceived barriers, subjective norms, perceived skills, selfefficacy, intentions to provide cessation treatment and tobacco cessation knowledge between those students receiving a lecture along with practice sessions using standardized patients and those students receiving only a traditional lecture?

Other questions were: Do dental students' attitude, perceived barriers, subjective norms, perceived skills, self-efficacy, cessation knowledge, and their type of training, tobacco status and use predict their intent to offer cessation treatment in practice? Does the time between receiving the lecture and participating in the practice sessions affect attitudes, barriers, subjective norms, perceived skills, self-efficacy, intentions to provide cessation treatment and tobacco cessation knowledge? 


\subsection{Conceptual Model}

The study's conceptual model included the variables of age, gender, race, training type, students' tobacco status and use as independent variables and attitudes, perceived barriers, subjective norms, perceived skills, self-efficacy, intentions to provide cessation treatment and cessation knowledge as dependent variables. These variables were chosen to be assessed in the study and to serve as the model to follow because of their possible influence on dental students' abilities to provide cessation treatment to patients using tobacco. Consistent correlations have been found between these factors and health professionals providing TCT (Butler et al., 2009; Hudmon et al., 2003; O'Donnell et al., 2010; Pendharkar et al., 2010; Rajasundaram et al., 2011; Shibly, 2010; Studts et al., 2011; Walsh et al., 2007).

The theory of planned behavior (TPB) provided support for using the variables of subjective norms, attitudes, perceived barriers, and intentions to provide TCT. According to the TPB in Figure 2.1 (see page 40), behavioral intention is predicted by the person's attitude toward the behavior, subjective norms, and perceived behavioral control (Francis et al., 2004). Based on this theory, dental students' intentions to provide TCT in practice is predicted by their attitude toward TCT, their beliefs about whether key people approve or disapprove of TCT, and if they perceive themselves to have control over providing TCT. 


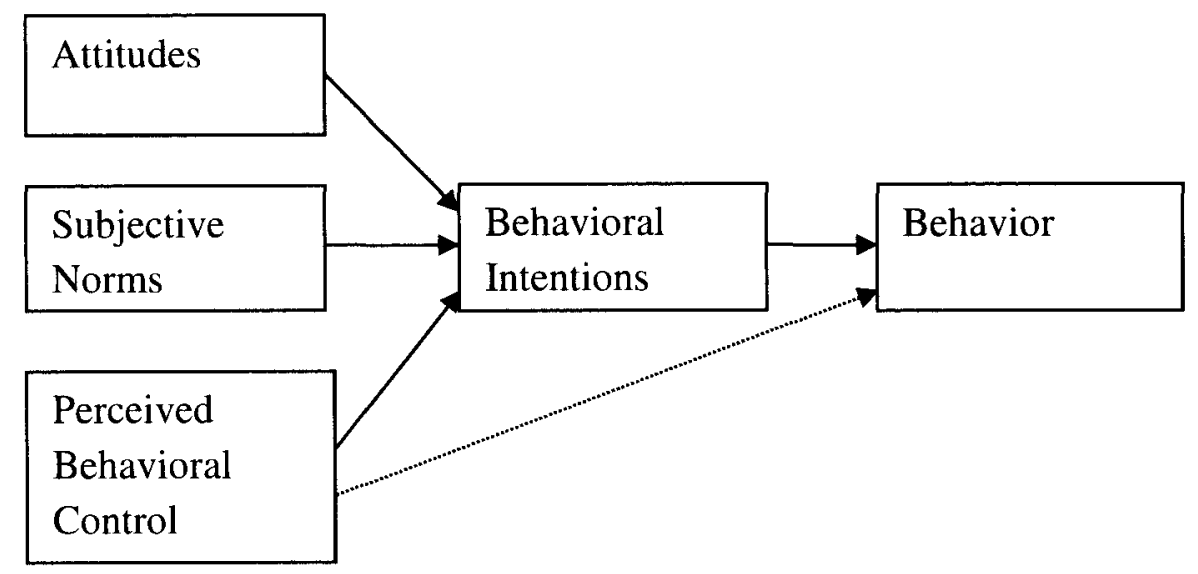

Figure 2.1 The Theory of Planned Behavior (Francis et al., 2004)

It is the goal of this study to identify the relationship between the type of training and its impact on the dependent variables to be able to address and overcome the problem of failing to provide TCT in the dental setting. Assessing dental students' attitudes, perceived barriers, subjective norms, level of perceived skills, self-efficacy, and tobacco cessation knowledge before and after tobacco cessation treatment education will allow the researcher to determine the amount of change in students' abilities as a result of the training program and specifically the inclusion of SPs (Butler et al., 2009; Studts et al., 2011). Previous research has revealed that students feel it is important to receive tobacco cessation treatment education to help their patients quit tobacco use (Clareboets et al., 2010; Walsh et al., 2007; Warren et al., 2011). Research has identified barriers that prevent dental students from offering cessation treatments to tobacco-using patients and that they lack confidence in their ability to provide TCT (Cannick et al., 2006; Rajasundaram et al., 2011; Rikard-Bell et al., 2003; Studts et al., 2011). Significant change found in the variables before and after training will suggest that tobacco cessation treatment education using standardized patients increases dental students' intent to 
provide TCT to their tobacco using patients. Dental students' attitudes, perceived barriers, subjective norms, perceived skills, self-efficacy, and tobacco cessation knowledge could be used as targets for designing training programs to promote TCT in practice. 


\section{CHAPTER 3}

\section{METHODS}

\subsection{Study Variables}

The independent variable in this study is the type of tobacco cessation educational method that dental students will receive in their training. Dental students receiving a traditional lecture only will be assigned to the control level of the educational method. Dental students receiving the same lecture along with practice sessions using standardized patients will be assigned the experimental level of the educational method. Dependent variables included in the conceptual model are dental students' attitudes, perceived barriers, subjective norms, perceived skill levels, self-efficacy, intent to provide tobacco dependence treatment and tobacco cessation knowledge. Other independent variables are age, gender, race, training types, and tobacco status and use. Controlling for possible confounding variables will improve the likelihood that changes in dental students' attitudes, perceived barriers, subjective norms, perceived skill levels, self-efficacy, intent to provide tobacco cessation treatment and tobacco cessation knowledge can be confidently attributed to the influence of the type of educational method used to train dental students in TCT. The confounding variables considered in this study are dental students' tobacco status, the amount of tobacco use and the differences in time between hearing the lecture and participating in the counseling sessions using standardized patients. 


\subsection{Research Design}

This was a group-randomized quantitative study with a pretest-posttest group design. It was an experimental study that evaluated the changes to dental students' attitudes, perceived barriers, subjective norms, perceived skills, self-efficacy, intentions to provide cessation treatment and tobacco cessation knowledge between those students receiving a lecture along with a practice session using standardized patients and those students receiving a traditional lecture only. After the study was submitted to and approved by the Institutional Review Board, dental students were invited to complete two printed questionnaires. A preamble regarding participants' rights and protection was attached to the pre-questionnaire (see Appendix E). Participation in the study was voluntary. By completing the questionnaire, participants agreed to take part in the study. The pre-lecture questionnaire was administered immediately before the tobacco cessation lecture and to all in attendance. This provided a baseline profile of the students' attitudes, barriers, subjective norms, perceived skills, self-efficacy, intentions to provide cessation treatment, and tobacco cessation knowledge. The control group of dental students took the post-lecture questionnaire immediately prior to participating in practice sessions with standardized patients and the debriefing session. Figure 3.1 shows the intervention group took the post-program questionnaire after completing the practice sessions with standardized patients and debriefing session (see page 44). 


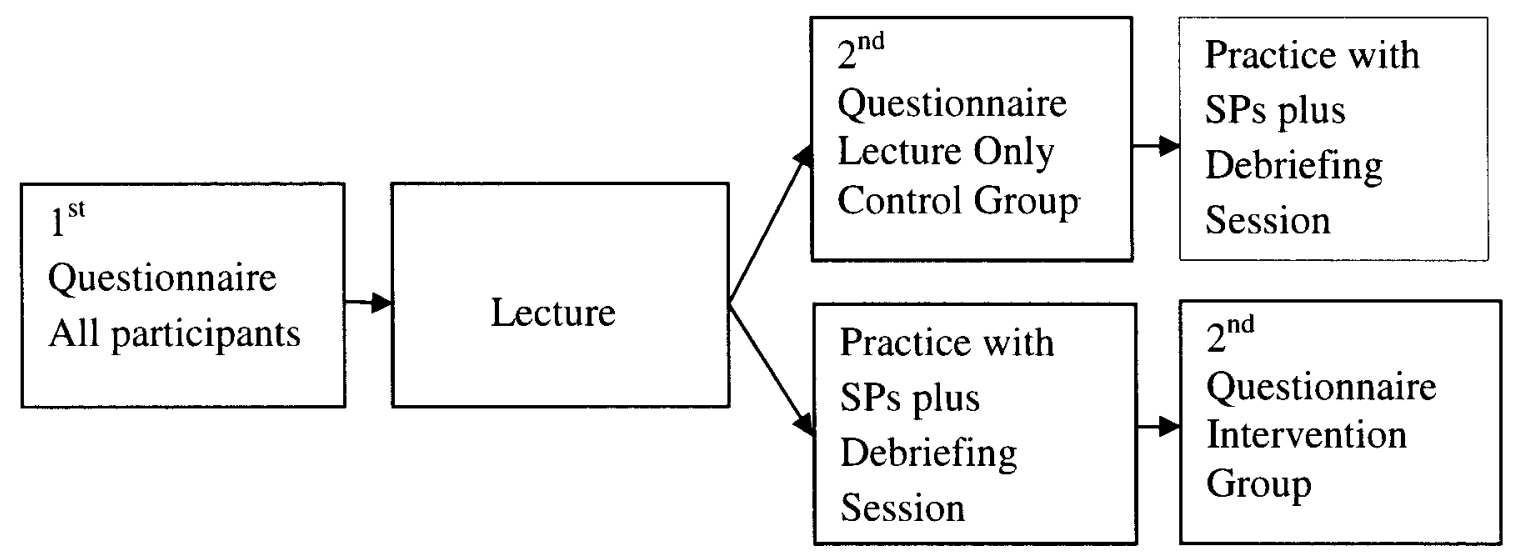

Figure 3.1. Administration of Questionnaires

\subsection{Participants}

The study included all first year dental students during the spring of 2012.

Attendance at the tobacco cessation lecture and participation in the practice sessions with standardized patients were requirements for the introductory course in clinical dentistry. The TCT training schedule for the course practice sessions using standardized patients was developed in the fall of 2011 and reflects having 120 dental students in the class. Three students withdrew or were lost from the program after the fall semester.

Students were given a number by a lab supervisor based on the descending alphabetical order of their last names. The number was called their bench number and identified where the student would be working in labs. For example, the supervisor gave a student whose last name was at the end of the alphabet, the number 1 . The next eleven students whose last names were at the end of the alphabet were given the numbers of 212. The director of the introductory course in clinical dentistry developed the schedule for the TCT practice sessions with standardized patients and assigned the students to 12member groups according to their individual bench numbers (see Appendix F). The 
schedule for the training was sent to all students and instructors through an online course management program designed for faculty and student communication. It included the assigned dates and times to arrive at the standardized patient clinic for the practice sessions using the students' bench numbers. It did not include a list of students in the experimental or control groups.

The groups were made up of twelve students because of the room availability in the Standardized Patient Program. For example, students with bench numbers 1-12 attended the first session of the first training date, and students with bench numbers 13-24 attended the second session of the first training date. There were five training dates: March 1, 8, 15, 29 and April 19. Five half days of practice sessions were planned with standardized patients. Two sessions of 12 students for a total of 24 students were planned on each half day. Three morning sessions were planned from 8:00 to 10:45 and two afternoon sessions were planned from 2:00 to 5:00. Each individual training session was 1.5 hours. On each training day, the first session of twelve students completed the second questionnaire after the practice sessions with SPs and the debriefing session. They became members of the intervention group. The second session of twelve students completed the second questionnaire before participating in the practice sessions with SPs and debriefing session. They became members of the control group. The students were not told if they were in the intervention or control group, but were aware that they completed the second questionnaire before or after the practice and debriefing sessions.

The first three practice session days were scheduled a week apart. The fourth session day was planned four weeks after the first and the fifth session day was planned seven weeks after the first session. The fourth day of practice sessions was scheduled 
two weeks after the third training day because of a vacation week for the students. The last practice day was scheduled three weeks after the fourth day due to scheduling conflicts at the Standardized Patient Clinic.

The first group of dental students on March 1 was the intervention group and students completed the second questionnaire after the practice and debriefing sessions. The second group of dental students was the control group and completed the second questionnaire before participating in the practice and debriefing sessions. It was planned that the questionnaire completion would take 15 minutes. On March 8, the process was repeated. The first group of students was the intervention group and the next group was the control group. This process continued for the next three half days (March 15, 29, and April 19). At the end of the process, there were 52 participants in the control group and 42 participants in the intervention group.

The course director, supporting faculty, and study investigators had access to the log of students' names and bench numbers. The log was kept confidential in a locked file cabinet and on a password protected computer in a locked area. The numbers were used to check attendance at the practice sessions. The students' names and numbers were not used on the questionnaires. The pre- and post- questionnaires were linked by using the last four digits of the student's social security number written by the student at the top of each questionnaire completed.

\subsection{Instrumentation}

The instrument was a questionnaire measuring the constructs of attitudes, perceived barriers, subjective norms, perceived treatment skills, self-efficacy, intentions to provide tobacco cessation treatment and tobacco cessation knowledge. The difference 
between those students receiving a lecture along with practice sessions using standardized patients and those students receiving a lecture only was evaluated by measuring the extent of changes in these constructs as a result of the training. Variations of the questionnaire were developed and given pre-lecture, post-lecture, and postprogram to evaluate the effectiveness of the different educational training methods (see Appendices G, H, and I). Table 3.1 (see page 49) shows the item differences between the questionnaires.

All questionnaires included items to assess participants' demographic characteristics of age, gender, race, tobacco status and use. The questionnaires also included:

- Two questions to assess dental students' attitudes toward tobacco cessation treatment on a scale ranging from strongly disagree to strongly agree,

- Two questions asking if the dental profession should be more or less active in helping patients to quit smoking and helping to prevent patients from starting smoking,

- One question to assess the types of barriers to counseling during each dental visit,

- Six questions to assess social pressures to counsel patients in practice on scales ranging from should not $(-3)$ to should $(+3)$, disapprove $(-3)$ to approve $(+3)$, do not (-3) to do (+3), and not at all (1) to very much (7),

- Seven questions to assess the perceived level of cessation treatment skills from poor to excellent, 
- Ten questions to assess the dental student's self-efficacy to counsel patients to quit tobacco use on a scale ranging from not at all confident to extremely confident,

- Thirteen questions to assess the dental student's intent to counsel patients on a scale from never to always (every visit),

- One question to determine when the dental student will assess the patient's willingness to quit tobacco use from at the initial visit to will not generally assess, and

- Ten questions to assess the student's knowledge of tobacco dependence and cessation treatment.

In addition to the questions on the pre-lecture questionnaire, the post-lecture questionnaire included the following process questions to be used for program modification in the future:

- One question to assess the estimation of the participant's previous knowledge of the program's information,

- One question to assess the expected use of the information when working with patients,

- Two questions to assess the level of agreement on a scale from strongly disagree to strongly agree that the lecture and handouts provided valuable information in preparing the participant to provide cessation counseling and made the participant feel competent in providing cessation counseling,

- One question to assess the student's belief that other schools of dentistry in Kentucky would benefit from receiving similar training, and 
- One question to assess what would the dental student change about the program.

Space was provided for the student's overall comments about the program.

In addition to the questions on the pre-lecture and post-lecture questionnaire, the post-program questionnaire included the following process questions to be used for program modification in the future:

- Three questions to assess the level of agreement on a scale from strongly disagree to strongly agree that the practice sessions with standardized patients increased the student's confidence in providing TCT, the feedback from the SPs was helpful, and the feedback from the debriefing session was useful.

Table 3.1 Item Differences between Pre-Lecture, Post-Lecture and Post-Program Questionnaires

\begin{tabular}{|c|c|c|c|}
\hline Items on questionnaire & \multicolumn{3}{|c|}{ Type of Questionnaire } \\
\hline & Pre-lecture & Post-Lecture & Post-Program \\
\hline Variables & $\sqrt{ }$ & $\sqrt{ }$ & $\sqrt{ }$ \\
\hline Demographics & $\sqrt{ }$ & $\sqrt{ }$ & $\sqrt{ }$ \\
\hline $\begin{array}{l}\text { Estimation of participant's } \\
\text { previous knowledge }\end{array}$ & & $\sqrt{ }$ & $\sqrt{ }$ \\
\hline $\begin{array}{l}\text { Participant's expected use of } \\
\text { information }\end{array}$ & & $\sqrt{ }$ & $\sqrt{ }$ \\
\hline Evaluation of lecture and handouts & & $\sqrt{ }$ & $\sqrt{ }$ \\
\hline $\begin{array}{l}\text { Assessment of student's belief } \\
\text { training would benefit other } \\
\text { schools }\end{array}$ & & $\sqrt{ }$ & $\sqrt{ }$ \\
\hline $\begin{array}{l}\text { Evaluation of SP counseling } \\
\text { sessions }\end{array}$ & & & $\sqrt{ }$ \\
\hline $\begin{array}{l}\text { Assessment of needed change to } \\
\text { program }\end{array}$ & & $\sqrt{ }$ & $\sqrt{ }$ \\
\hline Student's overall comments & & $\sqrt{ }$ & $\sqrt{ }$ \\
\hline
\end{tabular}




\subsection{Reliability and Validity of the Instrument}

There was published evidence of the validity of several scales used in the instrument (Butler et al., 2009; Corelli et al., 2005; Hudmon et al., 2003; Studts et al., 2011; Walsh et al., 2007). Two questions to measure attitudes toward TCT were validated in studies conducted by Studts et al. and Walsh et al (Studts et al., 2011; Walsh et al., 2007). The question to measure perceived barriers was validated in a study conducted by Studts et al (Studts et al., 2011). Six questions to measure subjective norms were developed using the Health Services Researcher's Manual to construct questionnaires based on the theory of planned behavior (Francis et al., 2004). Seven questions to measure the perceived level of TCT skills, ten questions to measure participants' self-efficacy to counsel patients to quit tobacco use, and ten questions to measure tobacco cessation knowledge were developed at the University of California San Francisco and validated in studies conducted by researchers Butler et al., Corelli et al., and Hudmon et al (Butler et al., 2009; Corelli et al., 2005; Hudmon et al., 2003; University of California San Francisco, 2011). Ten questions to measure participants' intentions to provide TCT were validated in studies conducted by researchers Studts et al and Walsh et al (Studts et al., 2011; Walsh et al., 2007). Three new questions to measure participants' intentions to assess a patient's readiness to quit, arrange follow-up counseling and counsel patients not interested in quitting were added to the pre-lecture, post-lecture, and post-program questionnaire. The new questions were added to thoroughly assess the participants' intentions to practice the 5 A's and 5 R's of TCT. Reliability of each conceptual group of questions was determined by use of the Cronbach's Alpha statistic. 


\subsection{Procedures}

First year dental students were invited to respond to pre- and post- self-reported questionnaires while participating in cessation training required in the clinical dentistry course. The participants were assigned to smaller groups to manage the large number of participants in the training (Murray, 1998). All students attending the tobacco cessation lecture responded to the first questionnaire prior to the lecture. The students were divided into an experimental group that received a lecture and counseling sessions with standardized patients and a debriefing session, and a control group that received a lecture only. The control group was asked to complete the second survey before the practice sessions with standardized patients; whereas, the intervention group was asked to complete the second questionnaire after the practice sessions with standardized patients and the 15 minute debriefing session.

A two hour lecture portion of the training was provided to all students at the same time and was provided by a certified tobacco health education specialist. The lecture presented strategies and recommendations in delivering effective tobacco cessation treatment based on the Public Health Services' Clinical Practice Guideline. The practice sessions using standardized patients were conducted in small groups of twelve students over a seven week period at a standardized patient clinic on campus. A debriefing session took place immediately after the practice sessions to allow time for questions and feedback.

There were twelve standardized patients for the twelve students participating in each practice session; each SP was paired with one student at a time. The standardized patients varied in their role play of readiness stages to quit tobacco use. Four of the SPs' 
were contemplating quitting tobacco use, four were willing to quit, and four were resistant to quitting. Each student interacted with three standardized patients in each of the different stages of readiness to quit tobacco use. In order to make each student's experience similar, the standardized patients were trained to closely follow the case description and use the checklist that accompanied each case scenario. The checklist included what is expected for the student to accomplish during the session. In the case of the patient who is ready to quit, the student was expected to set a quit date and to anticipate problems that the patient will have with quitting. Patients are to be made aware of the effects of withdrawal symptoms and given coping strategies. Nicotine replacement therapy is recommended and prescribed, and follow-up arrangements are made. The standardized patients were given key points in how to react to students' treatment recommendations (see Appendix J).

\subsection{Data Analysis}

Data from pre- and post-questionnaires of the intervention and control groups were entered into the Statistical Package for Social Sciences (SPSS) version 20.0 and evaluated using descriptive and statistical analysis. The following research question was answered using independent t-tests: Is there a difference in dental students' attitudes, perceived barriers, subjective norms, perceived treatment skills, self-efficacy, intentions to provide cessation treatment and tobacco cessation treatment knowledge between those students receiving a lecture along with practice sessions using standardized patients compared to those students receiving lecture only.

The next research question was answered using Linear Regression Analysis: Do dental students' attitudes perceived barriers, subjective norms, perceived skills, self- 
efficacy, tobacco cessation knowledge, and their training type, tobacco status and use predict intent to provide TCT? The final research question was answered using a univariate general linear model: Does the time between receiving the lecture and participating in the practice sessions affect attitudes, perceived barriers, subjective norms, perceived treatment skills, self-efficacy, intentions to provide cessation treatment and tobacco cessation knowledge?

Each variable was derived from responses to a subset of questions. Within each subset, responses were summed, making it possible to calculate means for students in the two groups, experimental and control. The differences found in the scales between the intervention and control groups determined the impact of the types of training. The analysis was limited to data collected from linkable pre- and post- questionnaires. 


\section{CHAPTER 4}

\section{RESULTS}

\subsection{Study Participants}

Of 120 freshman dental students starting the program in July 2011,117 were registered in the Introduction to Clinical Dentistry I course in the spring semester of 2012. Three students withdrew from the program. Of those students in the course, 98 (84\%) attended the tobacco cessation lecture on February 23 and were invited to participate in a study by completing two questionnaires. The other nineteen students were absent. Absenteeism was unusually high because of a rally taking place at the State Capital. Students that were absent were asked to view a videotaped version of the lecture before the practice sessions, but they were not included in the study. Of the 117 dental students in the course, 94 students $(80 \%)$ provided linkable questionnaires. Four participants' identifying numbers used on the questionnaires were not able to be matched. Figure 4.1 (see page 55) shows how the intervention and control groups were constituted. The group assignment resulted in an intervention group of 42 students (44.7\%) who completed the post- program questionnaire and a control group of 52 students $(55.3 \%)$ who completed the post-lecture questionnaire.

Of the 94 participants with linkable questionnaires, one participant included in the study failed to report demographic information and smoking status. The average age of the participants was 25.29 years ( $\mathrm{SD}, 3.991$; range $22-38$ years). There was not a significant difference in age $(\mathrm{P}=.432)$ between the intervention (Mean, 25.66; SD, 4.311) 
and control group (Mean, 25.00; SD, 3.736). In the study, 62.4\% (58) of the participants were male and $37.6 \%$ (35) were female.

\section{Enrollment}

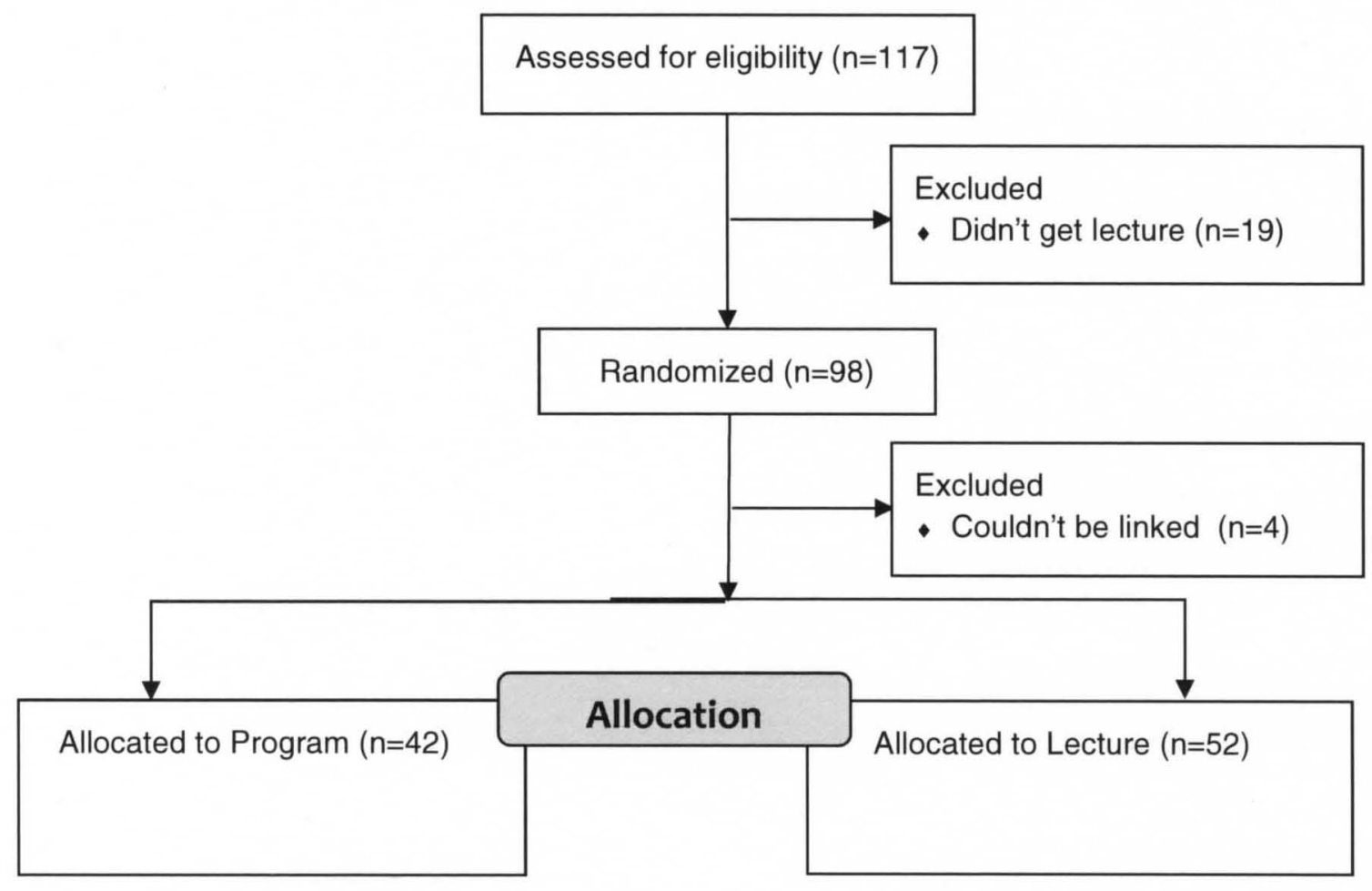

Figure 4.1 Consort 2010 Flow Diagram of Participants in Study

Table 4.1 (see page 56) shows there was no gender, race or ethnicity, tobacco status or use differences found between the intervention and control groups at Time 1. The participants' race and ethnicity was distributed between Asian (13.0\%), Native Hawaiian or Pacific Islander (1.1\%), Black or African American (3.3\%), White (81.5\%), and Spanish, Hispanic or Latino (1.1\%). A higher percentage of participants in the intervention group (12\%) reported at Time 1 they had smoked 100 or more cigarettes in their lifetime than the control group (6\%), but the difference was not significant. 
Table 4.1 Demographic Differences between the Intervention and Control Groups at Time 1

\begin{tabular}{lccl}
\hline $\begin{array}{l}\text { Demographic } \\
\text { Variables }\end{array}$ & \multicolumn{3}{c}{ Groups } \\
\hline Gender & $\begin{array}{c}\text { Intervention } \\
\mathrm{n}(\%)\end{array}$ & $\begin{array}{c}\text { Control } \\
\mathrm{n}(\%)\end{array}$ & $\mathrm{P}$ \\
\hline Male & $29(71)$ & $29(56)$ & \\
Female & $12(29)$ & $23(44)$ & \\
\hline Total & 41 & 52 & .139 \\
Race/Ethnicity & & & \\
\hline White & $31(77.5)$ & $44(85)$ & \\
Other & $9(23.5)$ & $8(15)$ & \\
\hline Total & 40 & 52 & .383 \\
& & & \\
Tobacco Status & & & \\
\hline Yes & $5(12)$ & $3(6)$ & \\
No & $36(88)$ & $49(94)$ & \\
\hline Total & 41 & 52 & .546 \\
& & & \\
Tobacco Use & & & \\
\hline Current & $2(5)$ & $5(10)$ & \\
Experimented & $26(63)$ & $19(36)$ & \\
Never tried & $13(32)$ & $28(54)$ & \\
\hline Total & 41 & 52 & $.328^{* *}$ \\
\hline
\end{tabular}

Note. $\mathrm{p}<.05$. ** Fisher's Extract Test was used. $\mathrm{n}=$ Number of participants. $\%=$ Percentage of participants. Number of participants in the intervention group ranged from 40-42. Number of participants in the control group was 52 .

Current tobacco users using cigarettes, cigars, pipes, snuff, or chewing tobacco could indicate either if they used tobacco once or more a day or less than once a day.

Participants who have experimented with tobacco use were those who used to use tobacco but quit and those who have experimented with tobacco a few times in the past.

One group of participants had never tried tobacco. The intervention group had the highest percentage of participants that had experimented with tobacco use and the intervention group had the highest percentage of current tobacco users and participants who had never tried tobacco. 


\subsection{Reliability and Validity of the Instrument}

At Time 2, the reliability was good for the set of items measuring attitude toward TCT (.904), perceived skills (.908), self-efficacy (.938), and intentions (.938) to provide TCT (Cokley, 2007). The reliability was fair for the set of items measuring subjective norms (.507), and the reliability was poor for the set of items measuring perceived barriers (.425) and tobacco cessation knowledge (.451).

\subsection{First Research Question}

The first research question answered in this study is: Is there a difference in dental students' attitudes, perceived barriers, subjective norms, perceived skills, selfefficacy, intentions to provide cessation treatment and cessation knowledge between those students receiving a lecture along with practice sessions using standardized patients and those students receiving lecture only.

\subsubsection{Attitude}

The attitude variable was computed by adding the values from the first two questionnaire items to assess the level agreement with statements: 1.) "It is important for members of my profession to discuss tobacco use with patients" and 2.) "A brief intervention ( 3 minutes) for tobacco cessation with my patients would be effective." The rating scale was: $0=$ strongly disagree, $1=$ moderately disagree, $2=$ somewhat disagree, $3=$ neither disagree or agree, $4=$ somewhat agree, $5=$ moderately agree, and $6=$ strongly agree. A higher total score indicated a higher level of agreement with the statements and a positive attitude toward TCT. The difference in attitude toward TCT from Time 1 to Time 2 was computed by subtracting the total value of the attitude variable at Time 1 from the total value of the attitude variable at Time 2. Table 4.2 (see page 58) shows no 
Table 4.2 Differences in Variables between the Intervention and Control Groups at Time 1 and Time 2. In Addition, Analysis of Differences in Variables over Time.

\begin{tabular}{|c|c|c|c|}
\hline Variables & $\begin{array}{c}\text { Intervention Group } \\
\mathrm{M}(\mathrm{SD})\end{array}$ & $\begin{array}{c}\text { Control Group } \\
\mathrm{M}(\mathrm{SD})\end{array}$ & $\mathrm{p}$ \\
\hline \multicolumn{4}{|l|}{ Attitude (Range: $0-8$ ) } \\
\hline Time 1 & $6.17(1.97)$ & $6.79(1.29)$ & .069 \\
\hline Time 2 & $6.81(2.09)$ & $6.54(2.10)$ & .534 \\
\hline Time 1 to Time 2 & $.64(2.61)$ & $-.25(2.27)$ & .079 \\
\hline \multicolumn{4}{|c|}{ Perceived Barriers (Range: $0-11$ ) } \\
\hline Time 1 & $7.76(1.64)$ & $7.85(1.92)$ & .822 \\
\hline Time 2 & $9.60(.94)$ & $8.71(1.58)$ & $.001 *$ \\
\hline Time 1 to Time 2 & $1.83(1.53)$ & $.87(1.78)$ & $.006 *$ \\
\hline \multicolumn{4}{|c|}{ Subjective Norms (Range: $0-36$ ) } \\
\hline Time 1 & $24.83(4.43)$ & $25.81(4.35)$ & .287 \\
\hline Time 2 & $27.38(3.47)$ & $26.48(4.50)$ & .289 \\
\hline Time 1 to Time 2 & $2.55(4.73)$ & $.67(3.42)$ & $.035^{*}$ \\
\hline \multicolumn{4}{|c|}{ Perceived Skills (Range: $0-28$ ) } \\
\hline Time 1 & $10.00(5.29)$ & $11.59(5.05)$ & .143 \\
\hline Time 2 & $18.52(4.93)$ & $15.00(5.01)$ & $.001 *$ \\
\hline Time 1 to Time 2 & $8.52(6.62)$ & $3.38(4.84)$ & $.000 *$ \\
\hline \multicolumn{4}{|l|}{ Self-Efficacy (Range: $0-40$ ) } \\
\hline Time 1 & $11.58(7.39)$ & $12.40(7.90)$ & .616 \\
\hline Time 2 & $25.21(6.54)$ & $19.76(6.10)$ & $.000^{*}$ \\
\hline Time 1 to Time 2 & $14.34(8.61)$ & $7.66(6.90)$ & $.000 *$ \\
\hline \multicolumn{4}{|l|}{ Intentions (Range: $0-52$ ) } \\
\hline Time 1 & $35.17(9.78)$ & $36.81(8.03)$ & .378 \\
\hline Time 2 & $42.88(6.29)$ & $38.42(8.31)$ & $.006 *$ \\
\hline Time 1 to Time 2 & $7.88(9.05)$ & $1.90(6.96)$ & $.001^{*}$ \\
\hline \multicolumn{4}{|c|}{ Tobacco Cessation Knowledge (Range: $0-10$ ) } \\
\hline Time 1 & $4.33(2.01)$ & $4.21(1.60)$ & .744 \\
\hline Time 2 & $6.88(1.63)$ & $6.81(1.81)$ & .838 \\
\hline Time 1 to Time 2 & $2.55(2.98)$ & $2.60(2.77)$ & .935 \\
\hline
\end{tabular}

Note. ${ }^{*} \mathrm{p}<.05 . \mathrm{M}=$ mean. $\mathrm{SD}=$ standard deviation. The number of participants in the intervention group varied from 38 to 42 . The number of participants in the control group varied from 50 to 52 . 
significant difference in participants' attitude toward TCT between the intervention and control groups at Time 1 and Time 2 . In addition, the difference in attitude toward TCT between the groups did not change significantly over time. Figure 4.2 (see page 59) displays the difference in attitude toward TCT between the intervention and control groups from Time 1 to Time 2. The control group's attitude toward TCT decreased at Time 2, and the intervention group's attitude increased. The change in attitude toward TCT between the groups was statistically nonsignificant.

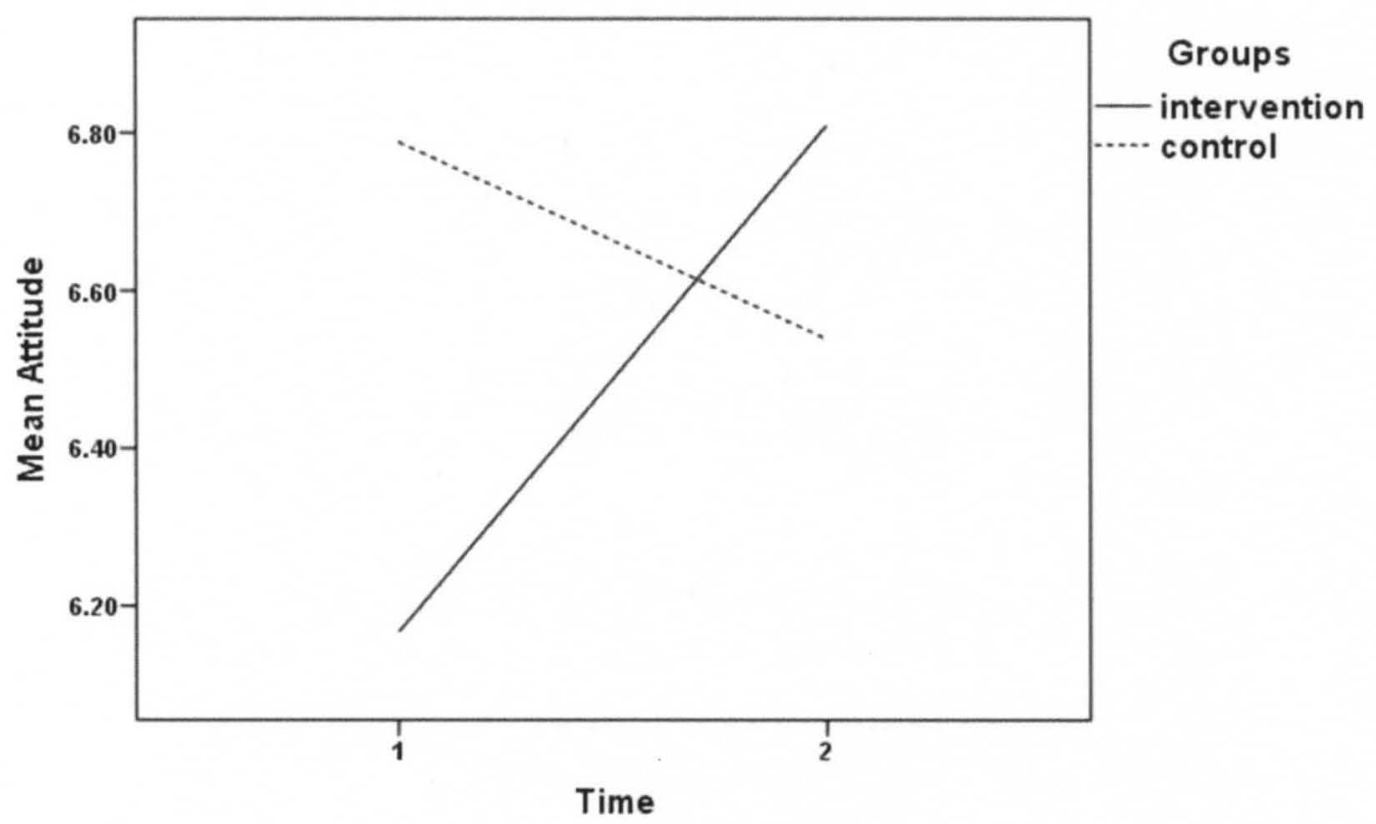

Note. $p<.05$. The attitude toward tobacco cessation treatment $(T C T)$ variable was computed by addinc the values from the first two questionnaire items to assess the level of agreement with the statements. The rating scale was: $0=$ strongly disagree, $1=$ moderately disagree, $2=$ somewhat disagree, $3=$ neither disagree of agree, $4=$ somewhat agree, $5=$ moderately agree, and $6=$ strongly agree. The difference in attitude toward TCT was computed by subtracting the total value of the attitude variable at Time 1 from the total value of the attitude variable at Time 2. The difference in attitude toward TCT between the intervention $(n=42)$ and control groups $(n=52)$ from Time 1 to Time 2 was statistically nonsignificant $(p=.079)$

Figure 4.2 The Difference in Attitude Toward Tobacco Cessation Treatment between the Intervention and Control Groups from Time 1 to Time 2 


\subsubsection{Perceived Barriers}

The perceived barriers variable was computed by adding the total number of barriers reported by participants. Participants were asked to select all factors that may limit their ability to counsel tobacco users during every visit. The rating scale for reporting barriers was: $0=$ no and $1=$ yes. A higher total score indicated a higher number of participants' perceived barriers in providing TCT. The difference in perceived barriers from Time 1 to Time 2 was computed by subtracting the total number of perceived barriers at Time 1 from the total number of perceived barriers at Time 2. Table 4.2 (see page 58) shows no significant difference in participants' perceived barriers between groups at Time 1 , but a statistically significant difference at Time 2 . In addition, the difference between groups over time was statistically significant. At Time 2 , the intervention group reported a significantly higher number of perceived barriers than the control group. Participants in the intervention group became more aware of barriers to TCT after participating in the practice and debriefing sessions. Figure 4.3 (see page 61 ) displays the difference in perceived barriers between the intervention and control groups from Time 1 to Time 2. The change between the groups was statistically significant. 


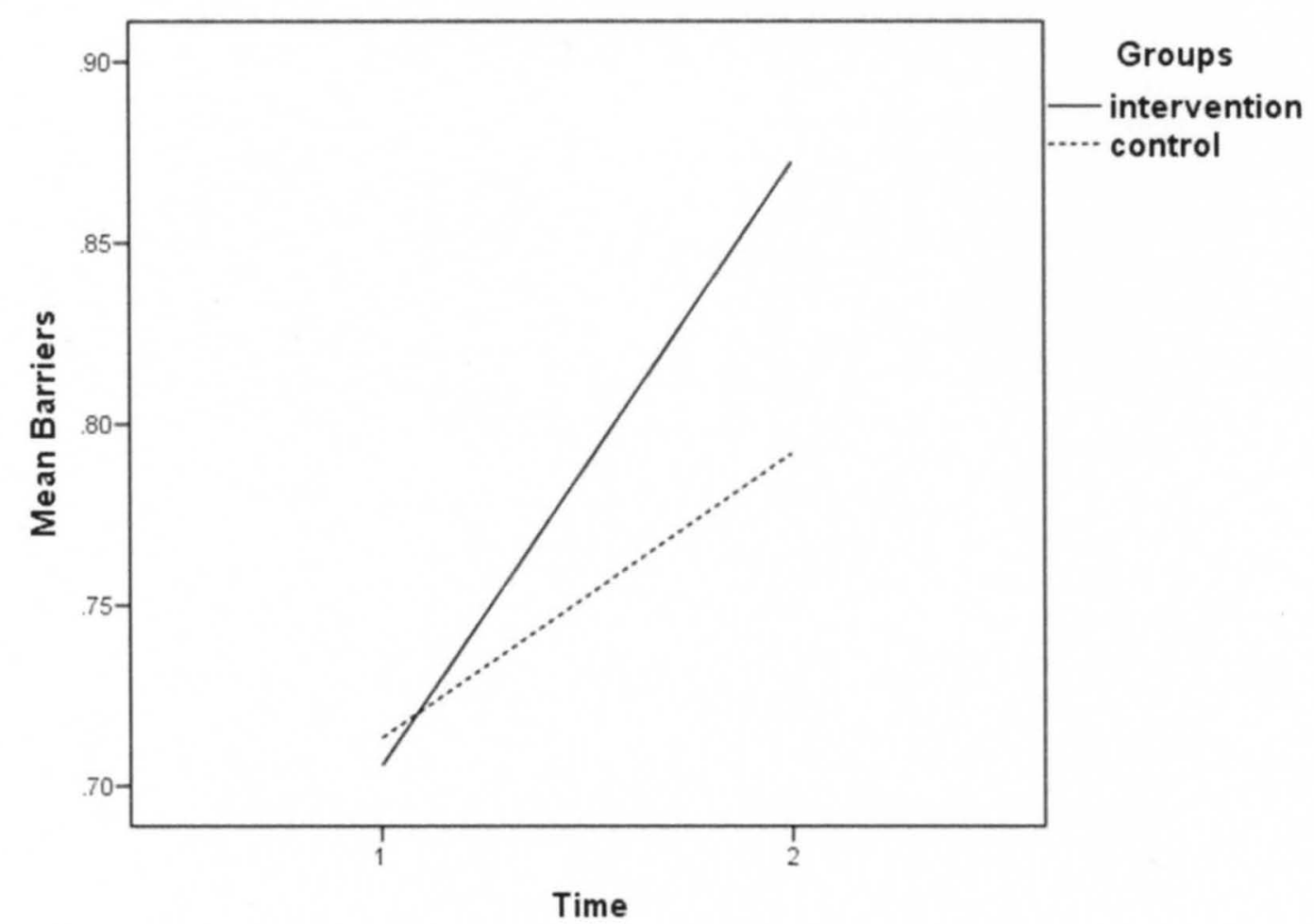

Note. $p<05$. The perceived barriers variable was computed by adding the total number of barriers reported by participants. The rating scale for reporting barriers was: $0=$ no and $1=$ yes. The difference in perceived barriers from Time 1 to Time 2 was computed by subtracting the total number of perceived barriers at Time 1 from the total number of perceived barriers at Time 2. The difference in perceived barriers between the intervention $(n=42)$ and control groups $(n=52)$ from Time 1 to Time 2 was statistically significant (.006).

Figure 4.3 The Difference in Perceived Barriers between the Intervention and Control Groups from Time 1 to Time 2

\subsubsection{Subjective Norms}

The subjective norms variable was computed by adding the values of six questions to assess the participants' level of perceived social pressures to counsel patients in quitting tobacco use. Questions were rated on a seven-point Likert scale; higher point values indicate a perceived social norm more supportive of counseling patients in quitting tobacco use. The difference in subjective norms from Time 1 to Time 2 was computed by subtracting the total number of participants' subjective norms at Time 1 from the total number of participants' subjective norms at Time 2. Table 4.2 (see page 58) shows no 
significant difference in subjective norms between the intervention and control groups at

Time 1 and Time 2. There was a statistically significant change in subjective norms

between the groups over time. Figure 4.4 (see below) displays the difference in

subjective norms between the intervention and control groups from Time 1 to Time 2 .

Both groups' subjective norms increased from Time 1 to Time 2. The intervention group

members had a significantly higher level of social pressures to counsel patients than the

control group members over time. They feel approval from others is important in

providing TCT in their practice.

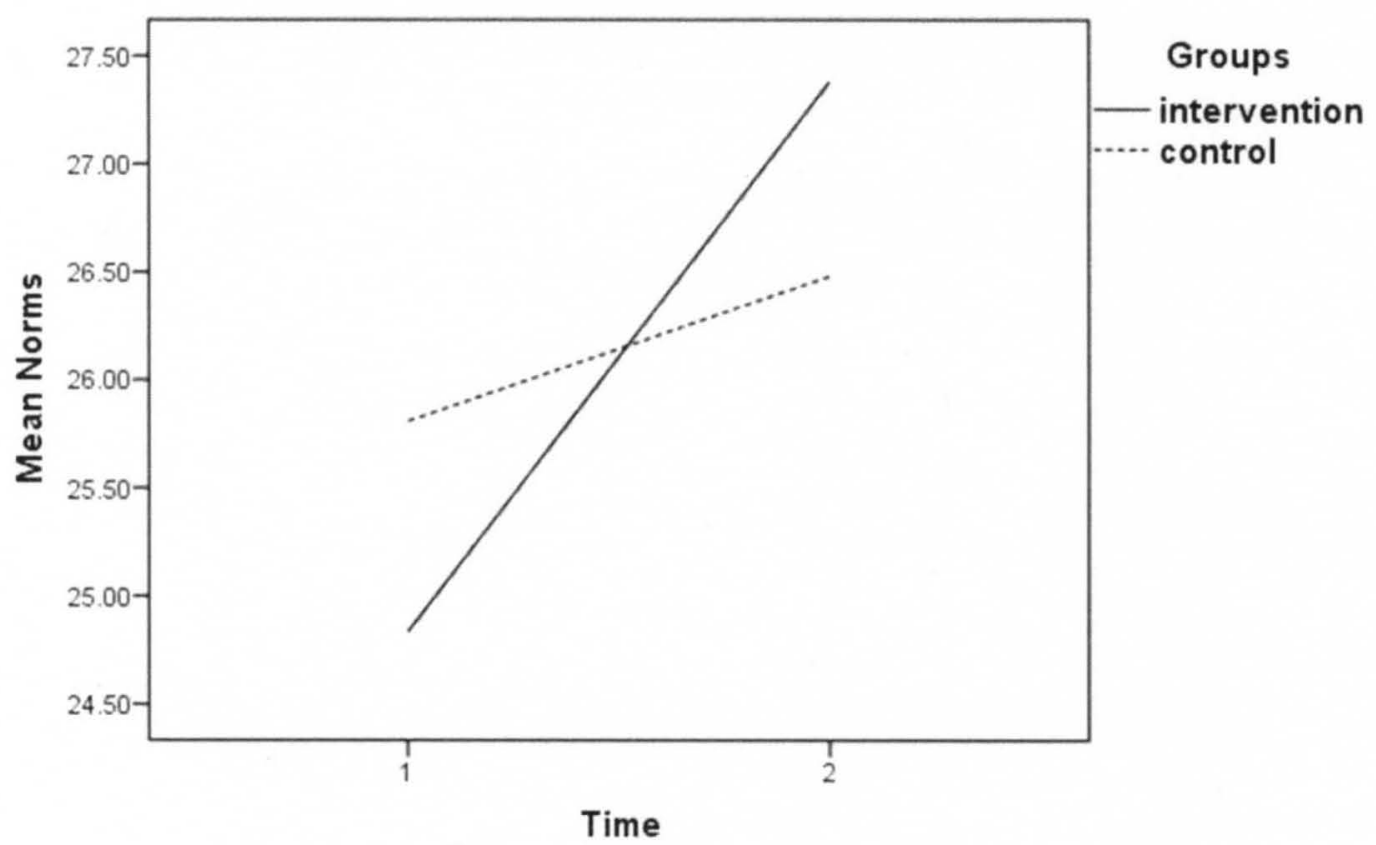

Note. $p<.05$. The subjective norms variable was computed by adding the values of six questions to assess the participants' level of perceived social pressures to provide tobacco cessation treatment (TCT). Questions were rated on a seven-point Likert scale; higher point values indicate a perceived social norm more supportive of providing TCT. The difference in subjective norms between the intervention and control groups from Time 1 to Time 2 was computed by subtracting the total number of participants' subjective norms at Time 1 from the total number of participants' subjective norms at Time 2. The difference in participants' subjective norms between the intervention $(n=42)$ and control groups $(n=52)$ from Time 1 to Time 2 was statistically significant $(p=.035)$

Figure 4.4 The Difference in Subjective Norms between the Intervention and Control Groups from Time 1 to Time 2 


\subsubsection{Perceived Skills}

The perceived skills variable was computed by adding the values of seven questions that assessed their perceived level of TCT skills from poor to excellent. The rating scale was: $0=$ poor, $1=$ fair, $2=\operatorname{good}, 3=$ very good, and $4=$ excellent. A higher total score indicated a higher level of perceived skills reported by participants. The difference in the participants' perceived skills was computed by subtracting the total value of perceived skills at Time 1 from the total value of perceived skills at Time 2 . Table 4.2 (see page 58) shows no significant difference in participants' perceived skills between the intervention and control groups at Time 1, but shows a statistically significant difference at Time 2 and a significant change between groups over time. Participants in the intervention group rated their perceived skills at a significantly higher level than the participants in the control group. Figure 4.5 (see page 64) displays the change in perceived skills between the intervention and control groups from Time 1 to Time 2. The intervention group's perceived skills increased at a significantly higher level than the control group's perceived skills. 


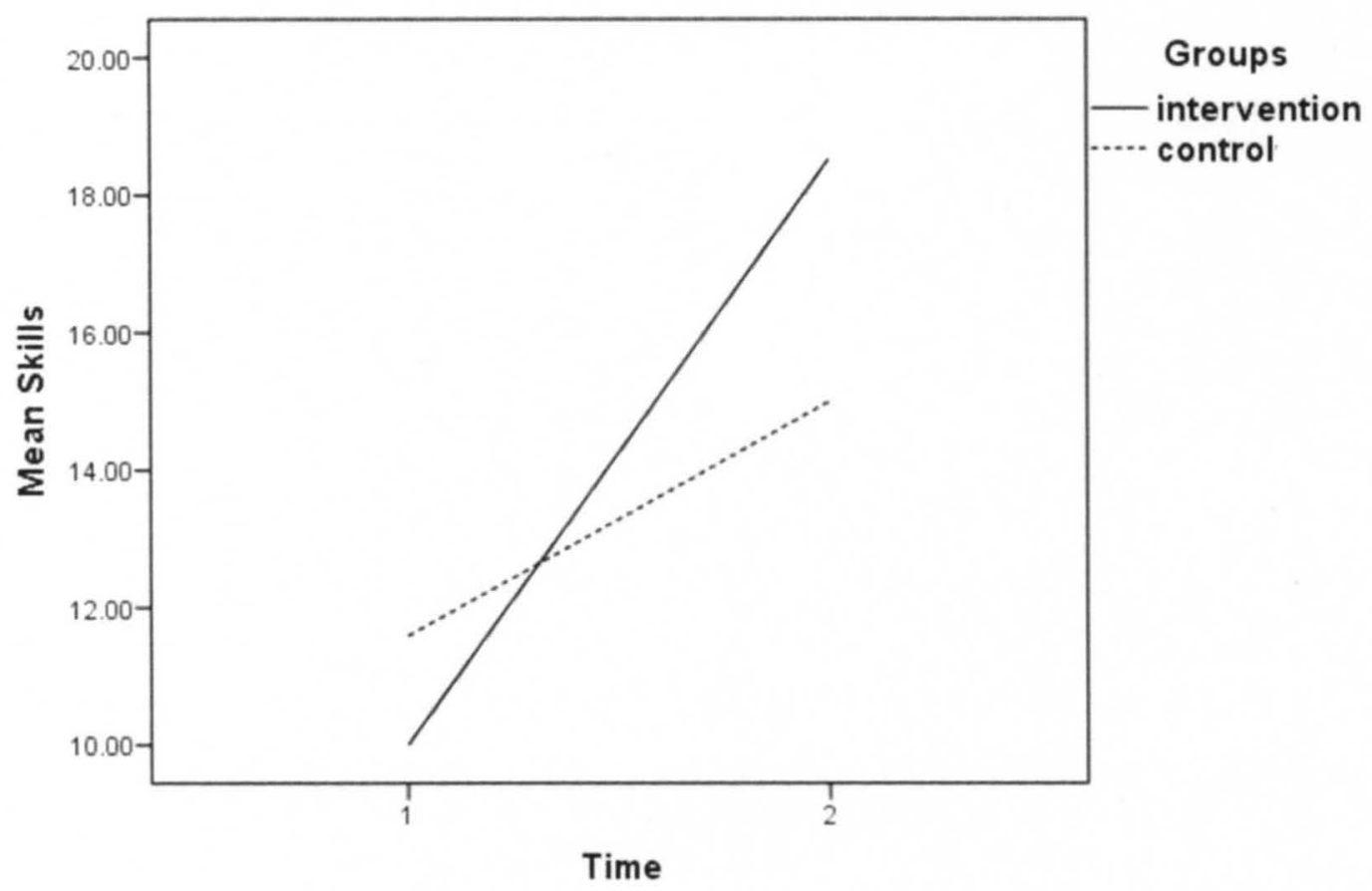

Note. $p<.05$. The perceived skills variable was computed by adding the values of seven questions that assessd their perceived level of tobacco cessation treatment skills from poor to excellent. The rating scale was: $0=$ poor, $1=$ fair, $2=$ good, 3 = very good, and $4=$ excellent. The difference in the participants' perceived skills was computed by subtracting the total value of perceived skills at Time 1 from the total value of perceived skills at Time 2 . The difference in perceived skills between the intervention $(n=42)$ and control groups $(n=52)$ from Time 1 to Time 2 was statistically significant $(.000)$

Figure 4.5 The Difference in Perceived Skills between the Intervention and Control Groups from Time 1 to Time 1

\subsubsection{Self-Efficacy}

The self-efficacy variable was computed by adding the values from ten questions to assess the participants' self-efficacy to counsel patients to quit tobacco use. The rating scale was: $0=$ not at all confident, $1=$ not very confident, $2=$ moderately confident, $3=$ very confident, and $4=$ extremely confident. A higher total score indicated a higher level of confidence in providing TCT. The difference in participants' self-efficacy from Time 1 to Time 2 was computed by subtracting the total value of self-efficacy at Time 1 from Time 2. Table 4.2 (see page 58) shows the difference in self-efficacy between the groups 
was not significant at Time 1, but there was a significant difference at Time 2 and a significant change between the groups over time. Figure 4.6 (see below) displays the difference in participants' self-efficacy between the intervention and control groups from Time 1 to Time 2. Participants in the intervention group rated their self-efficacy at a significantly higher level than the participants in the control group at Time 2 and there was a significant increase in self-efficacy between the groups over time.

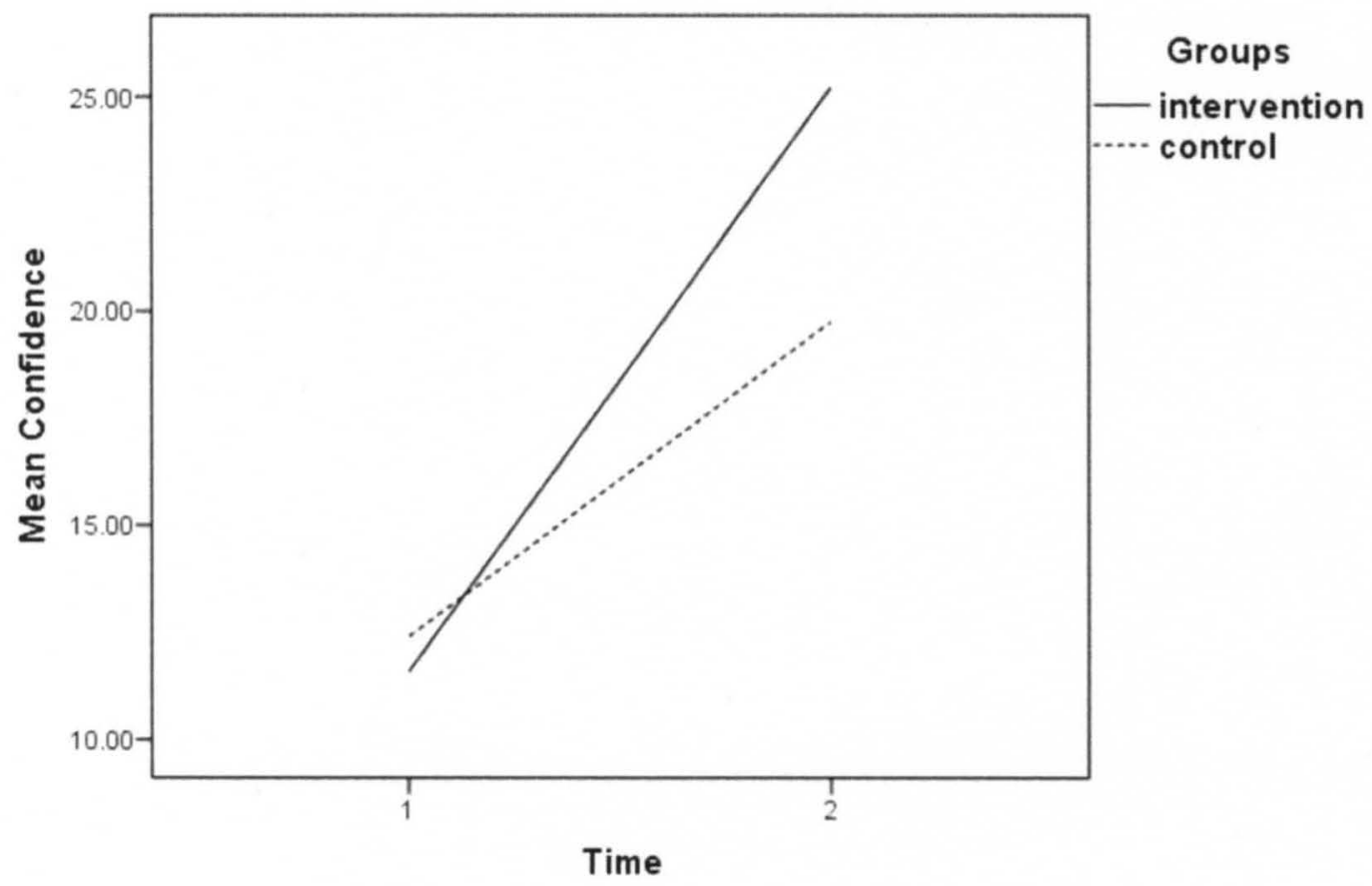

Note. $p<.05$. The self-efficacy variable was computed by adding the values from ten questions to assess the participants' self efficacy to provide tobacco cessation treatment. The rating scale was: $0=$ not at all confident, $1=$ not very confident, $2=$ moderately confident, $3=$ very confident, and $4=$ extremely confident. The difference in participants' self-efficacy from Time 1 to Time 2 was computed by subtracting the total value of self-efficacy at Time 1 from the total value of self-efficacy at Time 2 . The difference in participants' self-efficacy between the intervention $(n=42)$ and control groups $(n=52)$ from Time 1 to Time 2 was statistically significant $(000)$

Figure 4.6 The Difference in Self-Efficacy between the Intervention and Control Groups from Time 1 to Time 1 


\subsubsection{Intentions to Provide Tobacco Cessation Treatment}

Participants' intentions to provide TCT were computed by adding values from thirteen questions to assess the dental students' intent to counsel patients using the 5 A's and willingness to assist patients in quitting. The rating scale was: $0=$ never, $1=$ rarely, $2=$ sometimes, $3=$ almost always, and $4=$ always (every visit). A higher total score indicated a stronger intention to provide TCT. The difference in participants' intentions to provide TCT was computed by subtracting the total value of participants' intentions at Time 1 from the total value of participants' intentions at Time 2. Table 4.2 (see page 58) shows there was no significant difference in participants' intentions to provide TCT between the intervention and control groups at Time 1, but there was a significant difference at Time 2 and a significant change between the groups over time. Figure 4.7 (see page 67) displays the difference in participants' intentions between the intervention and control groups from Time 1 to Time 2. The strength of the participants' intentions to counsel patients to quit tobacco use was significantly changed by participating in the training using standardized patients. 


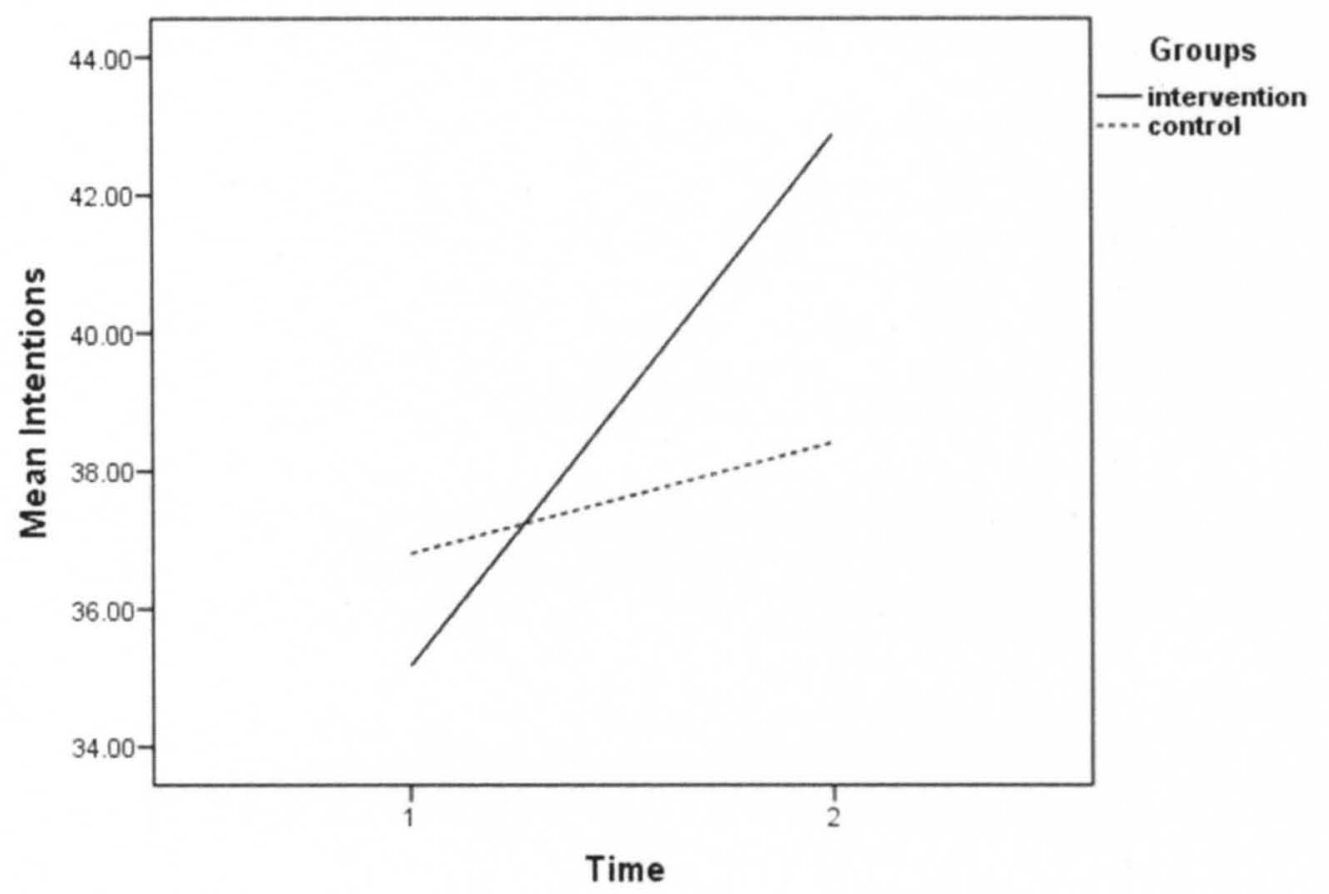

Note. Participants' intentions to provide tobacco cessation treatment (TCT) was computed by adding values from thirteen questions to assess participants' intent to treat tobacco use and dependence. The rating scale was: $0=$ never, $1=$ rarely, $2=$ sometimes, $3=$ almost always, and $4=$ always (every visit). The difference in participants' intentions to provide TCT was computed by subtracting the total value of participants' intentions at Time 1 from the total value of participants' intentions at Time 2 . The difference in participants' intentions to provide TCT between the intervention $(n=42)$ and control groups $(n=52)$ was statistically significant (.001).

Figure 4.7 The Difference in Intentions to Provide Tobacco Cessation Treatment between the Intervention and Control Groups from Time 1 to Time 2

\subsubsection{Tobacco Cessation Treatment Knowledge}

The tobacco cessation treatment knowledge variable was computed by adding the participants' total number of correct answers of the ten knowledge questions. The rating scale was: $0=$ incorrect and $1=$ correct. The higher total number indicated a higher number of correct answers. The difference in the participants' TCT knowledge was computed by subtracting the total number of participants' correct answers at Time 1 from the total number of participants' correct answers at Time 2. Table 4.2 (see page 58) shows no significant difference in TCT knowledge between the intervention and control 
groups at Time 1 and Time 2, and the change between groups over time was statistically nonsignificant. Figure 4.8 (see below) displays the difference in cessation treatment knowledge between the intervention and control groups from Time 1 to Time 2. There was not a significant change in participants' TCT knowledge between the groups over time.

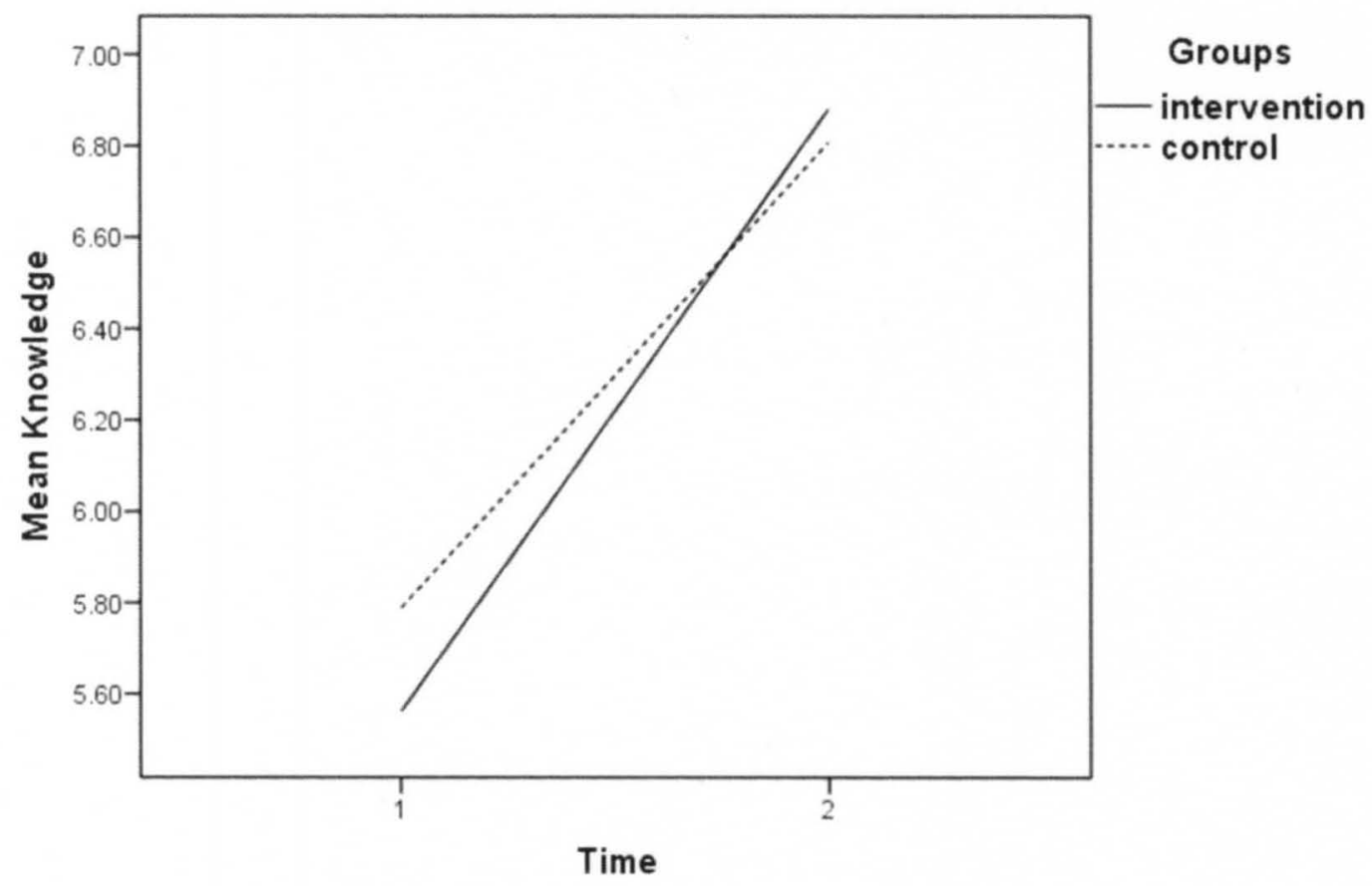

Note. $p<.05$. The tobacco cessation treatment $(T C T)$ knowledge variable was computed by adding the participants' total number of correct answers to ten knowledge questions. The rating scale was: $0=$ incorrect and $1=$ correct. The difference in the participants'TcT knowledge was computed by subtracting the total number of participants' correct answers at Time 1 from the total number of participants' correct answers at Time 2. The difference in participants' knowledge between the intervention $(n=42)$ and control groups $(n=52)$ from Time 1 to Time 2 was statistically nonsignificant (.935)

Figure 4.8 The Difference in Tobacco Cessation Treatment Knowledge between the Intervention and Control Groups from Time 1 to Time 2

\subsection{Second Research Question}

\subsubsection{Effect of Variables on Intent to Provide Tobacco Cessation Treatment}

The second research question was answered using Linear Regression: Do dental students' attitude, perceived barriers, subjective norms, perceived skills, self-efficacy, 
cessation knowledge, their training type, and particularly their tobacco status and use predict intent to provide TCT? Attitude toward TCT $(\mathrm{B}=1.31,95 \%$ CI $0.66-1.97, \mathrm{p}<$ .001 ), perceived barriers $(\mathrm{B}=14.46,95 \%$ CI $3.76-25.16, \mathrm{p}<.001)$, subjective norms $(\mathrm{B}=.31,95 \% \mathrm{CI}-.01-.62, \mathrm{p}<.001)$, perceived skills $(\mathrm{B}=.30,95 \% \mathrm{CI} .04-.56$ $\mathrm{p}<.001)$, and knowledge $(\mathrm{B}=.73,95 \% \mathrm{CI}-.07-1.53, \mathrm{p}<.001)$ increase intent to provide TCT. The type of training $(\mathrm{p}=.193)$ and self-efficacy $(.517)$ did not significantly impact intent. Also, tobacco status $(\mathrm{p}=.540)$ and the amount of tobacco use $(p=.621)$ did not significantly impact intent. The model fit the data well and explained over $46 \%$ of the variance in responses $\left(\mathrm{R}^{2}=0.463, \mathrm{p}<.001\right)$. The model is significantly better than an intercept only model.

\subsection{Third Research Question}

\subsubsection{Effect of Training Dates on Variables}

The third research question was answered using a univariate general linear model: Does the time between receiving the lecture and participating in the practice sessions affect attitudes, barriers, subjective norms, perceived skills, self-efficacy, intentions to provide cessation treatment and tobacco cessation treatment knowledge. Figures 4.9 through 4.15 (see pages 70-76) show no significant interaction between the groups and the five training dates on which the dental students participated in the practice sessions (March 1, 8, 15, 29 and April 19) for participants' attitudes $(\mathrm{p}=.948)$, perceived barriers $(p=.714)$, subjective norms $(p=.052)$, perceived skills $(p=.314)$, self-efficacy $(p=$ $.302)$, intentions to provide cessation treatment $(\mathrm{p}=.188)$ and tobacco cessation treatment knowledge $(\mathrm{p}=.066)$. In Figure 4.11 , the difference in subjective norms between the intervention and control groups from Time 1 to Time 2 at the different 
training dates was close to being significant. During the first training date, the intervention group was less influenced by others to provide TCT than the control group. At the next training dates, the intervention group was more influenced by others to provide TCT than the control group. However, none of these differences were significant.

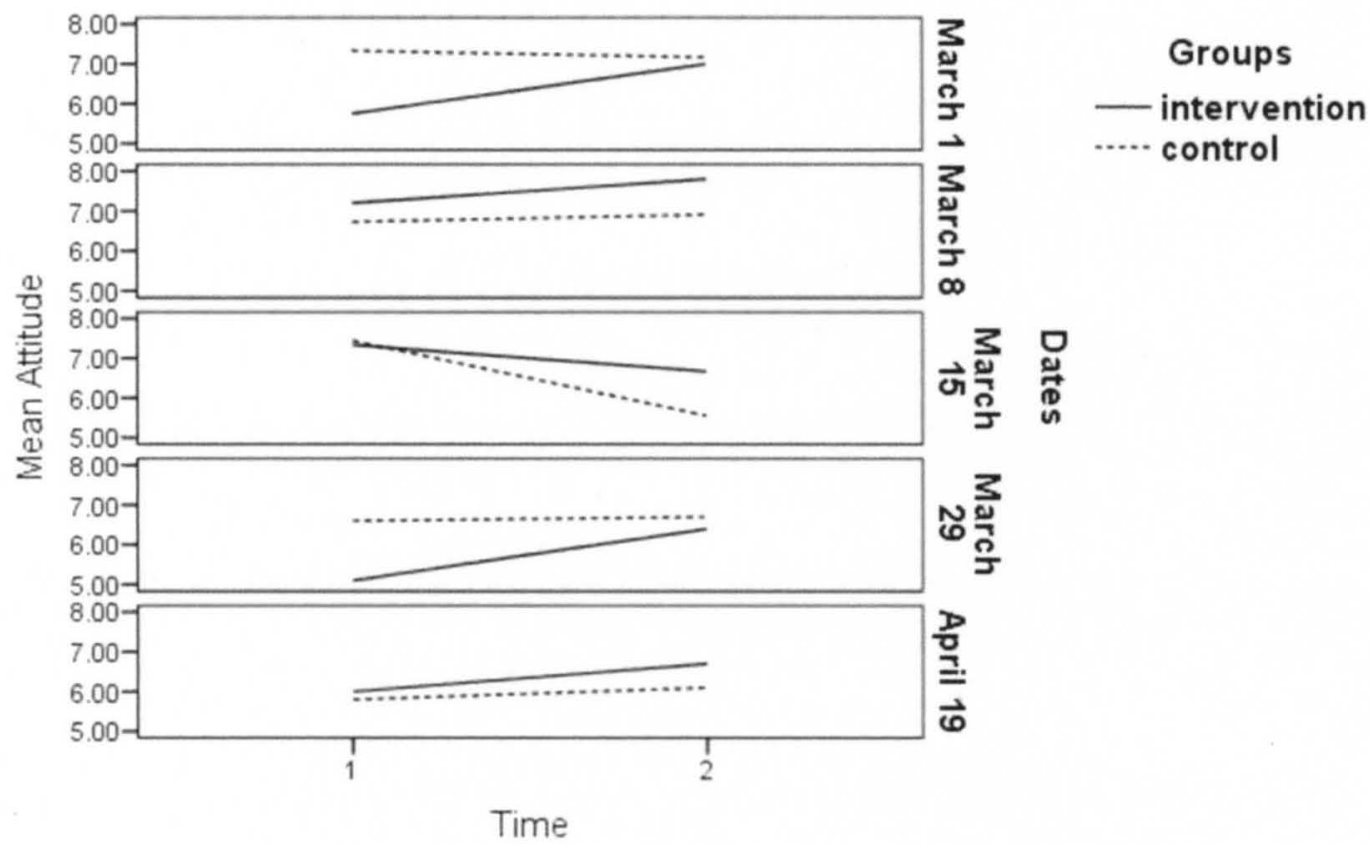

Note. $p<.05$. The attitude variable was computed by adding values from the first two questionnaire items to assess the level of agreement with the statements. The rating scale was: $0=$ strongly disagree, 1 = moderately disagree, 2 = somewhat disagree, $3=$ neither disagree or agree, $4=$ somewhat agree, $5=$ moderately agree, and $6=$ strongly agree. The difference in attitude toward tobacco cessation treatment (TCT) was computed by subtracting the total value of the attitude variable at Time 1 from the total value of the attitude variable at Time 2 . The difference in attitude toward TCT between the intervention $(n=42)$ and control groups $(n=52)$ from Time 1 to Time 2 at the different training dates was statistically nonsignificant $(p=948)$.

Figure 4.9 The Difference in Attitudes Toward Tobacco Cessation Treatment between the Intervention and Control Groups from Time 1 to Time 2 at Different Training Dates 


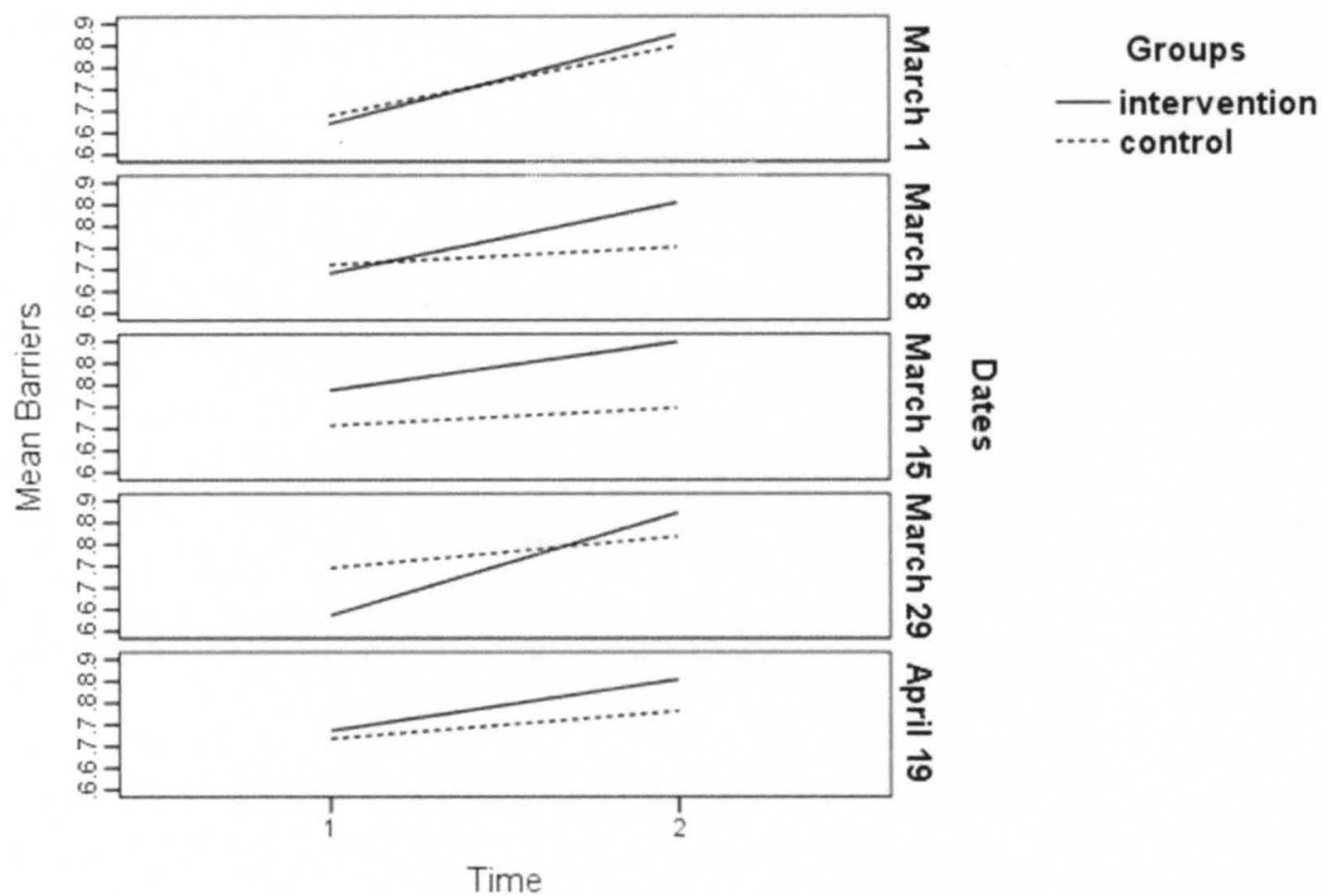

Note. $p<.05$. The perceived barriers variable was computed by adding the total number of barriers reported by participants. The rating scale for reporting barriers was: $0=$ no and $1=$ yes. The difference in perceived barriers from Time 1 to Time 2 was computed by subtracting the total number of perceived barriers at Time 1 from the total number of perceived barriers at Time 2 . The difference in perceived barriers between the intervention $(n=42)$ and control groups $(n=52)$ from Time 1 to Time 2 at different training dates was statistically nonsignificant $(.714)$

Figure 4.10 The Difference in Perceived Barriers between the Intervention and Control Groups from Time 1 to Time 2 at Different Training Dates 


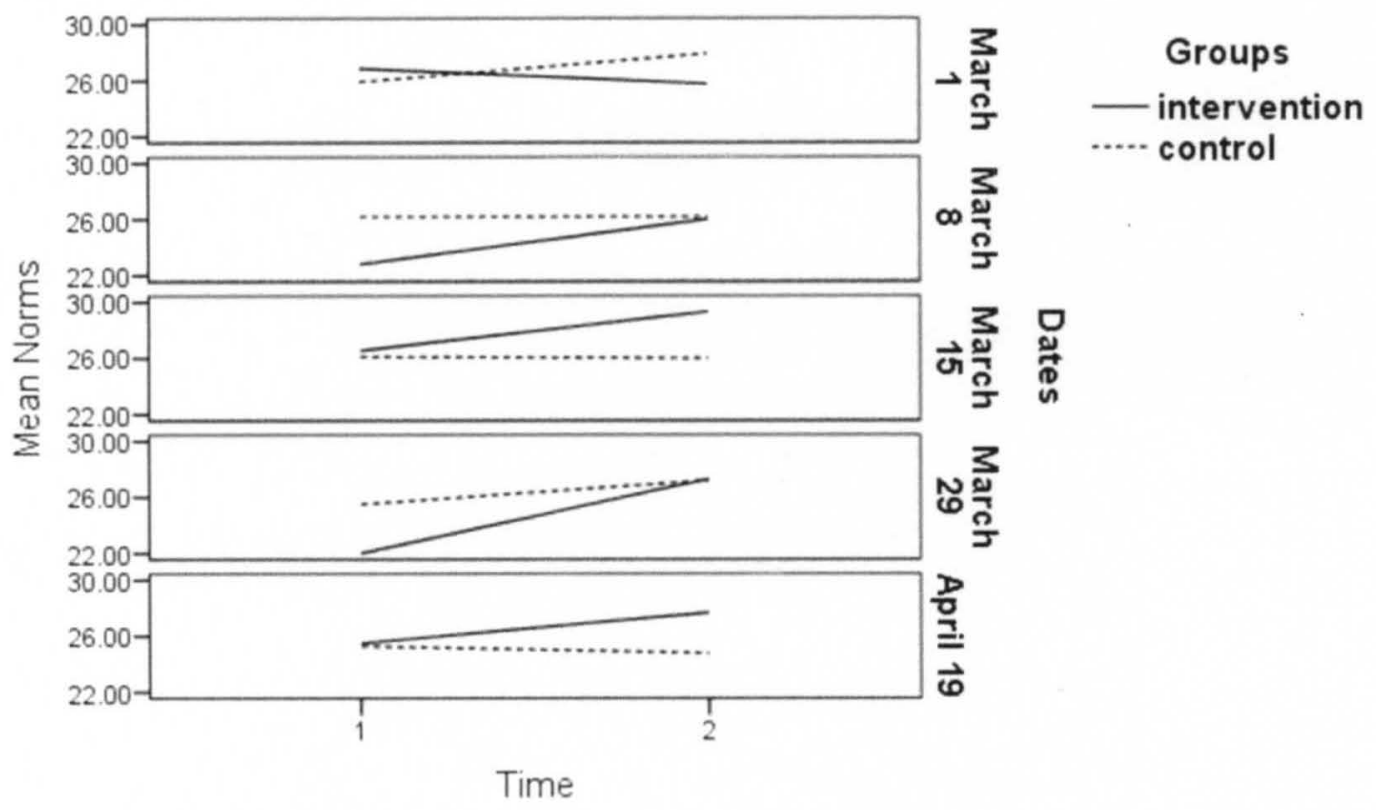

Note. $p<.05$. The subjective norms variable was computed by adding the values of six questions to assess the participants' level of perceived social pressures to provide tobacco cessation treatment (TCT). Questions were rated on a seven-point Likert scale; higher point values indicate a perceived social norm more supportive of providing TCT. The difference in subjective norms between the intervention and control groups from Time 1 to Time 2 was computed by subtracting the total number of participants' subjective norms at Time 1 from the total number of participants' subjective norms at Time 2. The difference in participants' subjective norms between the intervention $(n=42)$ and control groups $(n=52)$ from Time 1 to Time 2 at different training dates was statistically nonsignificant $(p=.052)$.

Figure 4.11 The Difference in Subjective Norms between the Intervention and Control Groups from Time 1 to Time 2 at Different Training Dates 


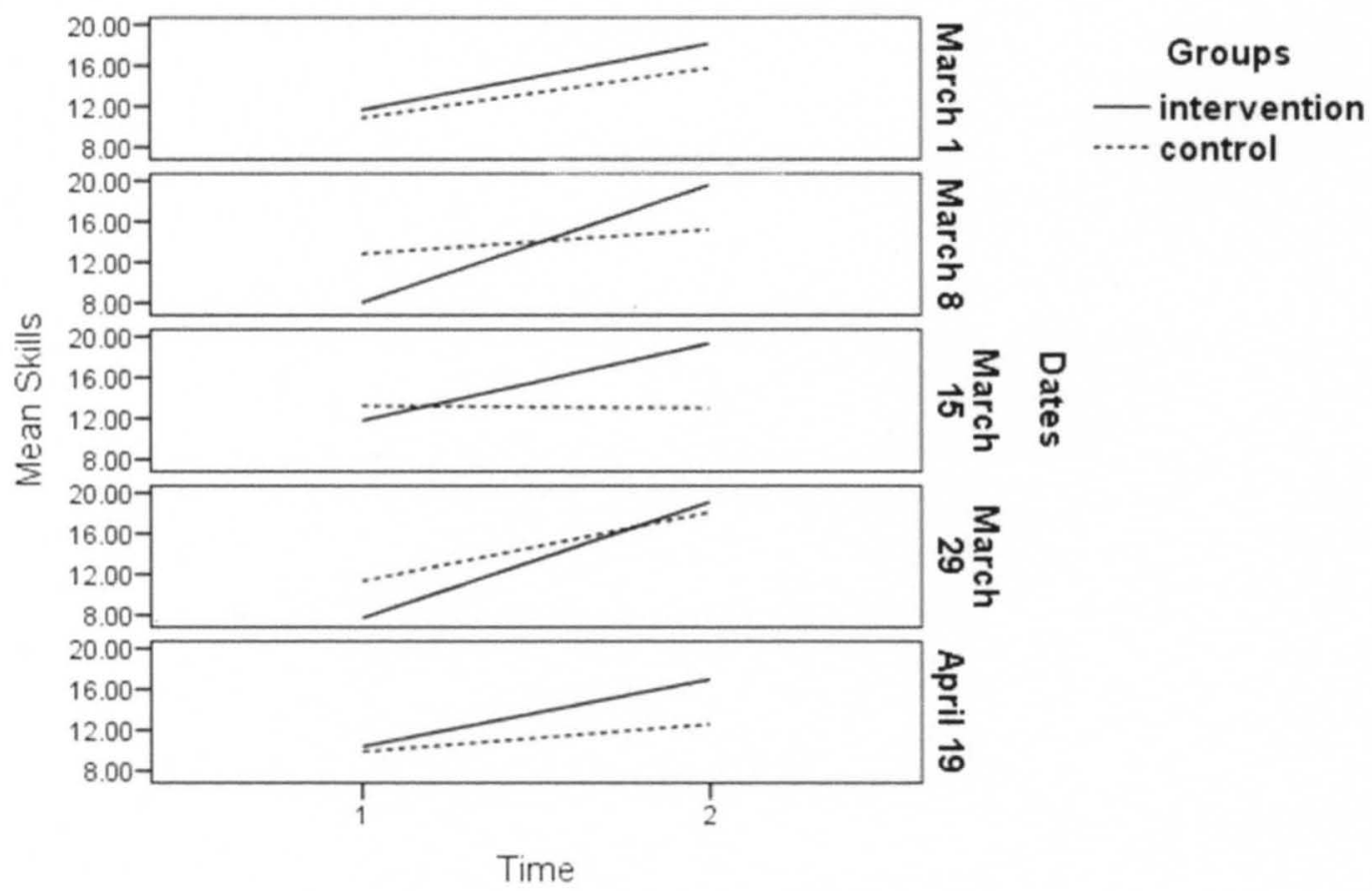

Note. $p<.05$. The perceived skills variable was computed by adding the values of seven questions that assessd their perceived level of tobacco cessation treatment skills from poor to excellent. The rating scale was: $0=$ poor, $1=$ fair, $2=$ good, $3=$ very good, and $4=$ excellent. The difference in the participants' perceived skills was computed by subtracting the total value of perceived skills at Time 1 from the total value of perceived skills at Time 2 . The difference in perceived skills between the intervention $(n=42)$ and control groups $(n=52)$ from Time 1 to Time 2 at different training dates was statistically nonsignificant (314).

Figure 4.12 The Difference in Perceived Skills between the Intervention and Control Groups from Time 1 to Time 2 at Different Training Dates 


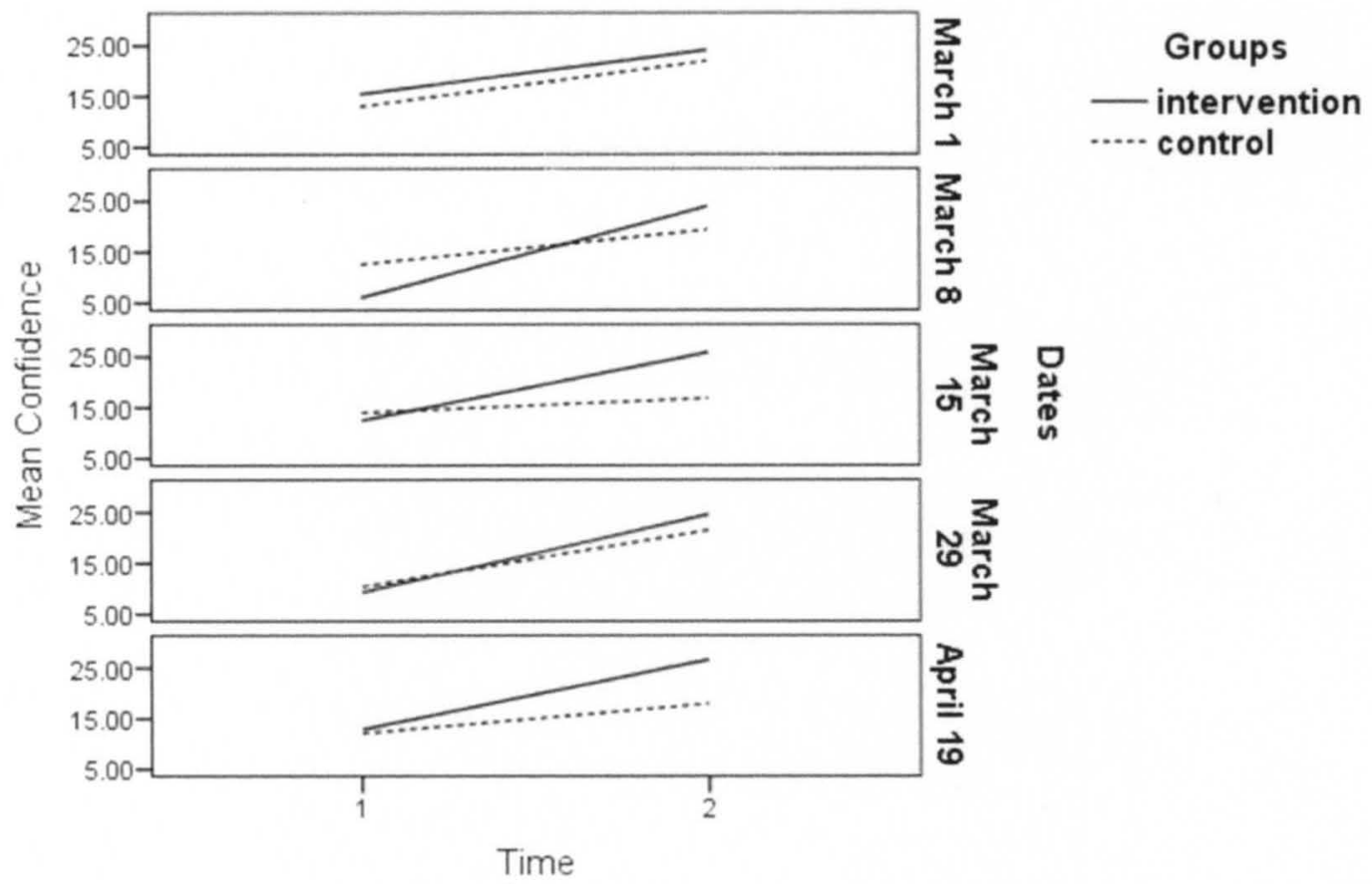

Note. $p<.05$. The self-efficacy variable was computed by adding the values from ten questions to assess the participants' self efficacy to provide tobacco cessation treatment. The rating scale was: $0=$ not at all confident, $1=$ not very confident, $2=$ moderately confident, $3=$ very confident, and $4=$ extremely confident. The difference in participants' self-efficacy from Time 1 to Time 2 was computed by subtracting the total value of self-efficacy at Time 1 from the total value of self-efficacy at Time 2 . The difference in participants' self-efficacy between the intervention $(n=42)$ and control groups $(n=52)$ from Time 1 to Time 2 at different training dates was statistically nonsignificant $(.302)$

Figure 4.13 The Difference in Self-Efficacy between the Intervention and Control Groups from Time 1 to Time 2 at Different Training Dates 


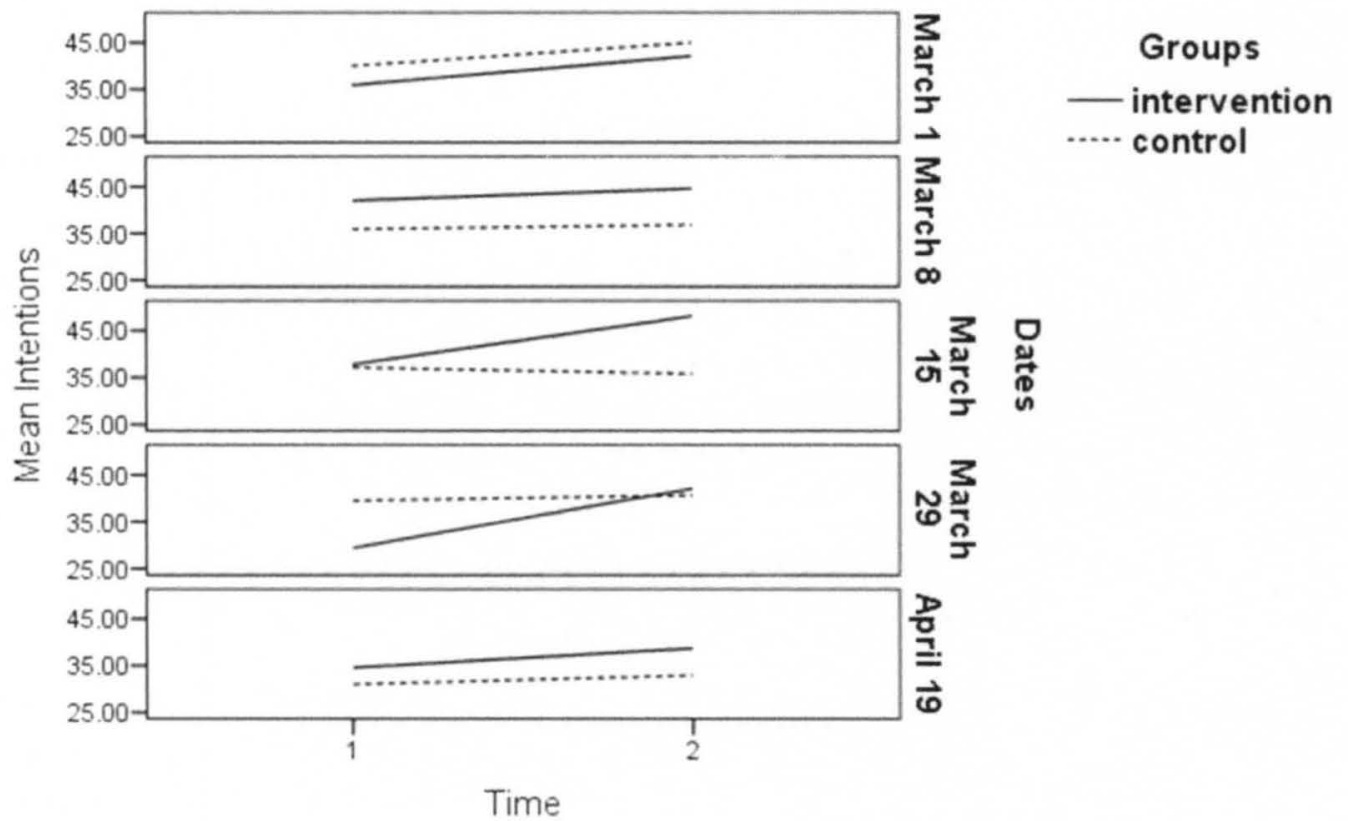

Note. $p<.05$. Participants' intentions to provide tobacco cessation treatment (TCT) was computed by adding values from thirteen questions to assess participants' intent to treat tobacco use and dependence. The rating scale was: $0=$ never, $1=$ rarely, $2=$ sometimes, $3=$ almost always, and $4=$ always (every visit). The difference in participants' intentions to provide TCT was computed by

subtracting the total value of participants' intentions at Time 1 from the total value of participants'

intentions at Time 2. The difference in participants' intentions to provide TCT between the intervention (n

$=42$ ) and control groups $(n=52)$ from Time 1 to Time 2 at different training dates was statistically nonsignificant (.188)

Figure 4.14 The Difference in Intentions to Provide Tobacco Cessation Treatment between the Intervention and Control Groups from Time 1 to Time 2 at Different Training Dates 


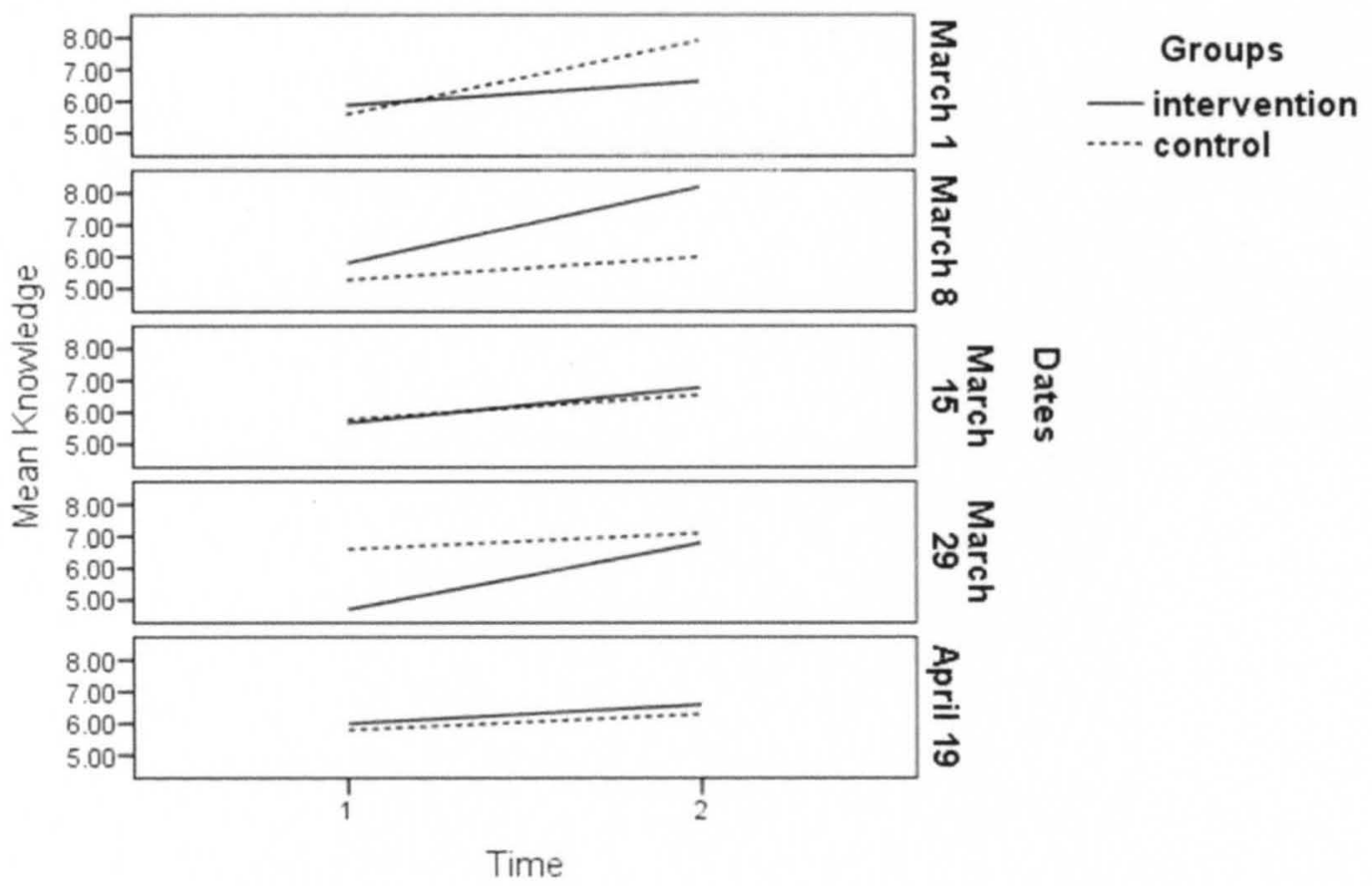

Note. $p<.05$. The tobacco cessation treatment (TCT) knowledge variable was computed by adding the participants' total number of correct answers to ten knowledge questions. The rating scale was: $0=$ incorrect and $1=$ correct. The difference in the participants' TCT knowledge was computed by subtracting the total number of participants' correct answers at Time 1 from the total number of participants' correct answers at Time 2. The difference in participants' knowledge between the intervention $(n=42)$ and control groups $(n=52)$ from Time 1 to Time 2 at different training dates was statistically nonsignificant $(.066)$

4.15 The Difference in Tobacco Cessation Treatment Knowledge between the Intervention and Control Groups from Time 1 to Time 2 at Different Training Dates 


\section{CHAPTER 5}

\section{CONCLUSIONS}

The difference in perceived barriers, subjective norms, perceived skills, selfefficacy and intentions between the intervention and control groups was significant over time, but the difference in attitude and tobacco cessation knowledge between groups was not. Freshman dental students receiving the practice sessions with standardized patients and the debriefing session were more influenced by other dental professionals' and patients' approval of TCT than the students receiving only a traditional lecture. They also perceived their cessation treatment skills had improved more than the students receiving a lecture only. Participation in the training using SPs increased dental students' confidence in treating tobacco use and dependence and their intentions to provide TCT. Similarly, Brame et al (2012) found that dental hygiene students' confidence was increased after tobacco cessation training using SPs more than lecture only. Dental students in the control group had an increase in scores of variables such as perceived barriers, subjective norms, perceived skills, self-efficacy, intentions to provide TCT, and tobacco cessation treatment knowledge as a result of lecture alone.

Statistically nonsignificant differences between the intervention and control groups in attitudes and tobacco cessation knowledge may be explained by: (a) the lecture and handouts provided the basic fundamentals of TCT needed for the practice sessions, (b) the sessions using SPs were designed to focus on counseling skills, not to change knowledge or attitude, and (c) TCT may be a low priority for dental students. Freshman dental students may not fully understand the negative consequences of tobacco use to the 
patients' oral health and their dental services. They need to develop an understanding of the importance of treating tobacco use and dependence during their formative years of training.

The intervention group showed improvement in attitude toward TCT and felt more social pressure to provide TCT, yet may not have perceived a significant amount of control over providing TCT. According to the theory of planned behavior, intention to provide TCT is predicted by attitude toward TCT, belief about whether key people approve or disapprove of TCT, and if they perceive to have control over providing TCT (Francis et al., 2004).

Participants' attitudes, perceived barriers, subjective norms, perceived skills and tobacco cessation knowledge did significantly impact intent to provide TCT but the type of training did not. Tobacco status and use did not have a significant impact on intent. This could be due to the low number of dental students in the study who use tobacco. Similar results were found by Fried, Reid, and DeVore (2004). They did not find a significant difference in students' responsibility toward TCT between students who used tobacco and those who did not use tobacco. There was also no significant impact from completing the post- questionnaires at different training dates.

There was a significant difference in the number of dental students' perceived barriers between the intervention and control groups at Time 2 and over time. Freshman dental students in the introductory clinical course identified more factors that limited their ability to counsel tobacco users during every visit after the training with SPs than after the lecture only training. The practice sessions using SPs may have increased the awareness of barriers to TCT more than the lecture. This may be due to the students' 
lack of clinical training and experience in counseling patients. This awareness may motivate students to learn more about TCT and to practice their skills before providing treatment. Previous studies have recommended to provide training to reduce barriers to TCT (Hudmon et al., 2003; Pendharkar et al., 2010; Studts et al., 2011; Vanobbergen et al., 2007; Victoroff et al., 2004). The participants' increased awareness of barriers to TCT after training raises concern for the need of educational methods that reduce barriers to TCT.

At Time 2, all participants reported that "TCT requires approval or order from a physician" and "TCT is not supported by my facility and administration" as factors that may limit their ability to counsel tobacco users during every visit. At Time $2,96.8 \%$ of the participants reported that tobacco cessation is performed by another member of the health care team and $96.8 \%$ of the participants reported that tobacco cessation is a low priority for them. This is an extremely high proportion of the freshman dental students in the study who after training did not value providing TCT. It will take much effort on the part of faculty members and administrators to motivate students to get involved in helping patients to quit tobacco use. While in the formative years of dental training, faculty members and administrators should make TCT a high priority in the clinical setting. These factors act as barriers to TCT and may reduce students' perceived behavioral control. This may affect their intentions to provide TCT and may eventually affect their treatment behavior (Francis et al., 2004).

It would be important in a successful effort to train students in TCT that the facility and administration work together to build strong support for the program. It is evident that additional research is needed to design a tobacco cessation program that 
reduces students' perceived barriers to TCT and improves their perceived behavioral control. Tobacco cessation programs could focus on educating students by explaining to the student that TCT: (a) does not require approval or order from a physician, (b) can be performed by all members of the health care team, and (c) is supported by the facility and administration.

Previous research indicates that dental students improve in attitude toward TCT after tobacco cessation training (O'Donnell et al., 2010; Vered et al., 2010; Victoroff et al., 2004). Similar results were found in this study except that participants in the control group agreed less when asked if dental professionals should discuss tobacco use with patients. The majority of participants in the intervention and control groups agreed that a brief intervention with patients would be effective in helping them quit tobacco use. Participants in both groups felt that the dental profession should be more active in helping patients quit smoking and in helping prevent patients from starting smoking. However, members in the intervention group were more likely to feel this way.

Using standardized patients may have made freshman dental students more aware of their lack of experience in TCT and increased their awareness of the need to gain knowledge of cessation counseling, adequate training, and counseling skills. More training in TCT could reduce barriers and raise students' confidence in providing cessation treatment (O'Donnell et al., 2010; Pendharkar et al., 2010). The perceived barriers will remain high without providing any additional education in TCT. Several participants in both groups suggested that more practice with standardized patients would improve the program. The theory of social cognitive theory suggests increasing students' 
confidence and reducing barriers by taking small steps and being specific about what change is needed (Rimer \& Glanz, 2005).

Both training methods received positive evaluations from the participants in the study. Participants indicated a high level of agreement that the lecture and handouts provided valuable information in preparing them to provide tobacco cessation counseling to their patients. To a lesser degree, participants felt competent to provide tobacco cessation counseling from the lecture and handouts alone. Participants in the intervention group indicated a high level of agreement that the practice sessions with standardized patients increased their confidence in providing tobacco cessation counseling, that the feedback provided by the standardized patients was helpful, and that the feedback provided during the debriefing session was useful.

Participants in the intervention group were receptive to the practice sessions with standardized patients and found the training valuable. The majority of participants found it very useful and effective. The participants' comments supported the use of standardized patients in the cessation training, but also suggested changes to improve the program. Several participants suggested having more training with standardized patients. Members of the intervention group suggested providing videos or real life counseling examples before the practice sessions, using a dental setting for training, finding a better time in the curriculum to conduct the training, and holding the practice sessions closer to the lecture. These changes could possibly improve students' attitudes, subjective norms, perceived skills, self-efficacy, intentions to provide TCT, and tobacco cessation treatment knowledge. They could also reduce perceived barriers. 


\subsection{Limitations}

A limitation may have been caused by administering the post-lecture questionnaire too near the time the control group was to participate in the practice sessions with SPs. The training with SPs was required for all students in the course. Participants in the control group may have been influenced by knowing they were going to receive the training with SPs immediately after completing the questionnaire. If the second questionnaire was administered one week after receiving the lecture, the control group's knowledge of participating in the practice sessions with SPs would have less likely influenced their answers on the post-lecture questionnaire.

I raise this concern after analyzing the control group's comments about how to change the program. Several members of the control group suggested that the practice sessions with SPs should be close to the lecture. One participant suggested that there should be more interviews with SPs and another suggested that the training should be more interactive. Their comments seem to have been influenced by the control group members knowing they were going to participate in the practice sessions with SPs after completing the post-lecture questionnaire. Administering the post-lecture questionnaire to the control group prior to the practice sessions with SPs and on the same training date as the intervention group did provide a better comparison of the changes in variables between the groups at the different training dates.

The psychometric properties of the instrument indicated that they did not adequately measure the extent of change in the perceived barriers, subjective norms, and cessation knowledge variables from baseline to Time 2 . The scales may not have been sensitive enough to determine the differences between the intervention and control 
groups. The Cronbach's Alpha for perceived barriers, subjective norms, and cessation knowledge was less than .60 , and it should be greater than .60 to be acceptable for research reliability (DeVellis, 2003). The findings suggest further development of scale items measuring these variables to improve the reliability and validity of the instrument.

Other limitations in the study include: (a) using group randomization that limited control over the intervention, (b) asking participants to self-report, (c) having testing effects created by administering the questionnaire before the lecture, (d) contamination between students scheduled on different training dates, (e) not allowing an adequate follow-up time period, (f) using multiple SPs that created training variation, and (g) creating student nervousness or anxiety due to their lack of experience in providing TCT.

Participants in the study were receptive to the tobacco cessation treatment training using standardized patients and the training significantly increased their subjective norms, perceived skills, self-efficacy, and intentions to provide TCT more than lecture only. Dental students perceived a higher level of skills and confidence in providing TCT. The study results did not indicate that the training increased participants' positive attitude toward TCT and their tobacco cessation knowledge. The results may be able to be generalized to other populations of dental students. They may not be able to be generalized to other health care professionals because the task of providing TCT varies among different health profession types.

\subsection{Future Research}

Future research is needed among dental students at different years of their training and at other schools to determine the impact of using standardized patients in tobacco cessation treatment training in the dental curriculum. The practice sessions may be more 
beneficial to students at a different time in the curriculum. The training may be more valuable to students in their later years of education and closer to their formal clinical training. It could be taken in small steps and the participants' should be made aware of its importance in the dental setting (Rimer \& Glanz, 2005). Additional training with standardized patients could be provided during the third year of dental training or it could be organized differently. The lecture could be provided during a dental students' first year training followed by practice sessions using standardized patients during the third year. At least the dental students should receive a refresher lesson during their third year of training.

Additional research is needed to determine the difference in variables between the groups over a longer period of time. Future research could reveal how dental students' increase in perceived skills, self-efficacy, and intentions gained from the training using SPs could be sustained during their formal training and practice (Brame et al., 2012). A longer term follow-up could reveal that intentions to provide TCT increase intervention in practice. This could be accomplished by surveying participants at the end of their clinical training and after having time to practice. It will be important to determine the role of clinical experience in increasing confidence and intentions to provide TCT (Brame et al., 2012). Research is also needed among other health care professionals at different stages of their training.

\subsection{Conclusion}

Using SPs in TCT training does show promise as an educational method that can increase dental students' subjective norms, perceived skills, self-efficacy, and intent to provide TCT. Dental students participating in the practice sessions using SPs felt more 
social pressure to provide TCT, perceived having improved their TCT skills, perceived having more confidence in providing TCT, and increased their intent to provide TCT in the dental setting. Feeling social pressure to provide TCT could increase the number of dentists providing TCT and the number of patients treated for tobacco use and dependence. A higher level of perceived skills could lead to greater confidence in their abilities and an increase in the number of patients receiving TCT. The evaluation of the program found that the practice sessions with SPs increased dental student confidence in providing TCT and was a positive learning experience. The study results indicate modifications are needed to improve students' attitude toward TCT, increase tobacco cessation knowledge, and reduce perceived barriers to providing TCT. Further research is needed to determine the effectiveness of the training using standardized patients in increasing dental students TCT in practice. Educators considering incorporating the use of standardized patients into TCT training will find this information useful. 


\section{REFERENCES}

American Academy of Periodontology. (2011). Tobacco use and periodontal disease.

Retrieved February 26, 2011, from http://www.perio.org/consumer/smoking.htm

American Dental Hygienists' Association. (2009). Ask. Advise. Refer. Three minutes or more can save lives. Retrieved October 23, 2011, from

$\underline{\text { http://www.askadviserefer.org/ }}$

Applegate, B. W., Sheffer, C. E., Crews, K. M., Payne, T. J., \& Smith, P. O. (2008). A survey of tobacco-related knowledge, attitudes and behaviors of primary care providers in Mississippi. Journal of Evaluation in Clinical Practice, 537-544.

Barker, G. J., Williams, K. B., Taylor, T. S., \& Barker, B. F. (2001). Practice behaviors of alumni trained as students in tobacco use cessation interventions. The Journal of Dental Hygiene, 75(II), 165-169.

Becker, K. L., Rose, L. E., Berg, J. B., Park, H., \& Shatzer, J. H. (2006). The teaching effectiveness of standardized patients. Journal of Nursing Education, 45(4), 103111.

Bolstad, A. L., Shen, J. J., Covelli, M., \& Torpey, M. (2012). Reliability of standardized patients used in a communication study on international nurses in the United States of America. Nursing and Health Sciences, 14, 67-73.

Bornais, J. A. K., Raiger, J. E., Krahn, R. E., \& El-Masri, M. M. (2012). Evaluating undergraduate nursing students' learning using standardized patients. Journal of Professional Nursing, 28(5), 291-296. 
Botelho, R., Wassum, K., Benzian, H., Selby, P., \& Chan, S. (2009). Address the gaps in tobacco cessation training and services: Developing professional organisational alliances to create social movements. Drug and Alcohol Review, 28(558-566). doi: $10.1111 / \mathrm{j} .1465-3362.2009 .00112 . \mathrm{x}$

Brame, J. L., Martin, R., Tovac, T., Stein, M., \& Curran, A. E. (2012). A randomized controlled trial of the effect of standardized patient scenarios on dental hygiene students' confidence in providing tobacco dependence counseling. Journal of Dental Hygiene, 86(4), 282-291.

Brown, L. J., Johns, B. A., \& Wall, T. P. (2002). The economics of periodontal diseases. Periodontology, 29, 223-234.

Butler, K., Rayens, M. K., Zhang, M., Maggio, L. G., Riker, C., \& Hahn, E. J. (2009). Tobacco dependence treatment education for baccalaureate nursing students. Journal of Nursing Education, 84(5), 249-254.

Cannick, G. F., Horowitz, A. M., Garr, D. R., Reed, S. G., Neville, B. W., Day, T. A., . . Lackland, D. T. (2007). Use of the OSCE to evaluate brief communication skills training for dental students. Journal of Dental Education, 7I(9), 1203-1209.

Cannick, G. F., Horowitz, A. M., Reed, S. G., Drury, T. F., \& Day, T. A. (2006). Opinions of South Carolina dental students toward tobacco use interventions. Journal of Public Health Dentistry, 66(1), 44-48.

Centers for Disease Control and Prevention. (2011a). Best practices for comprehensive tobacco control programs executive summary. Atlanta, GA.

Centers for Disease Control and Prevention. (2011b). Quitting smoking among adultsUnited States 2001-2010 MMWR. 60(44), 1513-1519. 
Centers for Disease Control and Prevention. (2011c). Quitting smoking among adultsUnited States, 2001-2010 (Vol. 60): U.S. Department of Health and Human Services.

Clareboets, S., Sivarajasingam, V., \& Chestnutt, I. G. (2010). Smoking cessation advice: Knowledge, attitude, and practice among clinical dental students. British Dental Journal, 208(4), 173-177.

Coan, L. L., Christen, A., \& Romito, L. (2007). Evolution of a tobacco cessation curriculum for dental hygiene students at Indiana University School of Dentistry. Journal of Dental Education, 71(6), 776-784.

Cokley, K. (2007). A psychometric investigation of the academic self-concept of Asian American college students. Educational and Psychological Measurement, 67(1), 88-99.

Corelli, R. L., Kroon, L. A., Chung, E. P., Sakamoto, L. M., Gundersen, B., Fenlon, C. M., \& Hudmon, K. S. (2005). Statewide evaluation of a tobacco cessation curriculum for pharmacy students. Preventive Medicine, 40, 888-895.

Cornuz, J., Humair, J.-P., Seematter, L., Stoianov, R., Melle, G. v., Stalder, H., \& Pecoud, A. (2002). Efficacy of resident training in smoking cessation: A randomized, controlled trial of a program based on application of behavioral theory and practice with standardized patients. Annals of Internal Medicine, $136(6), 429-437$.

Cromwell, J., Bartosch, W. J., Fiore, M. C., Hasselbad, V., \& Baker, T. (1997). Costeffectiveness of the clinical practice recommendations in the AHCPR Guideline 
for smoking cessation. JAMA, 278(21), 1759-1766. doi:

10.1001/jama.1997.03550210057039

Davis, J. M., Ramseier, C. A., Mattheos, N., Schoonheim-Klein, M., Compton, S., AlHazmi, N., . . Radley, N. (2010). Education of tobacco use prevention and cessation for dental professionals- a paradigm shift. International Dental Journal, $60(1), 60-72$.

Department of Health and Human Services. (2005). Morbidity and mortality weekly report: Tobacco use and cessation counseling-global health professionals survey pilot study, 10 countries, 2005.

DeVellis, R. F. (2003). Scale development: Theory and applications (Second ed. Vol. 26). Thousand Oaks California: Sage Publications.

Dolan, T. A., McGorray, S. P., \& Grinstead-Skigen, C. L. (1997). Tobacco control activities in U.S. dental practices. Journal of American Dental Association, 12(128), 1669-1679.

Fiore, M. C., Jaen, C. R., Baker, T. B., Bailey, W. C., Benowitz, N. L., Curry, S. J., . . . Lando, H. A. (2008). Treating tobacco use and dependence: 2008 update. Clinical practice guideline. Rockville, Maryland.

Francis, J. J., Eccles, M. P., Johnston, M., Walker, A., Grimshaw, J., Foy, R., . . Bonetti, D. (2004). Constructing questionnaires based on the theory of planned behavior: A manual for health services researchers. Newcastle upon Tyne, United Kingdom: Centre for Health Services Research. 
Fried, J. L., Reid, B. C., \& DeVore, L. E. (2004). A comparison of health professions student attitudes regarding tobacco curricula and interventionist roles. Journal of Dental Education, 68(3), 370-377.

Gelskey, S. C. (2002). Impact of a dental/dental hygiene tobacco-use cessation curriculum on practice. Journal of Dental Education, 66(9), 1074-1078.

Giacona, M. B. (2004). Tobacco cessation within the dental curriculum in the United States and internationally. New York State Dental Journal, 6(70), 40-43.

Gordon, J. S., Severson, H. H., Seeley, J. R., \& Christiansen, S. (2004). Development and evaluation of an interactive tobacco cessation CD-ROM educational program for dental students. Journal of Dental Education, 68(3), 361-369.

Harris, J. L., Patton, L. L., Wilder, R. S., Peterson, C. A., \& Curran, A. E. (2009). North Carolina dental hygiene students' opinions about tobacco cessation education and practices in their programs. $J$ Dent Educ, 73(5), 539-549.

Hinz, J. G. (2010). Teaching dental students motivational interviewing techniques: Analysis of a third-year class assignment. Journal of Dental Education, 74(12), $1351-1356$

Hudmon, K. S., Corelli, R. L., Chung, E., Gundersen, B., Kroon, L. A., Sakamoto, L. M., ... Prokhorov, A. V. (2003). Development and implementation of a tobacco cessation training program for students in the health professions. Journal of Cancer Education, 18(3), 142-149.

Johnson, G. K., \& Slach, N. A. (2001). Impact of tobacco use on periodontal status. Journal of Dental Education, 65(4), 313-321. 
Kentucky's Cabinet for Health and Family Services. (2011). Kentucky's tobacco quit line. Retrieved December 28, 2011, from http://chfs.ky.gov/NR/rdonlyres/D09C719B7753-4D1D-9B25-239872BD614B/0/QL FactSheet.pdf

Koerber, A., Crawford, J., \& O'Connell, K. (2003). The effects of teaching dental students brief motivational interviewing for smoking cessation counseling: A pilot study. Journal of Dental Education, 67(4), 439-447.

Landis, J. R., \& Koch, G. G. (1977). The measurement of observer agreement for categorical data. Biometrics, 33, 159-174.

Long-Bellil, L. M., Robey, K. L., Graham, C. L., Ninihan, P. M., Smeltzer, S. C., \& Kahn, P. (2011). Teaching medical students about disability: The use of standardized patients. Academic Medicine, 86(9), 1163-1170.

Maillet, J. P., Tax, C. L., Neish, N. R., \& Denny, A. L. (2010). Evaluation of outcomes for tobacco cessation counseling in a Dalhousie University Dental Hygiene Curriculum. Journal of Dental Education, 74(3), 311-317.

Martin, B. A., \& Chewning, B. A. (2011). Evaluating pharmacists' ability to counsel on tobacco cessation using two standardized patient scenarios. Patient Education and Counseling. doi: 10.1016/j.pec.2010.12.010

Murray, D. M. (1998). Design and analysis of group-randomized trials. New York, New York: Oxford University Press, Inc.

O'Donnell, J. A., Hamilton, M. K., Markovic, N., \& Close, J. (2010). Overcoming barriers to tobacco cessation counselling in dental students. Oral Health and Preventive Dentistry, 8(2), 117-124. 
Pendharkar, B., Levy, S. M., McQuistan, M. R., Qian, F., Squier, C. A., Slach, N. A., \& aquilino, M. L. (2010). Fourth-year dental students' perceived barriers to providing tobacco intervention services. Journal of Dental Education, 74(10), 1074-1085.

Rajasundaram, P., Sequeira, P. S., \& Jain, J. (2011). Perceptions of dental students in India about smoking cessation counseling. Journal of Dental Education, 75(12), $1603-1610$.

Rankin, K. V., Jones, D. L., \& Crews, K. M. (2010). Tobacco cessation education for dentists: An evaluation of the lecture format. Journal of Cancer Education, 25, 282-284. doi: 10.1007/s13187-010-0042-9

Research Science and Therapy Committee of the American Academy of Periodontology. (1999). Tobacco use and the periodontal patient. Journal of Periodontology, 70(11), 1419-1427.

Rikard-Bell, G., Groenlund, C., \& Ward, J. (2003). Australian dental students' views about smoking cessation counseling and their skills as counselors. Journal of Public Health Dentistry, 63(3), 200-206.

Rimer, B. K., \& Glanz, K. (2005). Theory at a Glance. A Guide For Health Promotion Practice.

Schmelz, A. N., Nixon, B., McDaniel, A., Hudmon, K. S., \& Zillich, A. J. (2010). Evaluation of an online tobacco cessation course for health professions students. American Journal of Pharmaceutical Education, 74(2), 1-9. 
Scott, D. A., Palmer, R. M., \& Stapleton, J. A. (2001). Validation of smoking status in clinical research into inflammatory periodontal disease. Journal of Clinical Periodontology, 28, 715-722.

Sheffer, C. E., Barone, C. P., \& Anders, M. E. (2009). Training health care providers in the treatment of tobacco use and dependence: Pre- and post-training results. Journal of Evaluation in Clinical Practice, 607-613.

Shibly, O. (2010). Effect of tobacco counseling by dental students on patient quitting rate. J Dent Educ, 2(74), 140-148.

Spangler, J. G., George, G., Foley, L. K., \& Crandall, S. J. (2002). Tobacco intervention training: Current efforts and gaps in U.S. medical schools. Journal of the American Medical Association, 9(288), 1102-1109.

Studts, J. L., Burris, J. L., Kearns, D. K., Worth, C. T., \& Sorrell, C. L. (2011). Evidencebased tobacco cessation treatment by dental hygienists. The Journal of Dental Hygiene, 85(1), 13-21.

Tomar, S. L. (2001). Dentistry's role in tobacco control. Journal of American Dental Association, 132, 305-345.

U.S. Department of Health and Human Services. (2010). Healthy People 2020. Rockville, MD: Retrieved from http://healthypeople.gov/2020/topicsobjectives2020/pdfs/hp2020objectives.pdf.

University of California San Francisco. (2011). Rx for change. Retrieved December 28, 2011, from http://rxforchange.ucsf.edu/ 
Vanobbergen, J., Nuytens, P., Herk, M. v., \& Visschere, L. D. (2007). Dental students' attitude towards anti-smoking programmes: A study in Flanders, Belgium. European Journal of Dental Education, 11, 177-183.

Vered, Y., Livny, A., Zini, A., Shabaita, S., \& Sgan-Cohen, H. D. (2010). Dental students' attitudes and behavior toward smoking cessation as part of their professional education. Teaching and Learning in Medicine, 22(4), 268-273.

Victoroff, K. Z., Danjulich-Huryn, T., \& Haque, S. (2004). Attitudes of incoming dental students toward tobacco cessation promotion in the dental setting. Journal of Dental Education, 68(5), 563-568.

Walsh, S. E., Singleton, J. A., Worth, C. T., Krugler, J. J., Moore, R., Wesley, G. C., \& Mitchell, C. K. (2007). Tobacco cessation counseling training with standardized patients. Journal of Dental Education, 71(9), 1171-1178.

Warren, C. W., Sinha, D. N., Lee, J., Lea, V., Jones, N., \& Asma, S. (2011). Tobacco use, exposure to secondhand smoke, and cessation counseling training of dental students around the world. Journal of Dental Education, 75(3), 385-405.

Weaver, R. G., Whittaker, L., Valachovic, R. W., \& Broom, A. (2002). Tobacco control and prevention effort in dental education. Journal of Dental Education, 66(3), 426-429.

Weidner, A. C., Gimpel, J. R., Boulet, J. R., \& Solomon, M. (2010). Using standardized patients to assess the communication skills of graduating physicians for the comprehensive osteopathic medical licensing examination (COMLEX) level 2performance evaluation (Level 2-PE). Teaching and Learning in Medicine, 22(1), $8-15$. 
Wilkerson, L., Lee, M., \& Hodgson, C. S. (2002). Evaluating curricular effects on medical students' knowledge and self-perceived skills in cancer prevention. Academic Medicine, 77(10), S51-S53. 
APPENDIX A

AGENDA 
Treating Tobacco Use and Dependence for the Dental Professional

\author{
Professional Education and Training Manager \\ Tobacco Treatment Specialist \\ Kentucky Cancer Program - University of Louisville
}

\begin{abstract}
AGENDA
Introduction

Status and impact of tobacco use in KY, the U.S., and among special populations

I. Barriers for healthcare providers to treating patients' tobacco use

II. Treating Tobacco Use and Dependence Clinical Practice Guideline Update 2008
\end{abstract}

III. Counseling patients who are willing to quit

IV. Resources for referral/KY Tobacco Quit Line

V. Counseling those not willing to quit - motivational interviewing

VI. Medications for cessation - advantages and disadvantages for each; recommendations for proper usage

VII. Relapse issues

VIII. Summary 
APPENDIX B

SMOKING CASE \# 1 


\section{SP Smoking Case \#1 \\ Contemplating Quitting}

1. Case Name: Elizabeth Smith

2. Author: Bass

3. Challenge: History \& Counseling

- Advise cessation

- Assess willingness to quit

- Discuss previous quit attempts

- Discuss and problem solve barriers to quitting

- Assist with nicotine dependency and provide therapy

- Discuss concerns with quitting

- Arrange follow-up

4. Goal: To assist dental professionals in obtaining skills necessary to perform brief interventions for smoking cessation.

5. Chief Complaint: None, Mrs. Smith is here to receive a six month dental evaluation and adult prophylaxis (professional cleaning of teeth).

6. Periodontal Status: Localized periodontitis, \#3 DL - 5mm pocket depth (PD), \#15 DF - 5mm PD

7. Soft tissue exam: Smoker's palate, tobacco stain on mandibular anterior teeth \#23-\#26

8. Hard tissue charting: Decay \#30 mesial occlusal (MO)

9. Case Summary: Mrs. Smith is a 32 year old woman who has just reentered the workforce. She will begin work as the Outreach Coordinator for the School of Business in one week. Her past medical history is not significant. The only hospitalizations she has had are for the birth of her two children, ages 1 and 4 years. The four year old has had "tubes in the ears" because of frequent ear infections and the 1 year old appears to be heading that way as well. Mrs. Smith' family history is non-contributory. Mrs. Smith does not suffer from depression or have any substance abuse problem other than tobacco. 
Mrs. Smith lives in Louisville with her two children and her husband. She began experimenting with smoking during high school and was smoking regularly by her freshman year in college. She has smoked a pack a day for the last-13 years. She successfully quit for both of her pregnancies (because of the adverse effects) but started smoking again soon after the birth of her children. Smoking was her 'break time,' 'allows her to relax,' and 'escape from the stresses of work.' Initially, smoking was a social experience, only smoking during breaks with other co-workers, but she would soon be smoking regularly both at home and at work. She knows the harmful health effects of smoking for herself (lung cancer, shortness of breath) and has attempted to quit two other times. The first time she quit for approximately three months going cold turkey. She did not have much withdrawal (she was only smoking 10-20 cigarettes a day then) but gained twenty pounds (she also knows being overweight is bad for her health). More recently, she has had difficulty concentrating and it takes her longer to get the things she needs to do done. She also has had difficulty in social situations because she and her husband would go out and the smell would cause her to crave the cigarettes terribly. Also, at parties when she would have a few drinks she would end up smoking as well. She and her husband also usually smoke when discussing the day in the evenings after putting their kids to bed.

Mrs. Smith smokes her first cigarette usually about thirty minutes after rising with her morning coffee. She usually smokes about a pack a day. She always sits in the smoking section of restaurants and finds herself 'needing' a cigarette if she is in a non-smoking building for more than about two hours.

The resident should first advise the patient to quit smoking in a clear, strong, and personalized manner. For example, "As your clinician, I need you to know that quitting smoking is the most important thing you can do to protect your health now and in the future. The clinic staff and I will help you." It would be even better if they personalize it by tying in the health effects of her children.

When asked your willingness to quit do not say no, but you are doubtful because you have quit and failed two times previously. You did not use nicotine replacement or other medication with either quit attempt. You have the following concerns: weight gain, social isolation at work, difficulty being 
around other smokers at home and at work, the difficulty concentrating she had when attempting to quit the last time as she is starting a new job. Tell the dental professional you would prefer to cut down and only smoke in social situations.

If the dental professional (a) tells you it is better to quit than cut down, (b) addresses your concerns re: weight gain, being around other smokers, etc. and (c) offers to help you make a quit plan, agree to make a quit attempt and end the scenario.

\section{If he/she does not address the above concerns continue to be resistant to quitting.}

9. Setting: Office

10. Demographics: As in case description

11. Required materials: Dental chart with medical history that identifies patient as a smoker.

12. Instructions to dental professional: Mrs. Smith is a thirty two year old woman who is about to reenter the workforce after spending the last year at home with her now one year old son. She is here today for a dental evaluation and adult prophylaxis (professional dental cleaning). As you can see from her chart, she is apparently a smoker. Her dental history revealed localized periodontitis: tooth \#3 DL - 5mm pocket depth (PD) and tooth \#15 DF - 5mm PD. Her oral exam revealed a smoker's palate and tobacco stain on teeth \#23 through \#26. Decay was found on tooth \#30.

13. Your task is to provide a brief smoking intervention for this patient. 


\section{Kentucky Cancer Program - University of Louisville School of Dentistry Treating Tobacco Use and Dependence Training}

Student:

Date:

SP:

\section{SP case \#1 "Smith - Contemplating Quitting" Checklist:}

1. Establishes rapport and has good communication skills (introduces self, makes eye contact, tailors counseling to the individual, doesn't "preach", doesn't use technical terms, doesn't use notes for entire visit, etc.)

2. Assesses smoking/tobacco use habits (number of cigarettes/amount of tobacco per day, how long you've been smoking/using tobacco, ability to refrain from smoking where prohibited, etc.)

3. Advises cessation (clear and concise, non-judgmental, relates use to dental health)

4. Addresses second-hand smoke issue with spouse/children/grandchildren

5. Discusses any previous quit attempts (acknowledges and supports efforts, explains that most try several times before successfully quitting, encourages to try again) Asks about thoughts on trying to quit with assistance in next 2 weeks

7. Explores possible reasons for previous failures to quit or for lack of interest in quitting currently (asks patient to verbalize pros \& cons of smoking AND quitting)

8. Tries to problem-solve for barriers that patient cites for quitting (social support, family support, workplace, symptoms of withdrawal, etc.)

9. Tells patient cutting back is not recommended

10. Discusses available resources for quit attempt (nicotine replacement, other pharmacotherapy, cessation classes, 1-800-QUIT-NOW, themselves, Web site www.BecomeAnEX.org, )

11. If not definite before, revisits willingness to set a quit date within next two weeks and if so, offers to send fax referral to Quit Line.

12. If not interested in Quit Line, arranges for some type of follow-up if quit date was set. 
13. Provides instructions on medication use if appropriate

***Please place a check mark beside items not addressed by student/resident*** 
APPENDIX C

SMOKING CASE \#2 
SP Smoking Case \#2

Resistant to Quitting

1. Case Name: Joe Jones

2. Author: Bass

3. Challenge: History \& Counseling

- Advise cessation

- Assess willingness to quit

- Discuss relevance of quitting to patient

- Identify risks of continued tobacco use

- Discuss potential rewards or benefits of quitting

- Address and problem solve patient's roadblocks to quitting

- Offer assistance when ready and plan to repeat message at future visits

4. Goal: To assist dental professionals in obtaining skills necessary to perform brief interventions for smoking cessation.

5. Chief Complaint: Mr. Jones is here for a periodontal assessment after four quadrants of scale and root planing.

6. Periodontal Status: Moderate periodontitis.

7. Oral exam: Smoker's palate. Heavy tobacco stain.

8. Hard tissue charting: \#19 missing, \#31 missing

9. Case Summary: Mr. Jones is a 65 year old gentleman who has just retired from

Lexmark. He plans on enjoying his retirement by playing golf in the summer and spending winters down in Florida. He was seen in clinic for four quadrants of scaling and root planing four weeks ago. Two weeks ago he had an episode of shortness of breath and diagnosis of acute bronchitis which was treated with a z-pack (an antibiotic). He complained of cough, subjective fevers, and shortness of breath at that time. His past medical history is significant only for erectile dysfunction in the past which improved when he quit drinking bourbon, high blood pressure which is well controlled on a low dose of a diuretic, shortness of breath which seems to have gotten worse over the last year culminating in this acute episode of bronchitis. Workup for his acute problem revealed an abnormal $\mathrm{x}$-ray indicating some chronic lung damage likely from smoking. This was confirmed with pulmonary function tests which show mild obstructive disease. A cardiac stress test was normal (you walked on the treadmill yesterday). He has never been hospitalized. Mr. Jones does not suffer from depression or have any current substance abuse problem other than tobacco. Mr. Jones lives in Lexington with his wife of 40 years who does not smoke.

Mr. Jones began experimenting with smoking during high school and was smoking regularly by his freshman year in college. He has smoked one to two packs a day for the last 45 years. He has never really quit. He says that several doctors have told him to quit in the past but they were all younger than him and have died young deaths 
from something or other anyway. So why should I quit now. Smoking was his 'break time,' 'allows him to relax,' and 'escape from the stresses of work.' Initially in college, smoking was a social experience, only smoking while going out and then during breaks with other co-workers. However, he would soon be smoking regularly both at home and at work. He knows the harmful health effects of smoking for himself (lung cancer, shortness of breath), but is in denial because of his physicians who were supposedly in good health and died at a younger age than him and his parents who smoked a lot more than him. Both parents lived into their 90's. He can still walk 18 holes of golf, but has gotten more short of breath walking up steps. $\mathrm{He}$ has never really tried to quit seriously. He made several feigned attempts when his children complained many years ago, but he would have problems controlling his temper. He was drinking excessively during this time.

Mr. Jones smokes his first cigarette usually about thirty minutes after rising with his morning coffee. He usually smokes about two packs a day. He finds himself 'needing' a cigarette if he is in a nonsmoking building for more than two hours.

The dental professional should first advise the patient to quit smoking in a clear, strong, and personalized manner. For example, "As your clinician, I need you to know that quitting smoking is the most important thing you can do to protect your health now and in the future. The clinic staff and I will help you." It would be even better if they personalize it by tying in the health effects of potential harms to the non-smoking spouse, smoking contributes to his cardiac risk because he is overweight, connection to periodontal disease, and explaining that even quitting at age 65 will be of some benefit in preventing further worsening despite the damage to your lungs. When asked his willingness to quit say you are not interested in quitting. You know you're addicted, you do not have any real physical impairment (e.g. everyone gets more short of breath as they get older), your parents smoked until they died in their 90's. You enjoy smoking (relaxes you, you get a break from everything else going on, it's a social thing.) The student should initiate a discussion about the risks associated with continued tobacco use and ask you to identify potential benefits of quitting. The student should also problem solve some of the challenges of quitting with you and offer

10. Setting: Office to assist you in a quit attempt when you are ready to make one.

11. Demographics: As in case description 
12. Required materials: Medical history showing shortness of breath, cardiac disease, moderate periodontitis, and identifies patient as a smoker.

13. Instructions to resident: Mr. Jones is 65 year old man who is presenting to your office for follow up. He presented last week to a medical doctor complaining of shortness of breath. While this was an acute problem he did admit to some worsening dyspnea over the last year especially when walking up stairs. The exam last week was significant for wheezing which is now resolved post Z-pack. The patient's medical history shows mild Chronic Obstructive Pulmonary Disease (COPD). His dental history shows moderate periodontitis, smoker's palate, heavy tobacco stain, and two missing teeth (\#19 and \#31). Your task is to provide a brief smoking intervention for this patient. 


\section{Kentucky Cancer Program - University of Louisville School of Dentistry Treating Tobacco Use and Dependence Training}

Student:

Date:

SP:

\section{SP case \#2 "Jones - Resistant to Quitting" Checklist:}

1. Establishes rapport (introduces self, makes eye contact, tailors counseling to the individual, doesn't "preach", doesn't use technical terms, doesn't use notes for entire visit, etc.)

2. Assesses smoking/tobacco use habits (number of cigarettes/amount of tobacco per day, how long you've been smoking/using tobacco, ability to refrain from smoking where prohibited, etc.)

3. Advises cessation (clear and concise, non-judgmental, relates tobacco use to dental health)

4. Addresses second-hand smoke issue with spouse/children/grandchildren

5. Discusses any previous quit attempts (acknowledges and supports efforts, explains that most try several times before successfully quitting, encourages to try again)

6. Asks about thoughts on trying to quit with assistance in next 2 weeks

7. Explores possible reasons for previous failures to quit or for lack of interest in quitting currently (asks patient to verbalize pros \& cons of smoking AND quitting)

8. Tries to problem-solve for barriers that patient cites for quitting (social support, family support, workplace, symptoms of withdrawal, etc.)

9. Discusses available resources when ready to try quit attempt (nicotine replacement, other pharmacotherapy, cessation classes, 1-800-QUIT- NOW , themselves, Web site www.BecomeAnEX.org,

***Please place a check mark beside items not addressed by student/resident*** 
APPENDIX D

SMOKING CASE \#3 


\section{SP Smoking Case \# 3 \\ Ready to Quit}

1. Case Name: Ann Bowmont

2. Author:

3. Challenge: History \& Counseling

- Ask about tobacco use

- Advise cessation

- Assess willingness to quit

- Discuss previous quit attempts

- Discuss and problem solve barriers to quitting

- Assist with developing a quit plan

- Evaluate nicotine dependence and prescribe pharmacotherapy

- Arrange follow up

4. Goal: To assist dental professionals in obtaining skills necessary to perform brief interventions for smoking cessation.

5. Chief Complaint: Ann Bowmont, a 35-year-old attorney who considers herself a heavy smoker, is at her general dentist's office to try and quit smoking before she gets pregnant.

6. Periodontal Status: Gingivitis.

7. Oral exam: Smoker's palate. Tobacco stains.

8. Hard tissue charting: \#30 occlusal decay

9. Case Summary: Age: 35

Age Range: $31-40$

Marital Status: Married

Social History: I hope, Doctor, this won't take too long, I have to be in my office in 45 minutes. I'm a lawyer and just made partner and you know how it is: "busy, busy!" My specialty is taxes. It's demanding, but it's also exciting. I met my husband, Bob, a successful criminal lawyer, four years ago when we were students. We married three years ago. We both get to our respective offices by 7:00 AM, and neither of us gets home before 10:00 or 11:00 PM, so sometimes a week may go by without us talking. We belong to a good club, but don't use it much. I might go for a walk on the weekend, but most of my time is spent at work or with business colleagues. We frequently entertain out for business purposes.

My diet isn't that good, I eat on the run or have supper brought in so that I can work to make deadlines. Sometimes I meet Bob somewhere for supper. Most days I go home wound up, and I think I make it worse by drinking 4 or 5 cups of coffee a day.

Although I used to smoke some pot at parties, it did nothing for me. I also tried cocaine once, but didn't like it.

Although I used to bum a couple of cigarettes at parties in high 
school; in college, I started needing a few cigarettes to help me concentrate, particularly if I had an exam the next day. As the stress and competition increased, I started smoking regularly. Then came the law boards and my job with the firm, and I found I needed more than a pack a day to handle the pressure. I continued smoking daily and over the course of the past two years, my smoking has increased to nearly two packs a day. It seems to be taking more nicotine to help me focus, but it's not affecting my life. I'm very successful at work and my relationship with my husband is good. He enjoys a cigarette from time to time but doesn't smoke as much as I do. We want to start a family and I know I need to stop smoking.

I've been trying to limit myself to just a half pack of cigarettes a day lately; but it's not really enough. Now I'm jittery and irritable during the day. I have to be sharp at work. Work is really important to me. I'm ambitious and I don't want withdrawal to interfere with my career. This is the first time I have tried to quit smoking.

History of Present Illness: I've been taking the pill for the last 10 years up until one month ago. I want to have a baby, but I know I should quit smoking before I get pregnant. I've tried cutting down on my own, but I'm not sure that I can quit on my own. I'm not sure I can give up my morning coffee and cigarette.

Past Medical History: I've been healthy all my life. The only time I was ever in the hospital was when I was rushed to the emergency room in summer camp after I'd been stung by a bee and had a severe allergic reaction to it. I'm allergic to penicillin, and I've also had hay fever since I was eleven.

Family History: My father's seventy and a retired mechanic. He and my mother, who's 66, have been happily married for 46 years. My father was put on medication for high cholesterol two years ago and Mom's taking estrogen since menopause to counteract osteoporosis. For the most part, they're very healthy. Both of my parents smoked, but my Dad quit after his brother died. My father's brother died of lung cancer due to excessive smoking. Smoking was part of our upbringing, but never a problem for anyone in our immediate family. I have two older brothers. One became a Buddhist and a strict vegetarian, so he doesn't smoke at all now. Everyone in my family leads really busy lives; we don't see each other that much. Even so, we're close. I haven't told them yet that I am trying to get pregnant, but I know they'll be thrilled. 
Habits:

Tobacco: Up to 2 packs a day; trying unsuccessfully to cut back.

Alcohol: Occasional glass of wine with dinner.

Illegal Drugs: None now; tried pot and cocaine in college.

Rx Medications: None.

OTC Drugs: Occasional Tylenol for headaches.

Diet: Eats on the run; frequent dining out; few home-cooked meals.

Coffee: 4 to 5 cups per day.

Exercise: Uses stationary bicycle at home 3 times a week for 20 minutes.

History Checklist

- My husband and I are trying to get pregnant.

- I've never been pregnant before.

- I've been in good health.

- I've never had an STD (I was on the pill for 10 years).

- I've never had any surgery.

- I'm not on any medication.

- I'm allergic to bees and I have hay fever.

- I drink about 4 to 5 cups of coffee a day.

- I smoke and would like help quitting.

- I don't take street drugs.

- I do drink occasionally but will quit during pregnancy.

- I have up to 2 packs of cigarettes a day.

- I've been smoking that much for a couple of years.

- Smoking has never interfered with my work or my marriage.

- My parents are in good health; Dad has high cholesterol and Mom takes estrogen.

Vital Signs:

Temperature: 98.2 degrees oral

Pulse: 92

Blood Pressure: 130/95

Respiratory Rate: 14

10. Setting: Office

11. Demographics: As in case description

12. Required materials: None

13. Instructions to resident: (a dental examination is not necessary at this visit):

- Ms. Bowmont is a 35 year old successful tax attorney who presents to the office to quit smoking before getting pregnant. She begins work at 7:00 a.m. and doesn't get home until 10:00 or 11:00 p.m. Her work is very important to her. She has a good relationship with her husband who is a criminal attorney. Her overall health has been good. She eats on the run, frequently dines out, and drinks 4-5 cups of coffee per day. 
- The dental history shows gingivitis, tobacco stains, and occlusal decay on tooth \#30

- Take any notes you think necessary.

- Leave this file on the door when you have finished with the patient. 


\section{Kentucky Cancer Program - University of Louisville School of Dentistry Treating Tobacco Use and Dependence Training}

Student:

Date:

SP:

SP case \#3 “Bowmont - Ready to Quit" Checklist:

1. Establishes rapport and has good communication skills (introduces self, makes eye contact, tailors counseling to the individual, doesn't "preach", doesn't use technical terms, doesn't use notes for entire visit, etc.)

2. ____ Assesses smoking/tobacco use habits (number of cigarettes/amount of tobacco per day, how long you've been smoking/using tobacco, ability to refrain from smoking where prohibited, etc.)

3. Advises cessation (clear and concise, non-judgmental, relates use to dental health)

4. Addresses second-hand smoke issue with spouse/children

5. Discusses any previous quit attempts (acknowledges and supports efforts, explains that most try several times before successfully quitting, encourages to try again)

6. Asks about trying to quit with assistance in next 2 weeks and lets patient set date (congratulates on decision to quit)

7. Explores possible reasons for previous failures to quit

8. Tries to problem-solve for concerns with quitting patient cites (social support, spouse smoking, family support, workplace, symptoms of withdrawal, etc.)

9. Tells patient cutting back is not recommended

10. Discusses available resources for quit attempt (nicotine replacement, other pharmacotherapy, cessation classes, 1-800-QUIT- NOW, themselves, Web site www.BecomeAnEX.orge)

11. Explains and offers to send fax referral to Quit Line.

12. If not interested in Quit Line, arranges for some type of follow-up after quit date.

13. Provides instructions on medication use

***Please place a check mark beside items not addressed by student/resident*** 
APPENDIX E

PREAMBLE 
Tobacco Dependence Treatment Education for Dental Students Using Standardized Patients

January 19, 2012

Dear Volunteer:

You are being invited to participate in a research study by answering the attached survey before a tobacco cessation lecture and a second survey after the lecture or after the lecture and practice counseling sessions using standardized patients and a debriefing session. If you choose not to participate in the study, you do not have to complete the surveys. Even though you may choose not to participate in the study, all students in the clinical dentistry course will be required to complete the educational program consisting of a two hour lecture followed by three counseling practice sessions using standardized patients and a debriefing session. There are no known risks for your participation in this research study. The information collected may not benefit you directly. The information learned in this study may be helpful to others and will determine the effectiveness of the training. Your completed survey will be stored in a locked file cabinet in a locked office at the dental school. The survey will take approximately 15 minutes to complete.

Individuals from the Department of Periodontics, Endodontics, and Dental Hygiene, the Institutional Review Board (IRB), the Human Subjects Protection Program Office (HSPPO), and other regulatory agencies may inspect these records. In all other respects, however, the data will be held in confidence to the extent permitted by law. Should the data be published, your identity will not be disclosed.

Taking part in this study is voluntary. By completing this survey you agree to take part in this research study. You do not have to answer any questions that make you uncomfortable. You may choose not to take part at all. If you decide to be in this study you may stop taking part at any time. If you decide not to be in this study or if you stop taking part at any time, you will not lose any benefits for which you may qualify. If you have any questions, concerns, or complaints about the research study, please contact: Jacqueline A. Singleton at (502) 852-2611. 
If you have any questions about your rights as a research subject, you may call the Human Subjects Protection Program Office at (502) 852-5188. You can discuss any questions about your rights as a research subject, in private, with a member of the Institutional Review Board (IRB). You may also call this number if you have other questions about the research, and you cannot reach the study doctor, or want to talk to someone else. The IRB is an independent committee made up of people from the University community, staff of the institutions, as well as people from the community not connected with these institutions. The IRB has reviewed this research study.

If you have concerns or complaints about the research or research staff and you do not wish to give your name, you may call $1-877-852-1167$. This is a 24 hour hot line answered by people who do not work at the University of Louisville.

Sincerely,

Jacqueline A. Singleton, RDH, MEd 


\section{APPENDIX F \\ TRAINING SCHEDULE}




\section{Schedule for Tobacco Cessation Treatment Training}

Standardized patients (SPs) are actors or educators trained to portray patients in realistic clinical scenarios. Using SP interactions as a training method is an effective teaching and learning tool that offers a safe and controlled environment in which students can learn and practice interviewing and clinical skills. SPs are trained to evaluate the skills of the students and then give them immediate feedback. In addition, the instructors can observe the interaction and evaluate the progress of the student. Participants will experience three encounters with SPs representing various stages of change.

Who: Dental Class of 2015

When: $\quad$ Lecture - Thursday, February 23 from 8:45 to 10:45 a.m.

Lecture is in Room \#131 at the dental school

SP Practice Sessions - March 1, 8, 15, 29, \& April 19

Group Assignments - 8:00 - 9:30, 9:15 - 10:45, 2:00 - 3:30, or 3:30 - 5:00

Practice Sessions are in the Standardized Patient Clinic

Located on the $3^{\text {rd }}$ Floor of the Medical School Room $312 \mathrm{~A}$

Dress: $\quad$ Professional Attire (No "Dress Down Day" Attire)

Schedule: see table below

\begin{tabular}{|c|c|c|}
\hline Date & Time & Students \\
\hline March 1 & $8: 00-9: 30 \mathrm{AM}$ & $\# 1-\# 12$ (12 students) \\
\hline March 1 & $9: 15-10: 45 \mathrm{AM}$ & \#13-\#24 (12 students) \\
\hline March 8 & $8: 00-9: 30 \mathrm{AM}$ & \#25-\#36 (12 students) \\
\hline March 8 & $9: 15-10: 45 \mathrm{AM}$ & \#37-\#48 (12 students) \\
\hline March 15 & $8: 00-9: 30 \mathrm{AM}$ & \#97-\#108 (12 students) \\
\hline March 15 & $9: 15-10: 45 \mathrm{AM}$ & \#109-\#120 (12 students) \\
\hline March 29 & $2: 00-3: 30 \mathrm{PM}$ & \#73-\#84 (12 students) \\
\hline March 29 & $3: 30-5: 00 \mathrm{PM}$ & \#85-\#96 (12 students) \\
\hline April 19 & $2: 00-3: 30 \mathrm{PM}$ & \#49-\#60 (12 students) \\
\hline April 19 & $3: 30-5: 00 \mathrm{PM}$ & \#61-\#72 (12 students) \\
\hline
\end{tabular}

Directions: Cross the bridge over to the Medical School. After passing the computer lab, take the stairs to the third floor. Turn left when entering the hall and the standardized patient center is on the right (Room $312 \mathrm{~A}$ ).

Thank you for participating in the smoking cessation training program. 


\section{APPENDIX G}

\section{PRE-LECTURE QUESTIONNAIRE}


Last 4 Digits of your Social Security Number:

Date:

Pre Lecture Questionnaire

Please indicate your level of agreement with the following statements. (Fill in one circle for each statement)

Strongly Somewhat Neither agree Somewhat Strongly
Disagree Disagree or disagree Agree Agree

1. It is important for members of my profession to

discuss tobacco use with patients.

o

$\circ$

0

$\circ$

$\circ$

2. A brief intervention ( 3 minutes) for tobacco cessation with my patients would be effective.

$\circ$

$\circ$

$\circ$

$\circ$

$\circ$

3. Do you think that the dental profession should be more or less active in helping patients to quit smoking?
- More active
- No change is needed
- Less active

4. Do you think that the dental profession should be more or less active in helping to prevent patients from starting smoking?
- More active
- No change is needed
- Less active

5. Which of these factors may limit your ability to counsel tobacco users during every visit? (Fill in all that apply)

- I don't have enough time

- I don't have enough knowledge of cessation counseling

- I'm not adequately trained

- I don't have enough cessation counseling skills

- Patients might seek another provider if I discuss tobacco use with them

- The clinic/office may not get reimbursed for the service

- Tobacco cessation is a low priority for me

- Tobacco cessation is a low priority for my patients who are tobacco users

- These services require approval or order from a physician

- Tobacco cessation is not supported by my facility/administration

- Tobacco cessation is performed by another member of the health care team 
Please indicate your level of agreement with the following statements (Circle only one number for each statement).

6. Patients who use tobacco think I counsel them to quit.

should not $\begin{array}{llllllll}-3 & -2 & -1 & 0 & +1 & +2 & +3 & \text { should }\end{array}$

7. Dentists would of my counseling patients to quit tobacco use.

disapprove $\begin{array}{llllllll}-3 & -2 & -1 & 0 & +1 & +2 & +3 & \text { approve }\end{array}$

8. Other dentists counsel patients to quit tobacco use.

do not $-3 \quad-2 \quad-1 \quad 0 \quad+1 \quad+2 \quad+3$ do

9. Patients' approval of my practice is important to me.

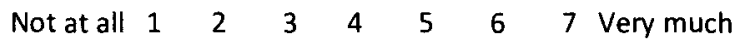

10. What dentists think I should do matters to me.

$\begin{array}{llllllll}\text { Not at all } & 1 & 2 & 3 & 4 & 5 & 6 & 7\end{array}$ Very much

11. Doing what other dentists do is important to me.

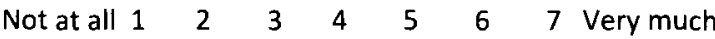

Please rate your level of skills for the following aspects of counseling: (Fill in one circle for each question)

12. Your overall ability to help patients quit using tobacco

- Poor O Fair o Good o Very Good O Excellent

13. Asking patient whether they use tobacco

- Poor o Fair o Good o Very Good O Excellent

14. Advising patients to quit using tobacco

- Poor o Fair o Good o Very Good O Excellent

15. Assessing patients' readiness to quit

o Poor O Fair O Good O Very Good O Excellent

16. Providing tobacco cessation assistance to patients who are thinking about quitting or trying to quit using tobacco

- Poor O Fair O Good o Very Good O Excellent

17. Arranging a follow-up counseling session with patients you assist with quitting

- Poor o Fair O Good o Very Good O Excellent

18. Counseling patients not interested in quitting

o Poor O Fair o Good o Very Good o Excellent 
How much confidence do you have in the following aspects of counseling patients to quit using tobacco? (Fill in one circle for each question)

How confident are you that you...

Not At All Not Very Moderately Very Extremely

Confident Confident Confident Confident Confident

19. Know the appropriate questions to ask patients when providing tobacco cessation counseling?

$\circ$

○

0

$\circ$

$\circ$

20. Have the skills needed to counsel for an addiction?

$\circ$

$\circ$

$\circ$

$\circ$

$\circ$

21. Have the skill to monitor and assist patients throughout their quit attempt?

$\circ$

$\circ$

$\circ$

$\circ$

$\circ$

22. Have sufficient therapeutic knowledge of the pharmaceutical products for tobacco cessation?

0

$\circ$

$\circ$

$\circ$

$\circ$

23. Know when a referral to a physician is appropriate?

$\circ$

$\circ$

$\circ$

$\circ$

$\circ$

24. Can create consumer awareness of why dentists should ask questions about tobacco use and encourage quitting?

$\circ$

$\circ$

$\circ$

$\circ$

○

25. Can sensitively suggest tobacco cessation to patients who use tobacco?

$\circ$

$\circ$

$\circ$

$\circ$

0

26. Are able to provide adequate counseling when time is limited?

o

o

0

○

0

27. Can help recent quitters learn how to cope with situations or triggers that might lead them to relapse back to using tobacco?

28. Can counsel patients who are not interested in quitting? 
In the future, how often do you intend to... (Fill in one circle for each question)

Almost Always
Never Rarely Sometimes Always (Every Visit)

29. Ask an individual patient about tobacco use?

30. Advise a tobacco-using patient to quit?

31. Assess a patient's readiness to quit?

$\circ \quad 0$

$0 \quad 0$

$\circ \quad 0$

$\circ$

0

32. Assist a tobacco-using patient who is willing to quit by referring them to outside support (e.g. cessation groups or quit lines)?

33. Arrange follow-up counseling?

34. Counsel patients not interested in quitting

$\circ$

$\circ$

$\circ$

$0 \quad 0$

00

$\circ$

$0 \quad 0$

$\circ$

$0 \quad 0$

$\circ \quad 0$

$\circ$

o

$\circ$

35. Which response best describes when you will assess a tobacco user's willingness to quit? (Fill in one circle)

- At initial visit

- During routine dental check-ups

- When patient presents with a tobacco-related oral health problem

- At every visit

- I will not have a routine time

- I will not generally assess

For a patient who is willing to quit, how often will you assist them by doing the following? (Fill in one circle)

Never Rarely Sometimes Always Always

36. Set a quit date and document in patient's chart 0

37. Provide practical counseling/problem solving

38. Encourage the patient to use current social support 0

39. Provide educational materials

40. Refer to outside support

(e.g., quitline, cessation groups)

41. Recommend the use of pharmacotherapy

42. Advise on proper usage of pharmacotherapy

0

\section{0}

\section{0}

O

o

o
0

0

o

$\circ$

0

$\circ$ $\circ$

0

$\circ$

○

$\circ$

$\circ$

$\circ$

$\begin{array}{ll}0 & 0 \\ 0 & 0 \\ 0 & 0 \\ 0 & 0 \\ 0 & 0\end{array}$

$0 \quad 0$

$0 \quad 0$ 


\section{Please fill in the BEST response to each of the following questions.}

43. For patients unwilling to quit smoking, which of the following approaches is not recommended?

- Encourage patient to cut back on cigarettes

- Identify risks and negative consequences of their tobacco use

- Ask the patient to identify potential benefits/rewards of stopping tobacco use

- Provide motivational information relevant to the patient's personal circumstances

44. Which one of the following practices is specifically recommended in the Clinical Practice Guideline?
- Encourage smokers to try to quit smoking without assistance before pharmacotherapy
- Identify tobacco use status at every visit
- Only give advice to those smokers who are willing to quit
- Give the same message or advice to every patient trying to quit for consistency

45. Which of the following medications is not considered a first line pharmacologic tobacco cessation agent?
- Clonidine
- Buproprion
- Varenicline
- None of the above

46. Which method of follow-up is helpful in encouraging a successful tobacco cessation attempt?
- A scheduled office visit
- A mailed letter/card
- A phone call to patient
- Any of the above

47. Most nicotine withdrawal symptoms tend to significantly diminish between after quitting?
- 24 to 72 hours
- 1 to 2 weeks
- 2 to 4 weeks
- 2 to 4 months

48. Which of the following statements is TRUE?

- Pharmacotherapy increases long-term abstinence rates four-fold, compared to a placebo

- Most tobacco users make multiple quit attempts before they are able to quit for good

- Smokeless tobacco is a safe alternative to cigarettes

- On average, individuals gain between 15 to 30 pounds after quitting

49. Patients who are not yet considering quitting should be:
- A. Strongly advised to quit
- B. Provided with brief motivational interventions
- C. Persuaded to quit in the next 30 days
- D. A and B are correct 
50. Which of the following is INCORRECT information to provide to patients who are about to begin therapy with bupropion?

- Take one tablet daily for three days, then take one tablet twice daily

- Quit smoking 7-14 days after initiating bupropion

- If you experience difficulty sleeping, take both tablets $(300 \mathrm{mg})$ in the morning instead of $150 \mathrm{mg}$ twice daily

- Bupropion can be used in combination with nicotine replacement therapy

51. With which of the following products does nicotine rapidly reach the central nervous system?
- Nicotine lozenge
- Nicotine nasal spray
- Nicotine gum
- Nicotine inhaler

52. Which of the following is NOT associated with nicotine withdrawal?

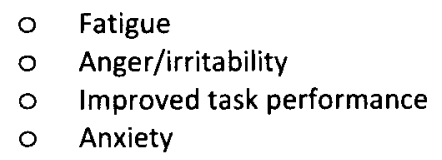

53. Have you smoked 100 or more cigarettes in your lifetime? (Choose one)
- Yes
- No

54. Which of the following best describes your tobacco use (cigarettes, cigars, pipes, snuff, or chew)? (Choose one)
- Use tobacco once or more a day
- Use tobacco less than once a day
- Used to use tobacco but quit $\rightarrow$ In what year did you quit?
- Experimented with tobacco a few times in the past
- Never tried tobacco

55. What is your sex?

- Male o Female

56. What is your age? Years

57. Which of the following best describes your race or ethnicity? (Choose one)
American Indian
- Asian
- Native Hawaiian or Pacific Islander
- Black or African American
- White
- Spanish, Hispanic or Latino
- Other:

Thank you for helping us to evaluate the tobacco cessation training program. 


\section{APPENDIX H}

POST- LECTURE QUESTIONNAIRE 
Last 4 Digits of your Social Security Number:

Date:

Post Lecture Questionnaire

Please indicate your level of agreement with the following statements. (Fill in one circle for each question)

Strongly Somewhat Neither agree Somewhat Strongly
Disagree Disagree or disagree Agree Agree

1. It is important for members of my profession to

discuss tobacco use with patients.

$\circ$

$\circ$

0

$\circ$

$\circ$

2. A brief intervention ( 3 minutes) for tobacco cessation with my patients would be effective.

$\circ$

$\circ$

0

$\circ$

3. Do you think that the dental profession should be more or less active in helping patients to quit smoking?
- More active
- No change is needed
- Less active

4. Do you think that the dental profession should be more or less active in helping to prevent patients from starting smoking?
- More active
- No change is needed
o Less active

5. Which of these factors may limit your ability to counsel tobacco users during every visit? (Fill in all that apply)
- I don't have enough time
- I don't have enough knowledge of cessation counseling
- I'm not adequately trained
- I don't have enough cessation counseling skills
- Patients might seek another provider if I discuss tobacco use with them
- The clinic/office may not get reimbursed for the service
- Tobacco cessation is a low priority for me
- Tobacco cessation is a low priority for my patients who are tobacco users
- These services require approval or order from a physician
- Tobacco cessation is not supported by my facility/administration
- Tobacco cessation is performed by another member of the health care team 
Please indicate your level of agreement with the following statements (Circle only one number for each statement).

6. Patients who use tobacco think I counsel them to quit.

should not $\begin{array}{llllllll}-3 & -2 & -1 & 0 & +1 & +2 & +3 & \text { should }\end{array}$

7. Dentists would of my counseling patients to quit tobacco use.

disapprove $\begin{array}{llllllll}-3 & -2 & -1 & 0 & +1 & +2 & +3 & \text { approve }\end{array}$

8. Other dentists counsel patients to quit tobacco use.

do not $\begin{array}{llllllll}-3 & -2 & -1 & 0 & +1 & +2 & +3 & \text { do }\end{array}$

9. Patients' approval of my practice is important to me.

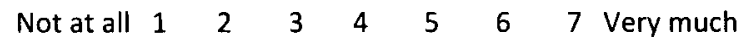

10. What dentists think I should do matters to me.

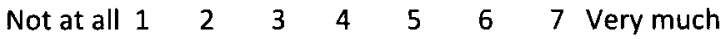

11. Doing what other dentists do is important to me.

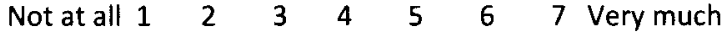

Please rate your level of skills for the following aspects of counseling: (Fill in one circle for each question)

12. Your overall ability to help patients quit using tobacco

o Poor o Fair o Good o VeryGood O Excellent

13. Asking patient whether they use tobacco

- Poor O Fair o Good o Very Good O Excellent

14. Advising patients to quit using tobacco

o Poor o Fair o Good o VeryGood o Excellent

15. Assessing patients' readiness to quit

- Poor O Fair O Good O Very Good O Excellent

16. Providing tobacco cessation assistance to patients who are thinking about quitting or trying to quit using tobacco

o Poor o fair o Good o Very Good o Excellent

17. Arranging a follow-up counseling session with patients you assist with quitting

- Poor o Fair o Good o VeryGood o Excellent

18. Counseling patients not interested in quitting

o Poor o Fair

○ Good O Very Good O Excellent 
How much confidence do you have in the following aspects of counseling patients to quit using tobacco? (Fill in one circle for each question)

How confident are you that you...

Not At All Not Very Moderately Very Extremely

Confident Confident Confident Confident Confident

19. Know the appropriate questions to ask patients when providing tobacco cessation counseling?

$\circ$

$\circ$

0

$\circ$

0

20. Have the skills needed to counsel for an addiction?

$\circ$ patients throughout their quit attempt?

22. Have sufficient therapeutic knowledge of the pharmaceutical products for tobacco cessation?

23. Know when a referral to a physician is appropriate?

24. Can create consumer awareness of why dentists should ask questions about tobacco use and encourage quitting?

$\circ$

$\circ$

0

0

$\circ$

25. Can sensitively suggest tobacco cessation to patients who use tobacco?

$\circ$

$\circ$

$\circ$ o

26. Are able to provide adequate counseling when time is limited?

27. Can help recent quitters learn how to cope with situations or triggers that might lead them to relapse back to using tobacco?

28. Can counsel patients who are not interested in quitting?
0

0
0

$\circ$

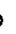
$\circ$

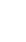

o 
In the future, how often do you intend to... (Fill in one circle for each question)

$\begin{array}{ccc}\text { Almost Always } & \text { Always (Every Visit) }\end{array}$

29. Ask an individual patient about tobacco use?

30. Advise a tobacco-using patient to quit?

31. Assess a patient's readiness to quit?

32. Assist a tobacco-using patient who is willing to quit by referring them to outside support

(e.g. cessation groups or quit lines)?

33. Arrange follow-up counseling?

34. Counsel patients not interested in quitting

$\begin{array}{lllll}0 & 0 & 0 & 0 & 0 \\ 0 & 0 & 0 & 0 & 0 \\ 0 & 0 & 0 & 0 & 0\end{array}$

$\begin{array}{lllll}0 & 0 & 0 & 0 & 0\end{array}$

$0 \quad 0 \quad 0 \quad 0$

$0 \quad 0 \quad 0 \quad 0$

35. Which response best describes when you will assess a tobacco user's willingness to quit? (Fill in one circle)

- At initial visit

- During routine dental check-ups

- When patient presents with a tobacco-related oral health problem

- At every visit

- I will not have a routine time

- I will not generally assess

For a patient who is willing to quit, how often will you assist them by doing the following? (fill in one circle)

Never Rarely Sometimes Always Always

36. Set a quit date and document in patient's chart $\quad 0$

37. Provide practical counseling/problem solving $\circ$

38. Encourage the patient to use current social support 0

39. Provide educational materials

40. Refer to outside support

(e.g., quitline, cessation groups)

41. Recommend the use of pharmacotherapy

42. Advise on proper usage of pharmacotherapy

\section{0}

o

0

$\circ$

0
0
0
0
0

$\begin{array}{lll}0 & 0 & 0 \\ 0 & 0 & 0 \\ 0 & 0 & 0 \\ 0 & 0 & 0 \\ 0 & 0 & 0\end{array}$

\begin{abstract}
0
\end{abstract}
0

$\circ$

0

o

o

o 
Please fill in the BEST response to each of the following questions.

43. For patients unwilling to quit smoking, which of the following approaches is not recommended?

- Encourage patient to cut back on cigarettes

- Identify risks and negative consequences of their tobacco use

- Ask the patient to identify potential benefits/rewards of stopping tobacco use

- Provide motivational information relevant to the patient's personal circumstances

44. Which one of the following practices is specifically recommended in the Clinical Practice Guideline?

- Encourage smokers to try to quit smoking without assistance before pharmacotherapy

- Identify tobacco use status at every visit

- Only give advice to those smokers who are willing to quit

- Give the same message or advice to every patient trying to quit for consistency

45. Which of the following medications is not considered a first line pharmacologic tobacco cessation agent?

- Clonidine

- Buproprion

- Varenicline

- None of the above

46. Which method of follow-up is helpful in encouraging a successful tobacco cessation attempt?
- A scheduled office visit
- A mailed letter/card
- A phone call to patient
- Any of the above

47. Most nicotine withdrawal symptoms tend to significantly diminish between after quitting?
- 24 to 72 hours
- 1 to 2 weeks
- 2 to 4 weeks
- 2 to 4 months

48. Which of the following statements is TRUE?

- Pharmacotherapy increases long-term abstinence rates four-fold, compared to a placebo

- Most tobacco users make multiple quit attempts before they are able to quit for good

- Smokeless tobacco is a safe alternative to cigarettes

- On average, individuals gain between 15 to 30 pounds after quitting

49. Patients who are not yet considering quitting should be:
- A. Strongly advised to quit
- B. Provided with brief motivational interventions
- C. Persuaded to quit in the next 30 days
- D. A and B are correct 
50. Which of the following is INCORRECT information to provide to patients who are about to begin therapy with bupropion?

- Take one tablet daily for three days, then take one tablet twice daily

- Quit smoking 7-14 days after initiating bupropion

- If you experience difficulty sleeping, take both tablets $(300 \mathrm{mg})$ in the morning instead of $150 \mathrm{mg}$ twice daily

- Bupropion can be used in combination with nicotine replacement therapy

51. With which of the following products does nicotine rapidly reach the central nervous system?
- Nicotine lozenge
- Nicotine nasal spray
- Nicotine gum
o Nicotine inhaler

52. Which of the following is NOT associated with nicotine withdrawal?
- Fatigue
- Anger/irritability
- Improved task performance
- Anxiety

53. Have you smoked 100 or more cigarettes in your lifetime? (Choose one)
- Yes
$\circ$ No

54. Which of the following best describes your tobacco use (cigarettes, cigars, pipes, snuff, or chew)? (Choose one)

- Use tobacco once or more a day

- Use tobacco less than once a day

- Used to use tobacco but quit _ In what year did you quit?

- Experimented with tobacco a few times in the past

- Never tried tobacco

55. What is your sex?
- Male
- Female

56. What is your age? Years

57. Which of the following best describes your race or ethnicity? (Choose one)

- American Indian

- Asian

- Native Hawaiian or Pacific Islander

- Black or African American

- White

- Spanish, Hispanic or Latino

o Other: 
58. Did you complete a pre-program survey for this course? (Choose one)

- Yes o No

59. Please estimate the following:

VALUES SHOULD SUM TO 100.

a. Percentage of the program information that was completely new to you

b. Percentage of the program information that you had been taught before but needed to review

c. Percentage of the program that you had been taught before and was an unnecessary review

TOTAL $100 \%$ for a, b, \& c

60. What percentage of the program information do you expect to use when you work with patients?

Please indicate your level of agreement with the following statements. (Fill in one circle for each question)

Strongly Somewhat Neither agree Somewhat Strongly
Disagree Disagree or disagree Agree Agree

61. The lecture and handouts provided valuable information in preparing me to provide tobacco cessation counseling to my patients.

o

0

$\circ$

62. I felt competent to provide tobacco cessation counseling from the lecture and handouts alone.

$\circ$

o

o

o

63. Do you believe that students at other schools of dentistry in KY would benefit from receiving the same, or similar, tobacco cessation training?

- Yes o No

64. What would you change about the program?

Overall Comments:

Thank you for helping us to evaluate the tobacco cessation training program. 


\section{APPENDIX I}

POST-PROGRAM QUESTIONNAIRE 
Last 4 Digits of your Social Security Number:

Date:

Post Program Questionnaire

Please indicate your level of agreement with the following statements. (Fill in one circle for each question)

Strongly Somewhat Neither agree Somewhat Strongly
Disagree Disagree or disagree Agree Agree

1. It is important for members of my profession to

discuss tobacco use with patients.

$\circ$

$\circ$

$\circ$

$\circ$

$\circ$

2. A brief intervention ( 3 minutes) for tobacco cessation with my patients would be effective.

$\circ$

$\circ$

$\circ$

3. Do you think that the dental profession should be more or less active in helping patients to quit smoking?
- More active
- No change is needed
- Less active

4. Do you think that the dental profession should be more or less active in helping to prevent patients from starting smoking?
- More active
- No change is needed
o Less active

5. Which of these factors may limit your ability to counsel tobacco users during every visit? (Fill in all that apply)

- I don't have enough time

- I don't have enough knowledge of cessation counseling

- I'm not adequately trained

- I don't have enough cessation counseling skills

- Patients might seek another provider if I discuss tobacco use with them

- The clinic/office may not get reimbursed for the service

- Tobacco cessation is a low priority for me

- Tobacco cessation is a low priority for my patients who are tobacco users

- These services require approval or order from a physician

- Tobacco cessation is not supported by my facility/administration

- Tobacco cessation is performed by another member of the health care team 
Please indicate your level of agreement with the following statements (Circle only one number for each statement).

6. Patients who use tobacco think I counsel them to quit.

should not $\begin{array}{llllllll}-3 & -2 & -1 & 0 & +1 & +2 & +3 & \text { should }\end{array}$

7. Dentists would of my counseling patients to quit tobacco use.

disapprove $\begin{array}{llllllll}-3 & -2 & -1 & 0 & +1 & +2 & +3 & \text { approve }\end{array}$

8. Other dentists counsel patients to quit tobacco use.

do not $\begin{array}{llllllll}-3 & -2 & -1 & 0 & +1 & +2 & +3 & \text { do }\end{array}$

9. Patients' approval of my practice is important to me.

$\begin{array}{lllllllll}\text { Not at all } & 1 & 2 & 3 & 4 & 5 & 6 & 7 & \text { Very much }\end{array}$

10. What dentists think I should do matters to me.

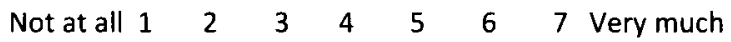

11. Doing what other dentists do is important to me.

$\begin{array}{llllllll}\text { Not at all } & 1 & 2 & 3 & 4 & 5 & 6 & 7\end{array}$

Please rate your level of skills for the following aspects of counseling: (Fill in one circle for each question)

12. Your overall ability to help patients quit using tobacco

- Poor O Fair o Good o Very Good O Excellent

13. Asking patient whether they use tobacco

- Poor o Fair o Good o Very Good O Excellent

14. Advising patients to quit using tobacco

o Poor o Fair o Good o Very Good O Excellent

15. Assessing patients' readiness to quit

○ Poor O Fair O Good O Very Good O Excellent

16. Providing tobacco cessation assistance to patients who are thinking about quitting or trying to quit using tobacco

o Poor o Fair o Good o Very Good o Excellent

17. Arranging a follow-up counseling session with patients you assist with quitting

- Poor o Fair o Good o Very Good O Excellent

18. Counseling patients not interested in quitting

o Poor o Fair o Good o Very Good O Excellent 
How much confidence do you have in the following aspects of counseling patients to quit using tobacco? (Fill in one circle for each question)

How confident are you that you...

Not At All Not Very Moderately Very Extremely

Confident Confident Confident Confident Confident

19. Know the appropriate questions to ask patients when providing tobacco cessation counseling?

0

$\circ$

$\circ$

0

$\circ$

20. Have the skills needed to counsel for an addiction?

$\circ$

0

0

$\circ$

21. Have the skill to monitor and assist patients throughout their quit attempt?

$\circ$

$\circ$

○

$\circ$

o

22. Have sufficient therapeutic knowledge of the pharmaceutical products for tobacco cessation?

$\circ$

0

0

$\circ$

23. Know when a referral to a physician is appropriate?

$\circ$

$\circ$

$\circ$

0

$\circ$

24. Can create consumer awareness of why dentists should ask questions about tobacco use and encourage quitting?

25. Can sensitively suggest tobacco cessation to patients who use tobacco?

26. Are able to provide adequate counseling when time is limited?

0

0

$\circ$

○

27. Can help recent quitters learn how to cope with situations or triggers that might lead them to relapse back to using tobacco?

28. Can counsel patients who are not interested in quitting? 
In the future, how often do you intend to... (Fill in one)

$$
\text { Never Rarely Sometimes Always (Every Visit) }
$$

29. Ask an individual patient about tobacco use?

30. Advise a tobacco-using patient to quit?

31. Assess a patient's readiness to quit?

32. Assist a tobacco-using patient who is willing to quit by referring them to outside support (e.g. cessation groups or quit lines)?

33. Arrange follow-up counseling?

34. Counsel patients not interested in quitting

$\begin{array}{lllll}0 & 0 & 0 & 0 & 0 \\ 0 & 0 & 0 & 0 & 0 \\ 0 & 0 & 0 & 0 & 0\end{array}$

$\begin{array}{lllll}0 & 0 & 0 & 0 & 0\end{array}$

00000

$\begin{array}{lllll}0 & 0 & 0 & 0 & 0\end{array}$

35. Which response best describes when you will assess a tobacco user's willingness to quit? (Fill in one)

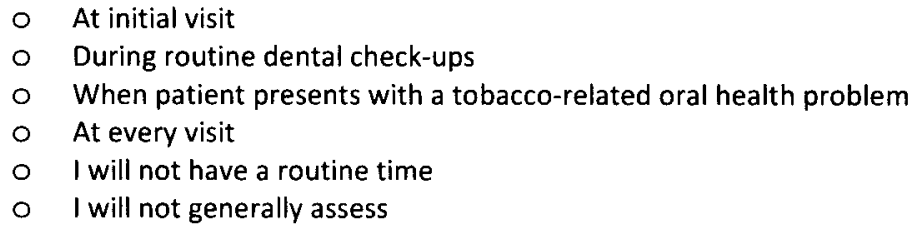

For a patient who is willing to quit, how often will you assist them by doing the following? (Fill in one)

$$
\text { Never Rarely Sometimes Always Always }
$$

36. Set a quit date and document in patient's chart $\quad \circ$

37. Provide practical counseling/problem solving $\quad \circ$

38. Encourage the patient to use current social support 0

39. Provide educational materials

40. Refer to outside support

(e.g., quitline, cessation groups)

41. Recommend the use of pharmacotherapy

42. Advise on proper usage of pharmacotherapy

\section{0}

$\circ$

$\circ$

o

0
0
0
0

$\begin{array}{lll}0 & 0 & 0 \\ 0 & 0 & 0 \\ 0 & 0 & 0 \\ 0 & 0 & 0 \\ 0 & 0 & 0\end{array}$

$\circ$

0

$0 \quad 0$

$\circ$

$\circ$

0 


\section{Please fill in the BEST response to each of the following questions.}

43. For patients unwilling to quit smoking, which of the following approaches is not recommended?

- Encourage patient to cut back on cigarettes

- Identify risks and negative consequences of their tobacco use

- Ask the patient to identify potential benefits/rewards of stopping tobacco use

- Provide motivational information relevant to the patient's personal circumstances

44. Which one of the following practices is specifically recommended in the Clinical Practice Guideline?

- Encourage smokers to try to quit smoking without assistance before pharmacotherapy

- Identify tobacco use status at every visit

- Only give advice to those smokers who are willing to quit

- Give the same message or advice to every patient trying to quit for consistency

45. Which of the following medications is not considered a first line pharmacologic tobacco cessation agent?

- Clonidine

- Buproprion

- Varenicline

- None of the above

46. Which method of follow-up is helpful in encouraging a successful tobacco cessation attempt?
- A scheduled office visit
- A mailed letter/card
- A phone call to patient
- Any of the above

47. Most nicotine withdrawal symptoms tend to significantly diminish between after quitting?

- 24 to 72 hours

- 1 to 2 weeks

- 2 to 4 weeks

- 2 to 4 months

48. Which of the following statements is TRUE?

- Pharmacotherapy increases long-term abstinence rates four-fold, compared to a placebo

- Most tobacco users make multiple quit attempts before they are able to quit for good

- Smokeless tobacco is a safe alternative to cigarettes

- On average, individuals gain between 15 to 30 pounds after quitting

49. Patients who are not yet considering quitting should be:
- A. Strongly advised to quit
- B. Provided with brief motivational interventions
- C. Persuaded to quit in the next 30 days
- D. A and B are correct 
50. Which of the following is INCORRECT information to provide to patients who are about to begin therapy with bupropion?

- Take one tablet daily for three days, then take one tablet twice daily

- Quit smoking 7-14 days after initiating bupropion

- If you experience difficulty sleeping, take both tablets $(300 \mathrm{mg})$ in the morning instead of $150 \mathrm{mg}$ twice daily

- Bupropion can be used in combination with nicotine replacement therapy

51. With which of the following products does nicotine rapidly reach the central nervous system?
- Nicotine lozenge
- Nicotine nasal spray
- Nicotine gum
- Nicotine inhaler

52. Which of the following is NOT associated with nicotine withdrawal?
- Fatigue
- Anger/irritability
- Improved task performance
- Anxiety

53. Have you smoked 100 or more cigarettes in your lifetime? (Choose one)
- Yes
- No

54. Which of the following best describes your tobacco use (cigarettes, cigars, pipes, snuff, or chew)? (Choose one)

- Use tobacco once or more a day

- Use tobacco less than once a day

- Used to use tobacco but quit $\rightarrow$ In what year did you quit?

- Experimented with tobacco a few times in the past

- Never tried tobacco

55. What is your sex?
- Male
- Female

56. What is your age? Years

57. Which of the following best describes your race or ethnicity? (Choose one)

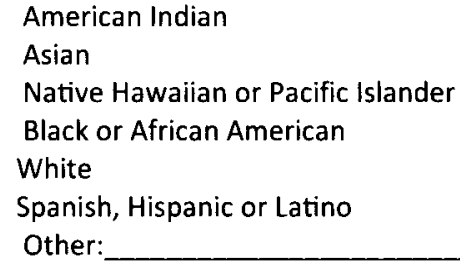


58. Did you complete a pre-program survey for this course? (Choose one)
○ Yes
○ No

59. Please estimate the following:

VALUES SHOULD SUM TO 100.

c. Percentage of the program information that was completely new to you

d. Percentage of the program information that you had been taught before but needed to review

$\%$

c. Percentage of the program that you had been taught before and was an unnecessary review

TOTAL $100 \%$ for a, b, \& c

60. What percentage of the program information do you expect to use when you work with patients?

Please indicate your level of agreement with the following statements. (Fill in one circle for each question)

Strongly Somewhat Neither agree Somewhat Strongly
Disagree Disagree or disagree Agree Agree

61. The lecture and handouts provided valuable information in preparing me to provide tobacco cessation counseling to my patients.

0

$\circ$

62. I felt competent to provide tobacco cessation counseling from the lecture and handouts alone.

$\circ$

0

○

$\circ$

63. The practice sessions with standardized patients increased my confidence in providing tobacco cessation counseling.

$\circ$

$\circ$

64. The feedback provided by the standardized patients was helpful.

$\circ$

$\circ$

0

$\circ$

$\circ$

65. The feedback provided during the debriefing sessions was useful.

$\circ$

0

$\circ$

0

0

66. Do you believe that students at other schools of dentistry in KY would benefit from receiving the same, or similar, tobacco cessation training?

- Yes o No 
67. What would you change about the program?

Overall Comments:

Thank you for helping us to evaluate the tobacco cessation training program. 


\section{APPENDIX J}

\section{KEY POINTS FOR STANDARDIZED PATIENTS CASES}




\title{
Kentucky Cancer Program - University of Louisville
}

\author{
Key Points for Dental Tobacco Treatment SP Cases
}

Mrs. Smith

- Is only contemplating quitting at this time.

- She will not agree to quit unless the student does a convincing or good job in encouraging her to do so.

- She then would enter into the agreement to try, still with some trepidation or doubt about being successful.

- The student should use medications as the factor that will make this quit successful vs. prior two attempts.

- If definitely quitting, the patient should receive some detailed information on taking the meds, not just a name.

- Cutting down/back should only be until the quit date if quitting, or the only agreement if not willing to quit at this time.

- Main difference from "contemplative" case for pharmacy students - that patient was pregnant and already had much more incentive to quit and therefore was more willing. This dental patient will be somewhat harder to convince.

$\underline{\text { Mr. Jones }}$

- The student should not spend much time on medical issues, but should focus on his/her expertise of dental correlations to smoking.

- They should do more asking than telling since he is resistant, to see what matters most to him, what would be most motivating, his perceived benefits of quitting, etc.

- He is not going to agree to quit in this visit, but if student does a good job, he will "think about it" - the most you can typically expect from this type of patient in one visit.

- Ideally, issues such as his desire to have a better golf game, concern for his wife with secondhand smoke, potential loss of teeth due to worsening periodontitis, and even cost of cigarettes saved would be addressed with him.

- The student should mention availability of "medications" which could help with withdrawal symptoms, but not go into detail on any specific one since he's not that interested.

- If asked to come back for a follow-up appt. on the subject anytime soon, you are not willing to do that since you're not yet ready to quit.

- If given a brochure on quitting, your body language suggests it's not going to be read by you. 
- This case is quite similar to the "resistant" case for the pharmacy students, but does not have as many possible drug contraindications.

$\underline{\text { Mrs. Bowmont }}$

- Since she is already willing, the student should not spend any valuable time "convincing" her to quit, but just congratulate her decision to quit with a very positive response.

- It would be a nice extra if the student explained that the patient is naturally having the hardest time giving up the last half-pack she's smoking now because she did not "lose" as much nicotine with the first part of cutting back as she will/would now with remaining cigarettes.

- They should reinforce the benefits of quitting smoking for the pregnancy.

- In their quit advice, they need to strongly discourage any alcohol use, including her wine with dinner.

- As this patient is already motivated, most of the time should be spent on the quit plan. She should be the one to determine her quit date within two weeks.

- Student should explain about different medications and give specific instructions on the one she chooses. Ones suiting her busy, demanding lifestyle should be suggested.

- She should absolutely be referred to the KY Quit Line, preferably with the Fax Referral process.

- They should offer follow-up with him or her about a week after the quit date.

- Problem solving for her barriers and concerns should take place.

- The only reason the hygienist should refer the patient to the dentist is for an $\mathrm{Rx}$ if a medication requiring one is chosen.

- It should be stressed that the entire quit process take place before becoming pregnant due to the importance of the medications, but the risk with taking any of them once pregnant.

- As opposed to the pharmacy case, this "willing" patient does not have any depression history, and any medication is an option for her. Ideally, the option for combination therapy would be mentioned if she were not able to successfully quit on one medication alone, due to her heavy smoking in the past. 


\section{CURRICULUM VITAE}

Full Name:

Employment Address:

Residence Address:

Birth Date:

Birthplace:

Marital Status

Education:
Jacqueline Ann Singleton, RDH, BS, MEd.

Department of Oral Health and

Rehabilitation

School of Dentistry

University of Louisville

501 South Preston Street

Louisville, Kentucky 40292

Telephone: (502) 852-2611

FAX: (502) 852-1317

E-mail: jasing02@louisville.edu

3103 Fairway Court

Floyds Knobs, Indiana 47119

Telephone: (812) 923-7188

October 12, 1955

Morganfield, Kentucky

Married: Husband-Alan

Children-Lee Thomas and Michael Newman

Master of Education

Occupational Training and Development

School of Education

University of Louisville

Louisville, Kentucky, May 2001

Bachelor of Health Science

College of Allied Health

University of Kentucky

Lexington, Kentucky, 1973-1977

Doctor of Philosophy in Public Health

Sciences-Health Promotion

University of Louisville

Louisville, Kentucky, 2007-2012 
Professional Dental Hygiene Licensure:

Experience:
Kentucky, June 1977, \#884

Indiana, July 1995, \#13003929

Associate Professor, July 2012 to present, School of Dentistry, University of

Louisville, Louisville, Kentucky

Director of the Dental Hygiene Program, April 2009 to present, School of Dentistry, University of Louisville, Louisville, Kentucky.

Interim Director of the Dental Hygiene Program, July 2008 to April 2009, School of Dentistry, University of Louisville, Louisville, Kentucky

Assistant Professor, February 2006 to present, School of Dentistry, University of Louisville, Louisville, Kentucky

Research Coordinator, 1998 to 2009, School of Dentistry, University of Louisville,

Louisville, Kentucky

Clinical Instructor, Dental Hygiene, November 2000 to 2/2006, School of Dentistry, University of Louisville, Louisville, Kentucky

Dental Hygiene Practice in Graduate Periodontics, April 1998 to February 2006, School of Dentistry, University of Louisville, Louisville, Kentucky

Dental Hygiene Private Practice, New Albany, Indiana, 1995-1998

Dental Hygiene Private Practice, Louisville, Kentucky, 1994 to 1995 and 1982-1984

Dental Hygiene Private Practice, Owensboro, Kentucky, 1978 to 1982 
Dental Hygiene Private Practice, Bern, Switzerland, 1977 to 1978

Professional Organizations:

Honors:

Course Participation:

Other Teaching Activity:
American Dental Education Association American Dental Hygienists' Association Kentucky Dental Hygienists' Association Louisville District Dental Hygiene Association

Omicron Kappa Upsilon

Dental Honor Society, 2008

Golden Key International Honour Society

Honor Society, 2008

Phi Kappa Phi

Honor Society, 2001

Sigma Phi Alpha,

Dental Hygiene Honor Society, 1977

Dean's List, University of Kentucky, 1974-1977

Links Junior Women's Honorary, 1975

Course Director

Dental Hygiene Theory I \& II

Principles of Practice II Lab

Statistics and Research Methods

Course Participation

Principles of Practice I, III and IV Introduction to Clinical Dentistry I

Dental Materials

Smoking Cessation, Annual ULSD Dental Hygiene Program Legacy Lecture, 2008 and 2007. One hour.

Ideas to Action (i2a) Seminar: Using Critical Thinking to Foster Student

Learning. One hour.

Professional Meeting Presentation:

Ergonomics. One hour. 
Clinical Teaching. One hour.

Research Activities:

Effect of Years of Teaching Experience and College Science Courses on Science Teacher Content Knowledge. Poster presented by Jacqueline A. Singleton and Edward S. Ingle at the 2011 Spring Research Conference, Jointly sponsored by The University of Cincinnati, The University of Kentucky, and The University of Louisville. 2011.

Clinical Study to Evaluate the Treatment of Gingivitis of Two Commercially Available Oral Care Products. (Funded by the Colgate-Palmolive Company, $\$ 100,000$ ). Key Personnel. 2008.

Calibration Study to Determine the AntiPlaque Efficacy of Commercial Dentifrices and an Oral Rinse. (Funded by the Colgate-Palmolive Company, $\$ 35,000$ ). Key Personnel. 2007.

Development of a Lab-on-a-Chip System for Saliva-Based Diagnostics. (Funded by the National Institute of Dental Craniofacial Research, \$404,874). Key Personnel. 2008.

Assessment of the Utility of Infrared Spectroscopy as a Novel Diagnostic Tool in Periodontics. (Funded by the National Institute of Dental Craniofacial Research, $\$ 275,000$ ). Key Personnel. 2008.

The Effect of Tobacco Cessation Training with Standardized Patients. (Survey of Alumni funded by the Louisville Metro Department of Public Health and Wellness, \$200). Principal Investigator. 2007. Tobacco Cessation Counseling Training with Standardized Patients. (Funded by the Louisville Metro Department of Public Health and Wellness, \$1400). Co-Investigator. 2007. 
An Investigation of the Effect of Listerine ${ }^{\circledR}$ Mouthrinse on Inflammatory Biomarkers and Induced Bacteremia Using an Experimental Gingivitis Model. (Funded by Pfizer, $\$ 300,000)$. Key Personnel. 2006 .

Tobacco Cessation Counseling Training with Standardized Patients. (Funded by the Louisville Metro Public Health and Wellness Department, \$1600).

Co-Investigator. 2006.

The Effect of Oral Hygiene and Dental Flossing on the Reduction of Bacteremia and Inflammation Markers in Chronic Gingivitis Population. (Funded by Procter \& Gamble, \$69,930). Key Personnel. 2005.

The Impact of Weight Change on Periodontal and Systemic Inflammation. (Funded by University of Louisville).

Key Personnel. 2004.

A Study to Compare the Effectiveness of a Battery-Powered Toothbrush for Removal of Dental Plaque When Compared to a Manual Toothbrush. (Funded by Procter \& Gamble, $\$ 58,391)$. Examiner. 2003.

A Study to Assess and Compare The Impact of Oral Hygiene Instructions on The Plaque Removal Efficacy of a Battery Powered Toothbrush. (Funded by Procter \& Gamble, $\$ 43,434)$. Examiner. 2003.

Qualifying Panelists for Toothbrush Studies. (Funded by Procter \& Gamble, \$96,000). Examiner 2002.

In-vivo Comparison of the Effects of a Sonicare Prototype and a Manual Toothbrush on Dental Stain. (Funded by Phillips Oral Healthcare, Inc., \$50,971). Examiner 2002. 
Quadrant Versus Full Mouth Scaling and Root Planing. (Funded by University of Louisville). Key Personnel. 2001-2002.

A Clinical Study to Compare Two Toothbrushes. (Funded by John O. Butler Company, \$87,836). Key Personnel. 2001.

A Pilot Study to Compare Two Levels of Scaling and Root Planing. (Funded by OraPharma, \$22,380). Key Personnel. 2000-2001.

Subgingival Chlorhexidine Gluconate Deposition Using a Variety of Treatment Applications - Fluid-dispensing Sonic Toothbrush. (Funded by Optiva Corporation, \$3000). Key Personnel. 1999-2000.

Multicenter Phase 3 Trial of Minocycline Periodontal Therapeutic System (Minocycline PTS): Adjunctive Use in Patients with Periodontitis. (Funded by OraPharma, Inc., \$215,096).

Key Personnel. 1998-2000.

Publications:

Sarah E. Walsh, Jacqueline A. Singleton, Celeste Worth, Jacqueline Krugler, Regan Moore, Gina C. Wesley, Charlene K. Mitchell. Tobacco Cessation Counseling Training with Standardized Patients.

Journal of Dental Education, American Dental Education Association, September 2007/Vol.71/No.9.

Research Committee:

Anahita Alvanpour, M.D. Does Oral Cancer Screening at the Kentucky State Fair (1996-2010) Identify High Risk Populations. Thesis for Master of Science in Oral Biology. 2011. 
Funding for Creative Activity:

Service:
Tobacco Cessation Counseling Training

With Standardized Patients. (Funded by the Louisville Metro Public Health and

Wellness Department, \$7253.) 2011-12.

Tobacco Cessation Counseling Training With Standardized Patients. (Funded by the Louisville Metro Public Health and Wellness Department, \$7253.) 2010-11.

Tobacco Cessation Counseling Training with Standardized Patients. (Funded by the Louisville Metro Public Health and Wellness Department, \$4316.) 2009-10.

Tobacco Cessation Counseling Training with Standardized Patients. (Funded by the Louisville Metro Public Health and Wellness Department, \$5568.) 2008-09.

Program Affiliations

Chair, Dental Hygiene Academic Achievement Committee Dental Hygiene Admissions Committee Dental Hygiene Advisory Committee Chair, Dental Hygiene Curriculum Committee

Secretary, Alpha Theta Chapter of Sigma Phi Alpha Dental Hygiene Honor Society Dental Hygiene Legacy Committee

School of Dentistry Affiliations

ULSD Council

ULSD Quality Assurance Committee

ULSD Assessment and Effectiveness

Committee

Clinic Operations and Patient Care

Committee

Clinic Operations and Patient Care/Patient Admissions Subcommittee

Student Leadership

University of Louisville Affiliations

Undergraduate Council

Chair, General Education Curriculum

Committee 
Course Proposal Subcommittee Living Learning Community Planning Group

i2a Faculty Learning Community

Remote Area Medical (RAM)

Pikeville, Kentucky

Somerset, Kentucky

Smile! KY

Colgate Bright Smiles, Bright Futures (BSBF)

Every 1 Reads

Professional Education Task Force, Metro Louisville Smoke Free Coalition, August 2000 to present

Steering Committee

Chairperson for

Professional Education Task Force

Metro Louisville Smoke Free Coalition

July 1, 2004 to June 30, 2006

Eucharistic Minister

St. Mary of the Knobs Church

1998 to present

Ad Hoc Committee

St. Mary of the Knobs Church

Floyds Knobs, Indiana

2004

Disciples in Mission Leadership Team, St. Mary of the Knobs Church Floyds Knobs, Indiana

2001 to 2004

Religious Education Teacher, St. Mary of the Knobs Church, Floyds Knobs, Indiana, 1991-1999, 2001 to 2004 
Board of Religious Education

St. Mary of the Knobs Church,

Floyds Knobs, Indiana, 1991 to 1994

President, Board of Religious Education, St. Mary of the Knobs Church,

Floyds Knobs, Indiana, 1992 to 1994

Cub Scout Den Leader, Pack 67, 1991 to 1998

Publicity Chairperson,

St. Mary of the Knobs P.T.O.

1989 to 1991

Trustee, Kentucky Dental Hygienists'

Association, 1981 